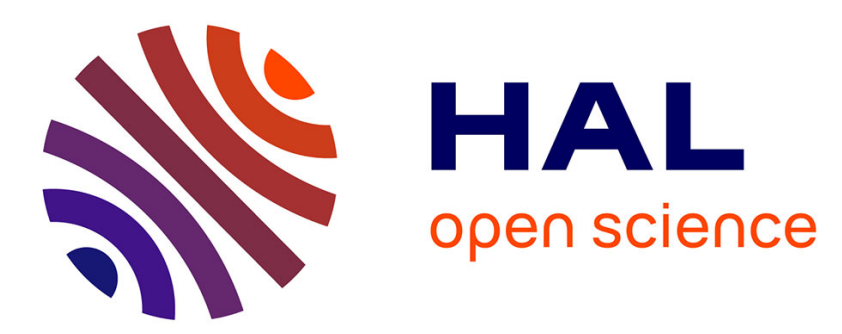

\title{
La flexibilité des prix relatifs et la mobilité du travail en Union monétaire
}

Joël Oudinet, Jacques Mazier, Sophie Saglio

\section{To cite this version:}

Joël Oudinet, Jacques Mazier, Sophie Saglio. La flexibilité des prix relatifs et la mobilité du travail en Union monétaire: Une comparaison Europe/États-Unis. Revue de l'OFCE, 2002, 4 (83), pp.325-388. halshs-00487521

\section{HAL Id: halshs-00487521 https://shs.hal.science/halshs-00487521}

Submitted on 31 May 2010

HAL is a multi-disciplinary open access archive for the deposit and dissemination of scientific research documents, whether they are published or not. The documents may come from teaching and research institutions in France or abroad, or from public or private research centers.
L'archive ouverte pluridisciplinaire $\mathbf{H A L}$, est destinée au dépôt et à la diffusion de documents scientifiques de niveau recherche, publiés ou non, émanant des établissements d'enseignement et de recherche français ou étrangers, des laboratoires publics ou privés. 


\section{La flexibilité des prix relatifs et la mobilité du travail en Union monétaire Une comparaison Europe/États-Unis}

Presses de Sc. Po. | Revue de l'OFCE

2002/4 - no 83

pages 325 à 388

ISSN 1265-9576

Article disponible en ligne à l'adresse:

http://www.cairn.info/revue-de-l-ofce-2002-4-page-325.htm

Pour citer cet article :

"La flexibilité des prix relatifs et la mobilité du travail en Union monétaire" Une comparaison Europe/États-Unis, Revue de l'OFCE, 2002/4 no 83, p. 325-388.

Distribution électronique Cairn.info pour Presses de Sc. Po..

(c) Presses de Sc. Po.. Tous droits réservés pour tous pays.

La reproduction ou représentation de cet article, notamment par photocopie, n'est autorisée que dans les limites des conditions générales d'utilisation du site ou, le cas échéant, des conditions générales de la licence souscrite par votre établissement. Toute autre reproduction ou représentation, en tout ou partie, sous quelque forme et de quelque manière que ce soit, est interdite sauf accord préalable et écrit de l'éditeur, en dehors des cas prévus par la législation en vigueur en France. II est précisé que son stockage dans une base de données est également interdit. 


\title{
LA FLEXIBILITÉ DES PRIX RELATIFS ET LA MOBILITÉ DU TRAVALL EN UNION MONÉTAIRE
}

\section{UNE COMPARAISON EUROPE/ÉTATS-UNIS}

\author{
Jacques Mazier, Joël Oudinet et Sophie Saglio \\ Laboratoire CEPN-CNRS \\ Centre d'économie de l'Université Paris-Nord
}

Avec la mise en place de l'euro, les mécanismes d'ajustement au sein de l'Union européenne sont modifiés en profondeur du fait de la disparition du taux de change comme variable d'ajustement. Ceux qui subsistent sont, à titre principal, la flexibilité des salaires et des prix relatifs, la mobilité des facteurs, particulièrement du travail, les politiques budgétaire et monétaire. Ces modes d'ajustement intraeuropéens constituent un enjeu dont l'importance dépend du caractère asymétrique ou non des chocs et des évolutions structurelles affectant le fonctionnement de l'UE. Le présent article s'intéresse aux mécanismes d'ajustement par le marché du travail à travers deux approches complémentaires.

La flexibilité des coûts et des prix relatifs est d'abord analysée à l'aide d'une maquette macroéconomique estimée pour les 14 pays européens. Cette maquette est utilisée pour étudier les conséquences de chocs d'offre ou de demande asymétriques affectant un pays et pour comparer les capacités de réaction des différents pays européens. Ces simulations montrent que la flexibilité des salaires et de l'emploi, et plus généralement la flexibilité des prix relatifs, ne permet qu'un rééquilibrage incomplet et très lent (au-delà de dix ans). Face à un choc négatif sur la demande interne, l'emploi et la production ne retrouvent pas leur niveau initial ou le retrouvent très lentement, et le taux de chômage demeure plus élevé. Le recours à l'instrument budgétaire serait plus approprié. Face à un choc inflationniste et à une perte de compétitivité, la hausse du chômage qui en résulte ne permet qu'un ajustement progressif et incomplet. Les disparités de réaction entre pays face à un choc de même ampleur apparaissent, enfin, non négligeables entre grands et petits pays, notamment en raison des inégalités dans le degré d'ouverture, qui donnent plus de poids aux effets de la compétitivité-prix dans les petits pays, mais aussi entre pays de même taille, du fait des différences structurelles existantes. Ces divergences sont source d'asymétries qui compliquent la conduite de la politique économique dans l'UE, particulièrement en ce qui concerne la politique monétaire commune. 
La mobilité de la main-d'œuvre est ensuite étudiée avec une modélisation des mouvements migratoires articulée avec un bloc prix-salaires-emploi proche du précédent modèle, appliquée au cas des États-Unis découpés en quatre grandes régions d'une taille voisine de celle des grands pays européens. Les simulations confirment que, comme dans le cas européen, la flexibilité des coûts et des prix relatifs n'autorise que des ajustements limités face à des chocs de demande ou d'offre affectant une région. La mobilité de la main-d'œuvre joue bien un rôle de rééquilibrage, mais celui-ci est d'une ampleur très réduite. Les mouvements migratoires répondent essentiellement à des évolutions structurelles, même aux États-Unis.

Des enseignements peuvent en être tirés pour le fonctionnement de l'Union monétaire européenne face à des évolutions asymétriques. La recherche d'une plus grande flexibilité du marché du travail aurait une traduction macroéconomique incertaine et n'aurait qu'une efficacité limitée pour accroître l'ampleur du rééquilibrage par le jeu des prix relatifs. L'espoir également entretenu qu'une plus grande mobilité intra-européenne de la main-d'œuvre pourrait constituer une réponse au moins partielle s'avérerait tout aussi vain.

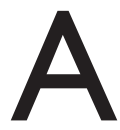

vec la mise en place de l'euro, les mécanismes d'ajustement au sein de l'Union européenne sont modifiés en profondeur. La fixation des parités intra-européennes a fait disparaître le taux de change comme variable d'ajustement au sein de la zone euro. Depuis la création du SME en 1979, cette variable avait perdu une partie de son importance, mais son rôle d'ajustement était loin d'avoir disparu pour corriger les effets d'un choc asymétrique ou les effets d'évolutions asymétriques à caractère structurel. Les dévaluations consécutives aux crises monétaires de 1992 et 1993 en ont été une dernière illustration. Les mécanismes d'ajustement sont entendus au sens large comme les mécanismes permettant à un pays, après un choc, de retourner au plein emploi ou à la situation initiale ou de réduire l'inflation. On ne s'interroge pas à ce stade sur les critères nouveaux de retour à l'équilibre qu'entraîne l'appartenance à l'Union monétaire.

Les mécanismes d'ajustement autres que le taux de change sont de plusieurs ordres. La flexibilité des salaires et des prix relatifs a été, dès le départ, mise en avant par les promoteurs de la monnaie unique (Commission européenne, 1990). Elle s'inscrit dans la logique des modèles de désinflation compétitive qui trouvent ainsi un prolongement naturel (Blanchard et Muet, 1993). La mobilité des facteurs, particulièrement celle du travail, est présentée comme un autre mode d'ajustement potentiel, conformément aux théories traditionnelles des zones monétaires optimales. Les politiques budgétaires sont également susceptibles d'intervenir au niveau régional, dans la limite des marges de manœuvre des politiques budgétaires nationales fixées par le Pacte de stabilité, ou au niveau fédéral, selon des modalités institutionnelles qui resteraient à définir dans le cas européen. 
Ces modes d'ajustement autres que le taux de change constituent un enjeu dont l'importance dépend de la nature asymétrique ou non des chocs et des évolutions structurelles affectant le fonctionnement de l'UE. Ces asymétries reflètent les différences dans les caractéristiques institutionnelles et structurelles propres à chaque pays et leur impact sur les mécanismes macroéconomiques. Les forces d'agglomération et de diffusion qui s'exercent au sein d'un espace unifié sont susceptibles de renforcer ou d'atténuer ces facteurs d'asymétries, comme l'a montré une abondante littérature dans le domaine de l'économie géographique.

Ces questions ont donné lieu à un ensemble de travaux empiriques portant à la fois sur les pays européens et sur les États-Unis qui constituent depuis plus d'un siècle un espace monétaire unifié d'une taille comparable à celle de l'UE. Bien que le processus historique de formation des États-Unis et les bases institutionnelles actuelles soient très différents du cas européen, la confrontation s'avère fructueuse. En laissant de côté les travaux sur l'impact des politiques budgétaires, les principales conclusions sont les suivantes.

- Une étude de la flexibilité des salaires en Europe au cours des années 1990 montre que celle-ci est trop limitée pour pouvoir compenser la disparition du taux de change en tant qu'instrument face à un choc spécifique. En revanche, les différences existant d'un pays à l'autre en matière de flexibilité salariale ne seraient pas susceptibles de créer de fortes asymétries, ce qui rendrait a priori plus aisée la régulation conjoncturelle au sein de I'UE (Cadiou, Guichard et Maurel, 1999).

- Une analyse des ajustements au sein de l'espace américain au niveau des États montre également que les ajustements d'emploi et de salaires ne permettent de compenser que partiellement les chocs régionaux. La mobilité inter-régionale de la main-d'œuvre jouerait en revanche un rôle rééquilibrant important, à la différence de ce qui peut prévaloir en Europe (Blanchard et Katz, 1992). Cette dernière thèse est cependant contestée par certains, qui considèrent que les migrations inter-régionales correspondent à un phénomène permanent qui n'est pas réversible à court terme et peut plus difficilement apparaître comme un facteur de rééquilibrage (Buiter, 1995). Des travaux plus récents mettent en avant le rôle redistributif que pourrait jouer la diversification inter-régionale des portefeuilles dans l'espace américain, mais l'insuffisance des données rend les vérifications difficiles (Melitz et Zumer, 2002).

- La nature des chocs susceptibles d'affecter l'UE donne lieu à débat, même si plusieurs éléments plaident en faveur de la persistance, voire du renforcement, de facteurs asymétriques. Les inégalités régionales ont eu tendance à se renforcer au cours des années 1980 et 1990, ce qui constitue un facteur d'asymétries, malgré le mouvement de convergence des économies nationales. La concentration des activités par pays, mesurée par l'indice de spécialisation de Krugman, 
s'est accrue depuis les années 1980 et les indices de concentration par industries au niveau de l'ensemble de l'UE ont augmenté dans de nombreux cas (Midelfart-Knarvik et alii, 2000). La concentration des activités dans l'espace américain, bien qu'en déclin depuis les années 1950, est plus marquée qu'au sein de l'UE. La spécialisation croissante des économies en termes de contenu technologique et de qualité des produits (développement des échanges intra-branche de qualité) est une autre cause d'asymétries, mais qui est compensée par le déclin des échanges inter-branches (Fontagné, Freudenberg et Péridy, 1998). Les différences institutionnelles existant entre les pays européens (en matière de systèmes bancaires et financiers ou en matière de relations sociales par exemple) peuvent, enfin, être à l'origine de réponses différenciées selon les pays face à un choc les affectant d'une manière uniforme. Ce constat doit cependant être nuancé si l'on en croit l'étude sur la flexibilité salariale déjà citée.

Le présent article étudie les mécanismes d'ajustement par le marché du travail à travers deux approches complémentaires :

— La flexibilité des coûts et des prix relatifs est d'abord analysée à l'aide de simulations de chocs d'offre et de demande sur une maquette macroéconomique estimée au niveau des 14 pays européens. Ces simulations montrent que la flexibilité des salaires et de l'emploi ne peut servir de substitut au taux de change comme variable d'ajustement, et que les disparités de réaction entre pays face à un choc de même ampleur apparaissent non négligeables.

— La mobilité de la main-d'œuvre est ensuite étudiée avec une modélisation des mouvements migratoires articulée avec un bloc prixsalaires-emplois proche du précédent modèle, et appliquée au cas des États-Unis découpés en quatre grandes régions. Les simulations confirment que, comme dans le cas européen, la flexibilité des prix et des coûts relatifs n'autorise que des ajustements limités face à des chocs affectant une région. La mobilité de la main-d'œuvre joue bien un rôle de rééquilibrage, mais celui-ci est d'une ampleur très réduite. Plusieurs enseignements peuvent être tirés de ces résultats pour le fonctionnement de la zone euro. 


\section{Flexibilité des coûts et des prix relatifs et Union monétaire}

\section{Un modèle macroéconomique simplifié}

La flexibilité des coûts et des prix relatifs dans les pays de l'UE est étudiée à l'aide d'un modèle macroéconomique simple décrivant les mécanismes d'ajustement du marché du travail. Ce modèle intègre à la fois la flexibilité des salaires et des prix relatifs, qui permet d'ajuster le taux de change réel, et la flexibilité externe qui met l'accent sur les aspects institutionnels du contrat de travail (ajustement de l'emploi et flexion des taux d'activité).

Le modèle est complété par un bouclage par la demande. La demande externe est étudiée d'une manière complète avec des équations d'exportation et d'importation séparant les échanges intraeuropéens et extra-européens, et comportant des effets de compétitivité-prix et des effets de demande. La décomposition en échanges intra et extra-européens a été faite pour permettre le fonctionnement du modèle en interdépendance. Les prix des échanges extérieurs sont modélisés d'une manière simple à l'aide de comportements de marge estimés pour l'ensemble des pays européens. La demande interne n'a pas donné lieu à une modélisation détaillée pour ne pas alourdir le modèle. Une simple élasticité par rapport aux revenus salariaux réels a été retenue dans la fonction de consommation estimée sur l'ensemble des pays de l'Union européenne. Lorsque le modèle fonctionne dans sa version offre, la demande interne est considérée comme exogène, et seuls sont pris en compte les effets de compétitivité-prix. Cette modélisation simplifiée de la demande interne présente l'inconvénient de ne prendre en compte, ni l'effet négatif des salaires sur les profits et donc sur l'investissement, ni l'impact de l'inflation et du taux d'intérêt réel sur la demande interne.

Les équations sont estimées sous la forme d'un modèle à correction d'erreur qui permet, de prendre en compte à la fois la dynamique de court terme et la cible de long terme. Les relations de long terme sont présentées dans l'encadré. À court terme, des variables supplémentaires interviennent, comme le taux d'utilisation des capacités de production dans l'équation du prix du PIB. Les résultats économétriques sont donnés en annexe. 


\section{Les relations de long terme}

Salaires réels par tête $(w / p c)$

$\log (w / p c)=\log (Q / N)+a 1 U+a 2$

avec $Q / N=$ productivité du travail, $U=$ taux de chômage $(a 1<0)$

Prix du PIB $(p)$

$\log (p)=\log (w)-\log (Q / N)$

Prix à la consommation $(p c)$

$\log (p c)=\mu \log (p m)+(1-\mu) \log (p)$

avec $p m=$ prix des importations de biens et services toutes zones, $\mu=$ part des importations de biens et services dans le PIB.

Productivité du travail $(Q / N)$

$\log (Q / N)=a+b t$

avec $t=$ trend temporel.

Population active $(P A)$

$\log (P A)=d 1 \log (N)+(1-\mathrm{d} 1) \log (P A T)$

avec $P A T=$ population active en âge de travailler $(15-64$ ans $), N=$ emploi.

$U=(P A-N) / P A$

Bouclage par la demande

Consommation (Cons)

$\log ($ Cons $)=c 1 \log (w N / p c)$

Avec $(\mathrm{wN} / \mathrm{pc})=$ revenus salariaux réels.

La demande interne

$D I=$ Cons + Exo, Exo étant le solde.

Exportations intra-européennes $(X I)$

$\log (X I)=d 1 \log (D E I)+d 2 \log (p x c i / p x)$

Avec $X I=$ exportations intra-européennes, $D E I=$ demande européenne adressée au pays, $p x=$ prix des exportations toutes zones, $p x c i=$ prix des exportations des concurrents européens.

Importations intra-européennes $(M I)$

$\log (M I)=f 1 \log (D I)+f 2 \log (\mathrm{pmi} / \mathrm{p})$

Avec $\mathrm{DI}=$ demande intérieure, $\mathrm{pmi}=$ prix des importations intra-européennes.

Exportations extra-européennes $(X E)$

$\log (X E)=d 1 \log (D E)+d 2 \log ($ pxce/px $)$

Avec $X E=$ exportations extra-européennes, $D E E=$ demande extra européenne adressée au pays, $p x=$ prix des exportations toutes zones, $p x c e=$ prix des exportations des concurrents extra-européens

Importations extra-européennes $(M E)$

$\log (M E)=f 1 \log (D I)+f 2 \log (p m e / p)$

Avec $D I=$ demande intérieure, $p m e=$ prix des importations extraeuropéennes, $M E=$ importations extra-européennes.

Prix des importations toutes zones $(\mathrm{pm})$

$\log (p m)=\varphi \log (p m i)+(1-\varphi) \log (p m e)$

Avec $\varphi=$ part des importations en provenance de I'UEM dans les importations totales, $\mathrm{pm}=$ prix des importations toutes zones.

Prix des exportations des concurrents toutes zones

$\log ($ pxc $)=h 1 \log ($ pxci $)+(1-h 1) \log ($ pxce $)$ 
Prix des exportations $(p x)$ toutes zones

$\log p x=g 1 \log p+(1-g 1) \log (p x c)$

Équilibre des biens et services

$Y=D I+X I-M I+X E-M E+S O$

Avec $Y=P I B$, et $S O$ le solde.

Les interdépendances entre les 14 pays européens sont prises en compte dans les calculs du prix des importations intra-européennes, du prix des exportations des concurrents européens et de la demande intra européenne qui est une moyenne pondérée des importations des pays européens partenaires (voir l'annexe sur les données pour le détail de ces trois calculs). Les exportations et les importations ont été estimées pour les seuls produits manufacturiers.

Le modèle est estimé pour les 14 pays de l'UEM (hors Luxembourg) sur la période 1983-1999 en données annuelles. La période d'estimation est réduite aux années 1980 et 1990, en raison des ruptures qui sont intervenues depuis le début des années 1980 . À partir de cette époque, la recherche d'une plus grande flexibilité selon des modalités propres à chaque pays a profondément transformé le fonctionnement du marché du travail. De même, les formes de la concurrence intra-européenne ont été renouvelées avec la mise en œuvre du Marché unique, puis avec la transition vers l'Union monétaire. Des estimations économétriques ont également été réalisées sur la période 1970-1985, de manière à tenter d'apprécier la portée de ces ruptures.

Comme nous souhaitions étudier l'ensemble des pays européens, nous avons dû nous contenter de données annuelles. L'utilisation de données trimestrielles aurait permis une meilleure analyse de la dynamique de court terme et un test de la validité des relations de long terme grâce à la prise en compte des problèmes de cointégration. Mais il aurait fallu réduire le champ d'analyse ou trimestrialiser des données annuelles, ce qui aurait réduit le contenu informatif. Pour compenser l'utilisation d'une période d'estimation assez courte, nous utilisons l'économétrie de panel, ce qui permet de tester les différences structurelles existantes entre les pays européens, Guichard et Laffargue (200I), Hervé (200I). Plus précisément, la spécification de l'équation est commune à tous les pays, mais seules les valeurs de ses coefficients peuvent varier. Nous pouvons alors tester plus aisément les différences structurelles existantes entre les pays du panel, en effectuant une série de tests emboîtés. La stratégie de tests emboîtés va d'un modèle général (où tous les coefficients sont différents pour l'ensemble des pays du panel), à un modèle particulier (où les coefficients sont identiques pour l'ensemble des pays). Cette stratégie de tests permet de déterminer si les coefficients des pays prennent des valeurs différentes. 
Deux types d'enseignements pourront en être tirés concernant les problèmes posés par le fonctionnement de la zone euro. On pourra, en premier lieu, mesurer si la flexibilité du marché du travail peut, ou non, constituer une réponse suffisante pour compenser les effets d'un choc. On pourra, en second lieu, apprécier si les différences dans les mécanismes d'ajustement du marché du travail sont, ou non, sources d'asymétries entre les pays de la zone euro. Par rapport à l'étude du CEPII déjà citée (Cadiou, Guichard et Maurel, 1999), le modèle proposé retient une analyse plus détaillée des ajustements par les coûts et les prix (formation des prix et flexion des taux d'activité en particulier) et un bouclage par la demande interne et externe plus complet (le modèle du CEPII n'étudie que les aspects d'offre).

\section{Une synthèse des paramètres représentatifs des ajustements}

Une synthèse des ajustements par les prix relatifs peut être faite à partir de quatre paramètres représentatifs issus du modèle (tableau I et tableau 2). S'agissant du marché du travail, trois indicateurs ont été retenus, la sensibilité à moyen terme du salaire réel au chômage, le délai moyen d'ajustement de l'emploi, la flexion des taux d'activité, c'est-à-dire l'élasticité de la population active par rapport à l'emploi.

\section{Principaux paramètres représentatifs des ajustements}

\begin{tabular}{l|c|c|c|c|c}
\hline & $\begin{array}{c}\text { Sensibilité du salaire réel au } \\
\text { taux de chômage } \\
\text { à moyen terme }\end{array}$ & \multicolumn{2}{|c|}{$\begin{array}{c}\text { Délai d'ajustement de } \\
\text { l'emploi à la production }\end{array}$} & $\begin{array}{c}\text { Flexion du } \\
\text { taux } \\
\text { d'activité }\end{array}$ \\
\cline { 2 - 6 } & $1973-1989$ & $1983-1999$ & $197 I-1987$ & $1983-1999$ & $1982-1999$ \\
\hline Allemagne & $-0,0122$ & $-0,0659$ & $I, 95$ & 0,84 & 0,36 \\
France & $-0,0206$ & $-0,022$ & 2,55 & 0,08 & 0,28 \\
Italie & $-0,0703$ & $-0,0519$ & 2,55 & 0 & 0,65 \\
Royaume-Uni & 0 & $-0,0218$ & 2,55 & 0,4 & 0,23 \\
Espagne & $-0,0276$ & $-0,0712$ & 1,9 & 0,08 & 0,2 \\
Autriche & $-0,0362$ & $-0,0706$ & 2,2 & 0,3 & 0,77 \\
Belgique & $-0,0116$ & $-0,0601$ & 1,9 & 0,05 & 0,49 \\
Pays-Bas & $-0,0171$ & $-0,01$ & 2,55 & 0,84 & 0,45 \\
Danemark & $-0,036$ & 0 & 2,55 & 0,7 & 0,5 \\
Suède & $-0,1221$ & $-0,089 \mid$ & 1,5 & 0,63 & 0,46 \\
Finlande & $-0,0637$ & $-0,0338$ & 2,55 & 0,46 & 0,31 \\
Irlande & $-0,0265$ & 0 & $I, 9$ & 0,84 & 0,4 \\
Portugal & $-0,0977$ & 0 & 2,55 & 0,84 & 0,8 \\
\hline
\end{tabular}

Source : Calculs des auteurs. 
II existe un décalage important entre ces indicateurs macroéconomiques et les caractéristiques institutionnelles du marché du travail (Cadiou et alii, 1999). Des institutions plus libérales ne conduisent pas d'une manière mécanique à une plus forte flexibilité salariale au niveau macroéconomique. D'autres paramètres doivent en outre être pris en compte, comme l'indexation à court terme du salaire réel sur la productivité, qui est très forte en Italie, en Allemagne et en France, ou la sensibilité du salaire réel à court terme au chômage. En dehors du marché du travail, la somme des élasticités-prix du commerce extérieur constitue un paramètre central, mais d'autres variables comme la flexibilité du taux de marge à court terme dans les équations de prix sont aussi à considérer.

2. Somme des élasticités-prix du commerce extérieur 1981-1987

\begin{tabular}{l|c|c}
\hline & Echanges intra-UE & Échanges extra-UE \\
\hline Allemagne & 1,13 & 1,39 \\
France & 0,92 & 2,23 \\
Italie & 1,88 & 1,88 \\
Royaume-Uni & 1,10 & 2,48 \\
Espagne & 1,69 & 2,88 \\
Autriche & 1,25 & 1,96 \\
Belgique & 1,29 & 2,04 \\
Pays-Bas & 1,72 & 3,57 \\
Danemark & 2,08 & 1,74 \\
Suède & 1,91 & 2,61 \\
Finlande & 1,36 & 2,32 \\
Irlande & 1,78 & 4,25 \\
Portugal & 1,21 & 2,55 \\
\hline
\end{tabular}

Source : Calculs des auteurs.

En se limitant d'abord aux trois paramètres représentatifs des ajustements par le marché du travail, un premier constat se dégage clairement. Dans l'ensemble des pays, une réduction sensible des délais d'ajustement de l'emploi est intervenue entre les années 1970 et les années 1990. Ce mouvement est général, même si il a été plus marqué dans certains pays (Espagne, Italie, France, Belgique, Autriche) que dans d'autres. En revanche, la rigidité des salaires, mesurée par la sensibilité à moyen terme des salaires réels au taux de chômage, n'a pas été réduite d'une manière uniforme. C'est en Allemagne, Autriche, Belgique, Espagne et, dans une moindre mesure, au Royaume-Uni que ce mouvement de réduction a été le plus marqué.

L'Espagne se caractérise par un ajustement de l'emploi aux variations de la production très rapide, qui est cohérent avec les multiples mesures de libéralisation qui ont été prises depuis les années 1980. La sensibilité du salaire réel au taux de chômage à moyen terme est 
la plus élevée, et est à rapprocher de celle de la Suède, de l'Autriche et de l'Allemagne. En revanche, la faible flexibilité du taux d'activité est un facteur qui a tendu à amplifier les fluctuations du chômage.

Le Royaume-Uni est l'un des pays où la recherche d'une plus grande flexibilité a été menée d'une manière continue depuis les années 1980, en jouant sur l'ensemble des domaines (décentralisation des négociations, affaiblissement des syndicats, baisse des indemnités-chômage, faiblesse des contraintes sur les heures supplémentaires et les CDD). Pourtant, le délai d'ajustement de l'emploi et la flexibilité des salaires demeurent moyens. La rigidité du taux d'activité, liée notamment à des phénomènes de découragement et au retrait du marché du travail d'une fraction défavorisée de la population active, a contribué à une résorption plus rapide du chômage en période de reprise.

Les Pays-Bas, l'Allemagne et le Danemark correspondent à un cas de figure différent avec le maintien de négociations plutôt centralisées, la persistance d'un pouvoir syndical fort et des revenus de remplacement assez généreux. La flexibilité du travail a été davantage recherchée sur une base coopérative. Au total, l'ajustement de l'emploi y est plus lent, et la sensibilité du salaire réel au taux de chômage est élevée en Allemagne, relativement faible aux Pays-Bas et non significative au Danemark. Enfin, le taux d'activité fluctue d'une manière moyenne pour les Pays-Bas et le Danemark, ce qui facilite la réduction du chômage lors des phases de reprise.

La France et la Belgique sont dans des situations proches, avec des aspects contradictoires dans l'évolution du rapport salarial (recherche d'une plus grande flexibilité du travail sur une base assez régressive, révision à la baisse mais préservation des différents volets de la protection sociale, éclatement des relations sociales et faiblesse syndicale en France). L'ajustement de l'emploi à la production est très rapide dans ces deux pays, mais la rigidité salariale est restée assez élevée en France alors qu'elle est devenue faible en Belgique. La flexibilité des taux d'activité est moyenne en Belgique et faible en France.

La Suède, la Finlande et, dans une moindre mesure, l'Autriche sont dans des configurations très différentes. Ces pays se caractérisent par un niveau élevé de centralisation dans les négociations, une assez forte protection des salariés en matière de licenciement et de salaire minimum et un pouvoir syndical fort. Pourtant, la sensibilité du salaire réel au taux de chômage est élevée en Suède et en Autriche. En revanche, elle se situe dans une position intermédiaire en Finlande. L'Autriche est caractérisée par une vitesse d'ajustement de l'emploi à la production et une élasticité de la population active à l'emploi relativement élevées. Les délais d'ajustement de l'emploi sont moyens en Suède et en Finlande. Enfin, la flexion des taux d'activité est faible en Finlande et moyenne en Suède. 
L'Italie constitue un dernier cas avec une voie originale de recherche de la flexibilité à partir des années 1980. Face aux contraintes fortes sur les CDD et à un salaire minimum élevé, l'emploi dans les réseaux de PME, le travail familial et le travail au noir se sont développés, tandis que le recours à la $\mathrm{CIG}$ permettait de contourner les limites sur les licenciements collectifs. Les années 1990 ont été marquées par un durcissement, dans la plupart des domaines (indexation salariale, $\mathrm{CIG}$, emplois précaires). Au total, la sensibilité des salaires au taux de chômage est forte, et l'ajustement de l'emploi est très rapide. La flexion du taux d'activité est l'une des plus élevée, ce qui rend plus inerte l'évolution du taux de chômage.

Les élasticités prix du commerce extérieur sont estimées à la fois au niveau des échanges intra-européens et des échanges extraeuropéens. Elles font apparaître sur la période 198I-1997 une hiérarchie des pays assez conforme avec ce qui pouvait être attendu : forte élasticité-prix en Espagne, en Italie et en Irlande, mais aussi, ce qui est plus étonnant, au Danemark, aux Pays-Bas et en Suède ; faible élasticité en Allemagne, en Autriche, en France et en Belgique. La faible valeur au Portugal est également surprenante. Les élasticités prix sont plus fortes dans les échanges extra-européens que dans les échanges intra-européens, en raison de l'importance des échanges intra-branche de qualité et des échanges intra-firmes.

Depuis les années 1980, les effets hors-prix auraient eu tendance à se développer dans les échanges intra-européens, ce qui est cohérent avec la montée des échanges intra-branche de qualité. Cette évolution aurait eu pour conséquence de réduire l'efficacité des ajustements par les prix au sein de l'espace européen.

Les quatre paramètres, délai d'ajustement de l'emploi, sensibilité des salaires réels au chômage, flexibilité des taux d'activité et élasticités-prix du commerce extérieur, résument les modalités d'ajustement par les prix relatifs face à des chocs. Ils reflètent d'une manière complexe les formes institutionnelles propres à chaque pays. Replacés dans le modèle macroéconomique complet, ils permettent, à travers l'étude de simulations de chocs d'offre et de demande, de répondre à la première question qui était initialement posée. Face à la disparition du change comme variable d'ajustement, la flexibilité des coûts et des prix relatifs peut-elle constituer un mécanisme d'ajustement alternatif ?

\section{Chocs d'offre et chocs de demande en Union monétaire}

Trois types de chocs sont envisagés.

- Le premier correspond à une baisse de la demande interne (baisse des dépenses publiques, hausse du taux d'épargne des 
ménages). II s'agit d'un choc de demande asymétrique affectant un seul pays et touchant indirectement le marché du travail. Ces chocs permettent de mesurer si la flexibilité des prix et des coûts relatifs, principalement à travers l'ajustement par le marché du travail, est suffisante ou non pour compenser le choc initial. Les chocs étant de même ampleur dans chaque pays, il est possible d'apprécier si les différences structurelles existant entre les pays engendrent ou non des phénomènes de divergence.

- Le second type de choc affecte directement le marché du travail à travers une hausse du salaire nominal par tête (poussée salariale). II s'agit, là aussi, d'un choc asymétrique affectant un seul pays. Mais, comme précédemment, les différences d'évolution entre pays face à un choc de même ampleur peuvent être comparées.

- Le troisième type de choc est un choc d'offre correspondant à une hausse exogène du prix du PIB et affectant comme précédemment un seul pays.

Les simulations sont effectuées en laissant jouer les mécanismes d'ajustement sur une période suffisamment longue, de manière à pouvoir mieux les interpréter. Une prudence est nécessaire dans l'analyse des résultats car, pour certaines équations, de simples mécanismes de court terme sont prolongés à long terme, sans prendre en compte les facteurs qui interviennent en plus longue période comme l'accumulation de capital et les déterminants de la productivité.

\section{Les effets d'une baisse de la demande interne}

Plusieurs enseignements se dégagent de la simulation d'une baisse de la consommation des ménages de I \% (graphiques I).

- Face à un choc négatif sur la demande interne, les mécanismes d'ajustement par le marché du travail à travers la flexibilité des coûts et des prix relatifs ne permettent qu'un rééquilibrage incomplet et très lent, c'est-à-dire au-delà de dix ans. La production et l'emploi baissent à court terme, sous l'effet de la contraction de la demande, et le chômage augmente. Les salaires et les prix diminuent, entraînant un redressement de la production, grâce à l'amélioration de la compétitivité. Mais l'emploi et la production ne retrouvent pas à moyen terme leur niveau initial, et le taux de chômage demeure plus élevé.

Ces mécanismes ne peuvent donc servir que de substitut imparfait au taux de change comme variable d'ajustement dans le cadre de I'Union monétaire. Ce résultat concernant la lenteur du processus d'ajustement est cohérent avec les travaux plus anciens sur les politiques de désinflation compétitive, dont le coût en termes de chômage durable avait été souligné (Blanchard et Muet, 1993). II rejoint également les conclusions de Cadiou et alii (1999), mais en les renforçant. L'utilisation d'un modèle complet intégrant la demande, au 
lieu d'un simple modèle d'offre où la production ne dépend que du jeu des prix relatifs, montre en effet que la récession consécutive à un choc négatif est amplifiée par les effets induits restrictifs sur la demande interne, ce qui retarde le mouvement de reprise.

- Les petits pays font preuve d'une plus grande capacité de réaction face à un choc négatif, grâce à leur degré d'ouverture plus élevé qui donne plus de poids au mécanisme de relance par la compétitivité-prix. Ce résultat, dont l'ampleur doit être relativisée, est cohérent avec le fait que les petits pays européens ont enregistré de meilleures performances en matière d'emploi et de chômage durant les années 1980-1990, en partie parce que les mécanismes de désinflation compétitive y jouaient davantage.

- Plus généralement, les disparités d'évolution entre pays apparaissent non négligeables, même en se limitant à un horizon de court-moyen terme (cinq ans). Parmi les grands pays, c'est au Royaume-Uni que le redressement de l'emploi et du PIB est le plus rapide, en raison d'une baisse des salaires et des prix initialement plus prononcée. La hausse du chômage et les pertes d'emploi sont au contraire plus marquées en Espagne. Enfin, la poussée du chômage est davantage contenue en Italie, grâce à la flexion plus marquée des taux d'activité.

Au total, ces disparités sont plus importantes que dans l'étude de Cadiou et alii (1999), à la fois parce que les différences structurelles en matière d'emploi et de salaires semblent plus marquées dans nos estimations, et parce que la prise en compte des élasticités du commerce extérieur, de la flexibilité du taux de marge et de la flexion des taux d'activité rajoute des facteurs d'asymétrie supplémentaires, qui ont un impact tout à fait sensible dans plusieurs pays. Sans surestimer l'ampleur de ces divergences potentielles qui peuvent naître à la suite d'un choc de même ampleur dans chaque pays, cette question ne peut donc être négligée.

- Enfin, les résultats montrent qu'il serait vain de chercher à accentuer la flexibilité du marché du travail d'une manière systématique et uniforme dans l'espoir de renforcer les mécanismes d'ajustement par les prix et les coûts relatifs. Si, dans l'ensemble, la flexibilité du travail s'est bien accrue depuis les années 1980 dans tous les pays européens, notamment en termes de vitesse d'ajustement de l'emploi, les paramètres macroéconomiques caractéristiques de l'ajustement par le marché du travail ne s'articulent que d'une manière complexe et non linéaire avec les institutions et les réglementations du marché. 


\section{Réponse à un choc négatif de I \% sur la consommation des ménages en Europe}

\section{A. Grands pays}
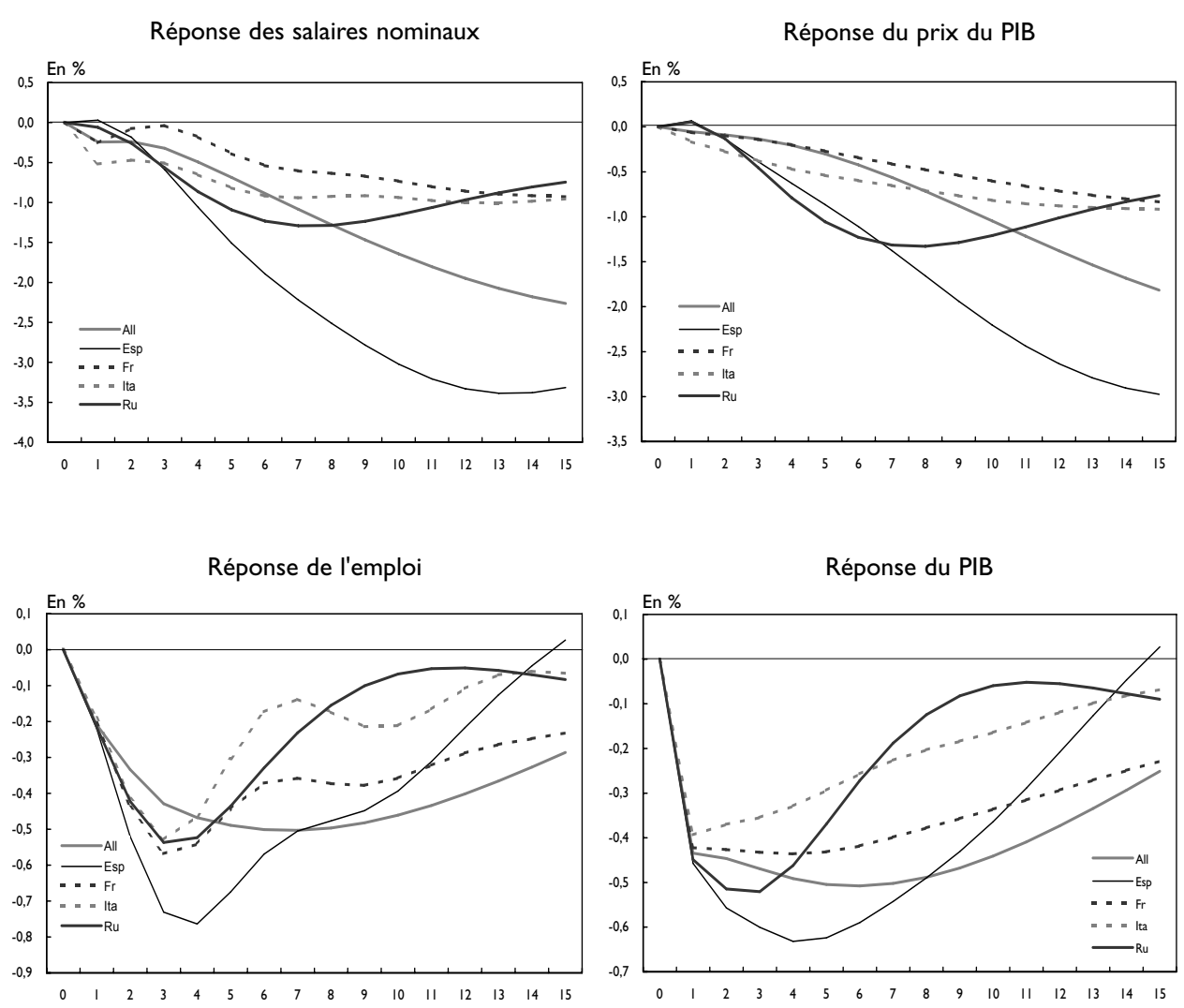

Réponse du taux de chômage
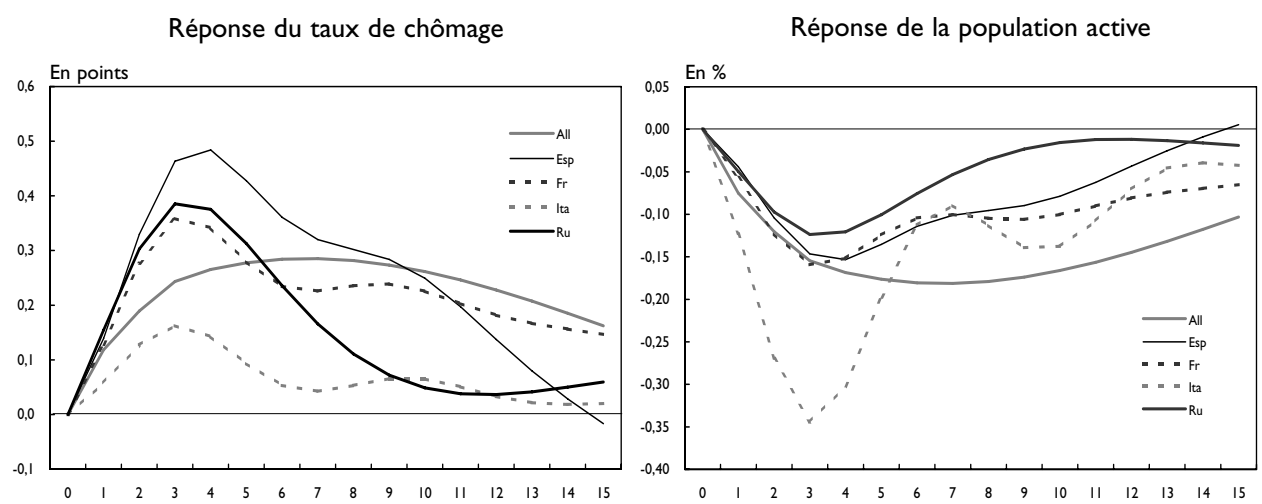

Source : Calculs des auteurs. 


\section{Réponse à un choc négatif de I \% sur la consommation des ménages en Europe}

\section{B. Petits pays}

Réponse des salaires nominaux

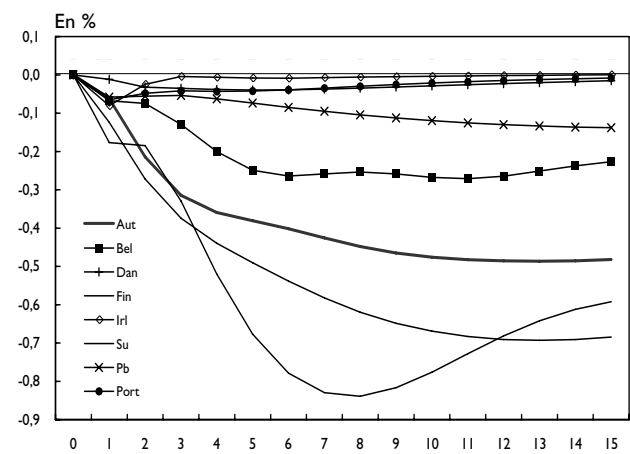

Réponse de l'emploi

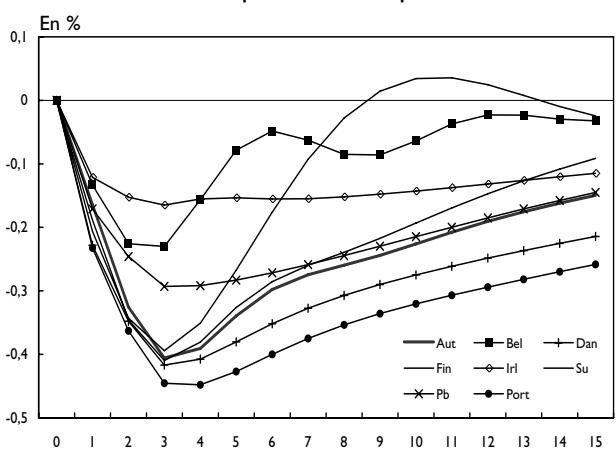

Réponse du taux de chômage

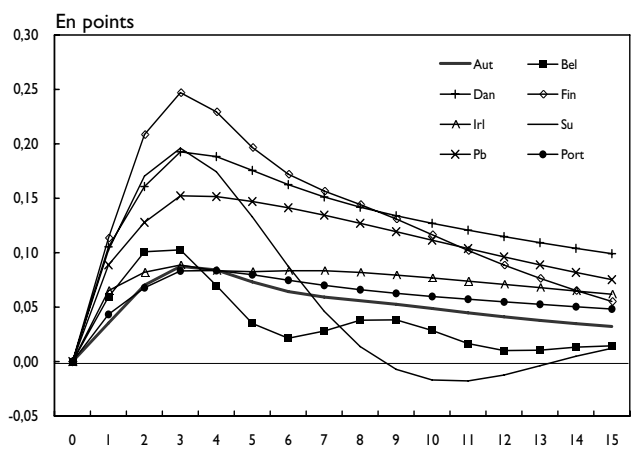

Réponse du prix du PIB

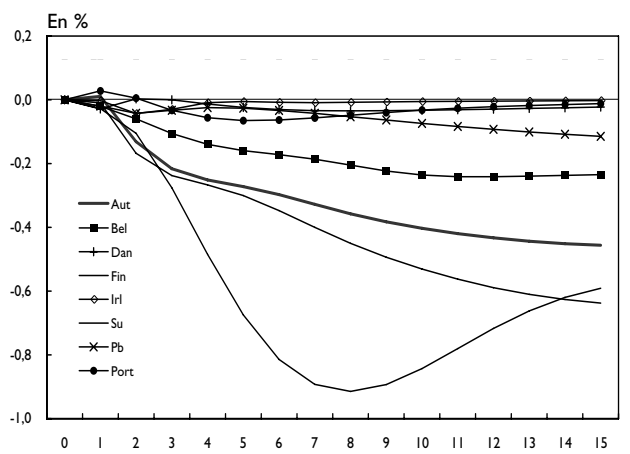

Réponse du PIB

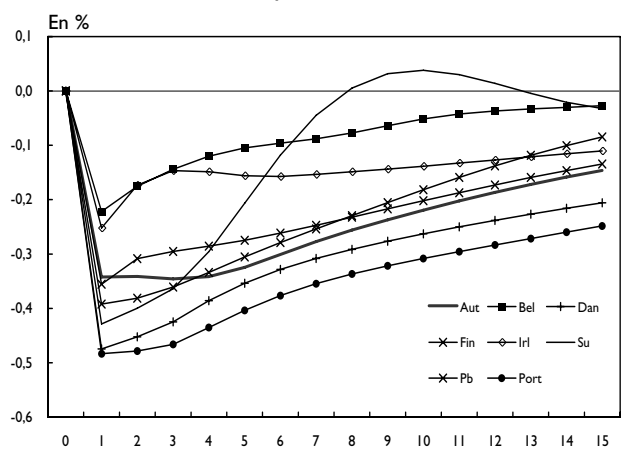

Réponse de la population active

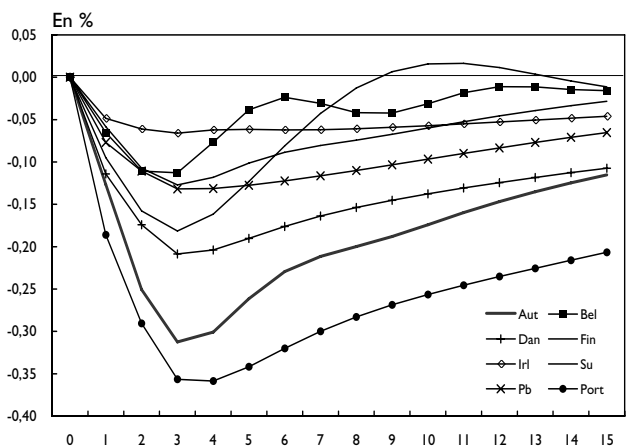

Source : Calculs des auteurs. 


\section{Les effets d'une hausse des salaires}

Plusieurs conclusions peuvent être tirées de la simulation d'une hausse de $10 \%$ du salaire nominal par tête ; elles confortent celles qui avaient été précédemment obtenues (graphiques 2).

- Face à une hausse des salaires, les gains en termes de croissance et de baisse du chômage ne sont que transitoires. Le dérapage inflationniste est amplifié par le jeu de la spirale prix-salaires, et induit un ralentissement par suite de la dégradation de la compétitivité-prix. La montée du chômage entraîne un freinage des prix. La hausse initiale des prix est ainsi maîtrisée à moyen-long terme, mais sans être effacée. Là encore, les ajustements par les prix et les coûts relatifs ne permettent qu'un rééquilibrage incomplet et lent (au-delà de dix ans). Ces résultats rejoignent ceux d'autres études (Cadiou et alii, 1999) en les renforçant. En se limitant à un simple modèle d'offre, la maîtrise du dérapage inflationniste et du chômage est en effet toujours lente, mais elle est plus marquée car il n'y a pas au départ d'effet amplificateur par la relance de la demande.

- Les petits pays européens se distinguent à nouveau. En raison de leur plus grand degré d'ouverture sur l'extérieur et du plus grand impact de la perte de compétitivité- prix, l'effet de relance initiale est plus limité. La poussée inflationniste est ainsi mieux contrôlée et les ajustements par les prix relatifs jouent davantage ; mais, au total, le coût en termes de perte d'emplois et de freinage de la croissance est plus prononcé et plus durable.

- Plus généralement, les disparités d'évolution entre pays sont significatives et paraissent plus importantes que celles mises en évidence dans d'autres études. Les pays se différencient par leur capacité d'ajustement face à un choc salarial aussi bien à court-moyen terme qu'à plus long terme. Parmi les grands pays, le Royaume-Uni se distingue à nouveau par l'ampleur de ses ajustements, avec de fortes pertes d'emplois à moyen terme et un redressement à plus long terme. Parmi les petits pays, la Suède maîtrise davantage la poussée inflationniste à moyen terme. 
Les effets d'une hausse du prix du PIB

Les effets d'un choc exogène de $10 \%$ sur le prix du PIB permettent de retrouver certains des enchaînements précédents (graphiques 3):

- La perte de compétitivité induit une chute de la production et une montée du chômage qui, à moyen terme, permet une maîtrise progressive du dérapage inflationniste. Mais l'ajustement par les prix relatifs n'autorise toujours qu'un rééquilibrage incomplet et lent.

- Les petits pays, plus ouverts sur l'extérieur, sont, sans surprise, davantage affectés, mais la reprise de la croissance et le redressement de l'emploi sont, dans l'ensemble, plus rapides.

- Les disparités entre pays se dégagent à nouveau clairement, avec la plus grande amplitude des ajustements britanniques ou la relative inertie du chômage italien. 


\section{Jacques Mazier, Joël Oudinet et Sophie Saglio}

\section{Réponse à un choc asymétrique de $10 \%$ sur les salaires nominaux en Europe}

\section{A. Grands pays}

Réponse des salaires nominaux

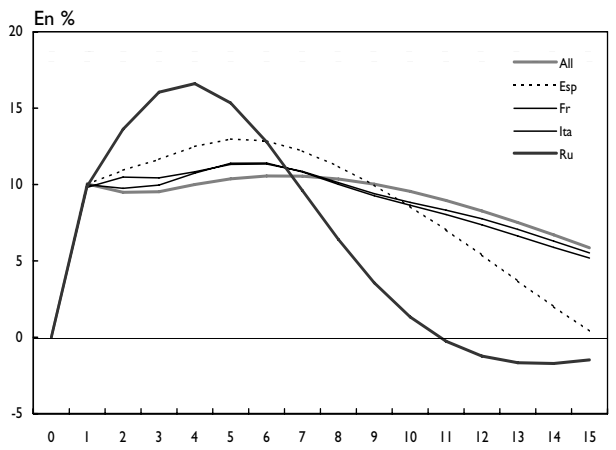

Réponse de l'emploi

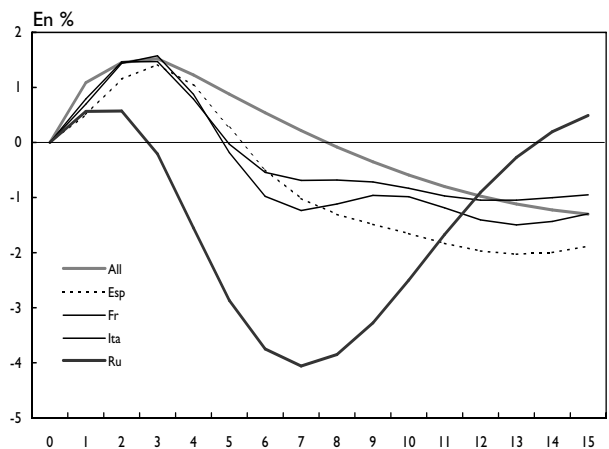

Réponse du taux de chômage

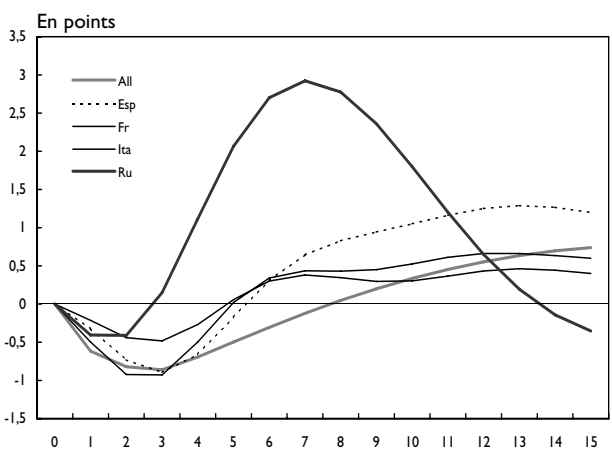

Source : Calculs des auteurs.
Réponse du prix du PIB

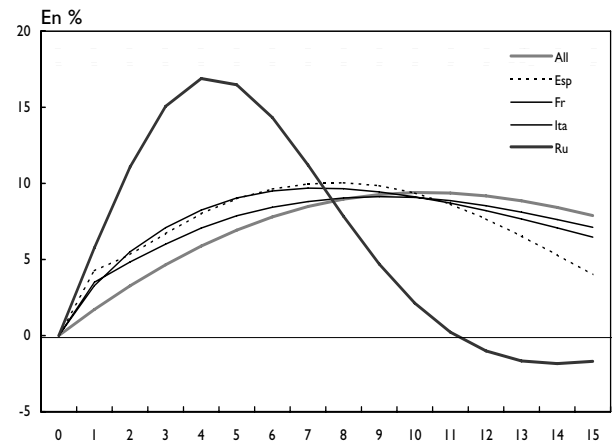

Réponse du PIB

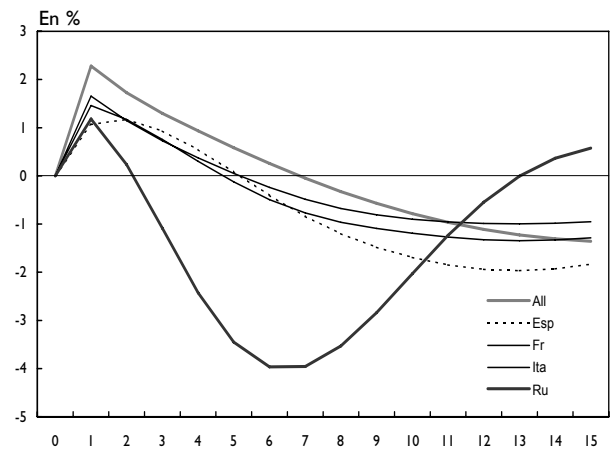

Réponse de la population active

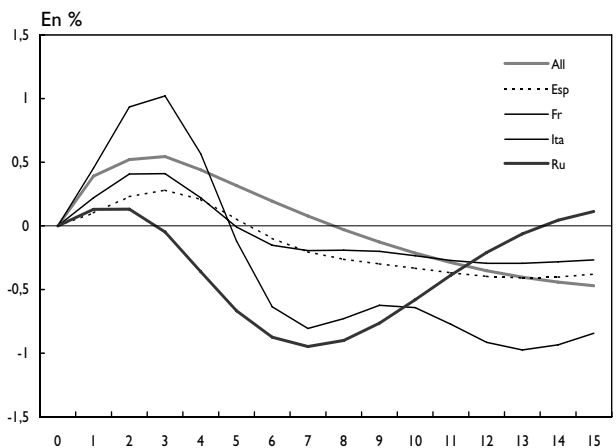




\section{Réponse à un choc asymétrique de $10 \%$ sur les salaires nominaux en Europe}

\section{B. Petits pays}

Réponse des salaires nominaux

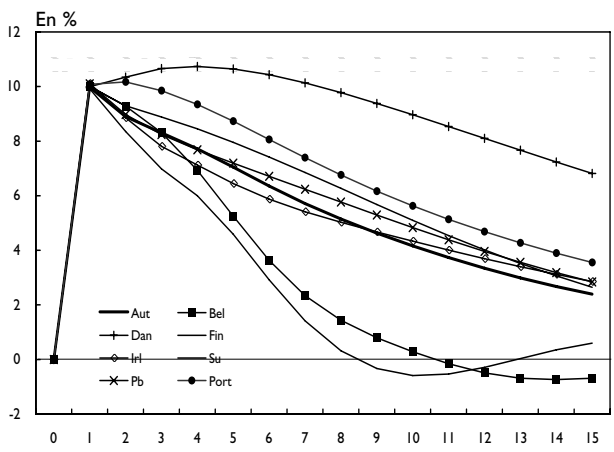

Réponse de l'emploi

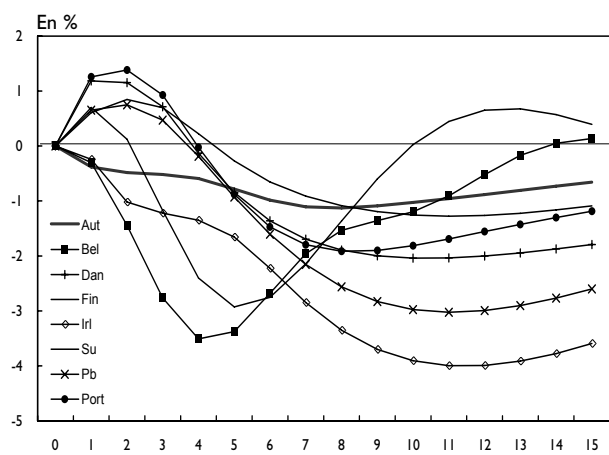

Réponse du taux de chômage

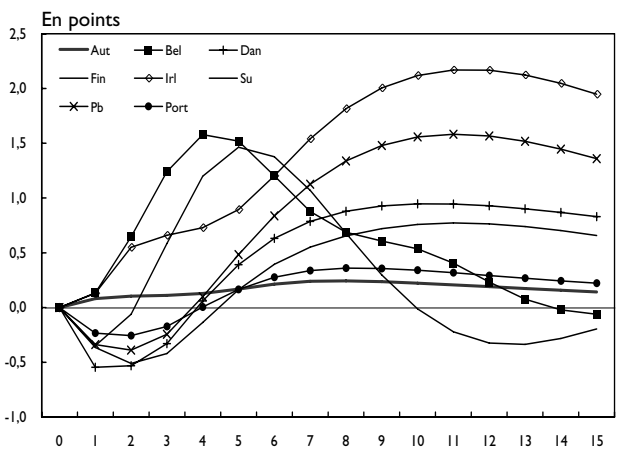

Source : Calculs des auteurs.
Réponse du prix du PIB

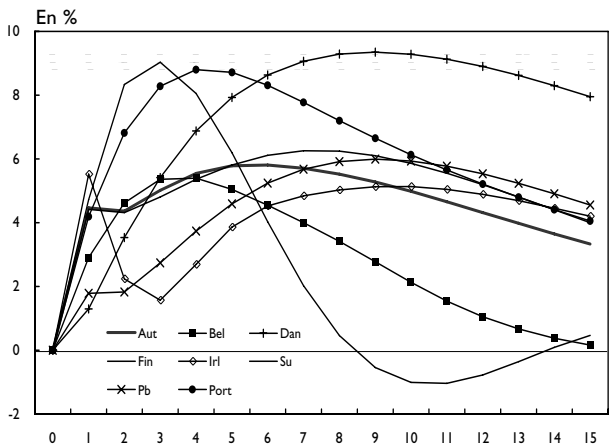

Réponse du PIB

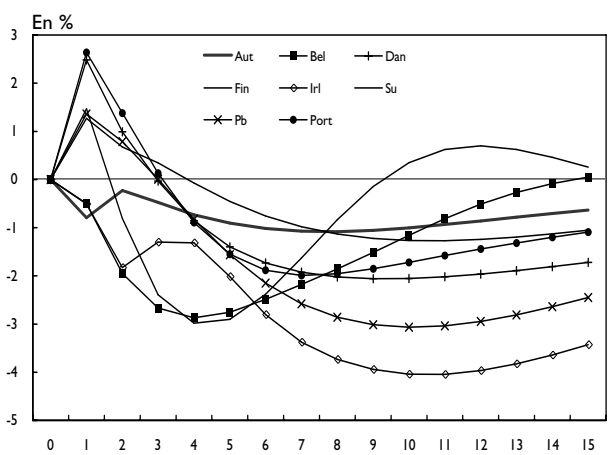

Réponse de la population active

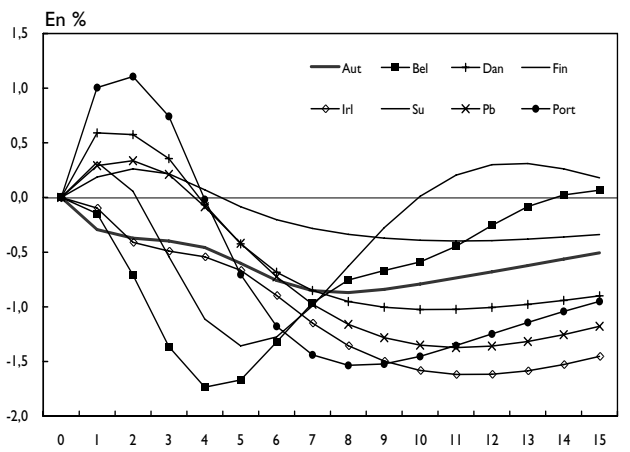




\section{Jacques Mazier, Joël Oudinet et Sophie Saglio}

\section{Réponse à un choc asymétrique de $10 \%$ sur le prix du PIB}

en Europe

\section{A. Grands pays}

Réponse des salaires nominaux

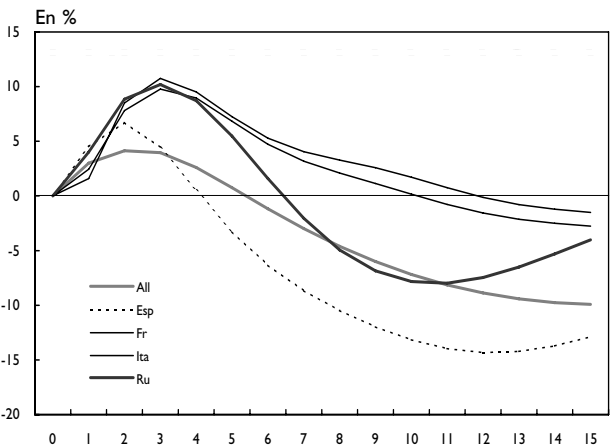

Réponse de l'emploi

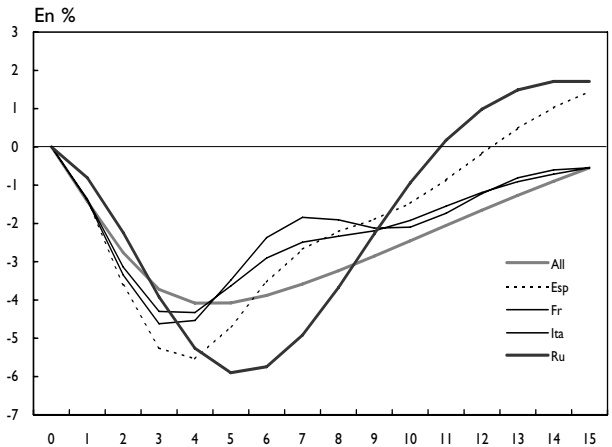

Réponse du taux de chômage

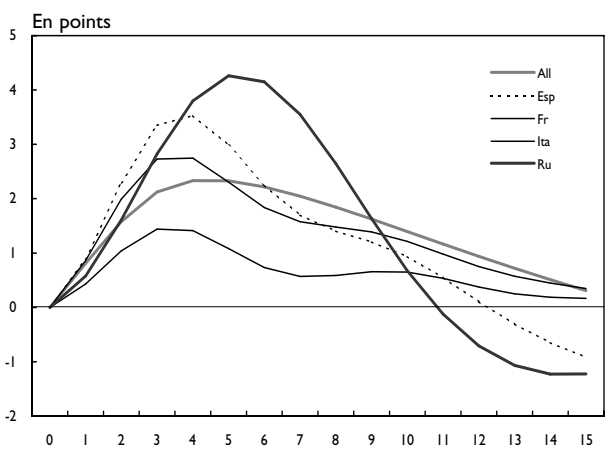

Source : Calculs des auteurs.
Réponse du prix du PIB

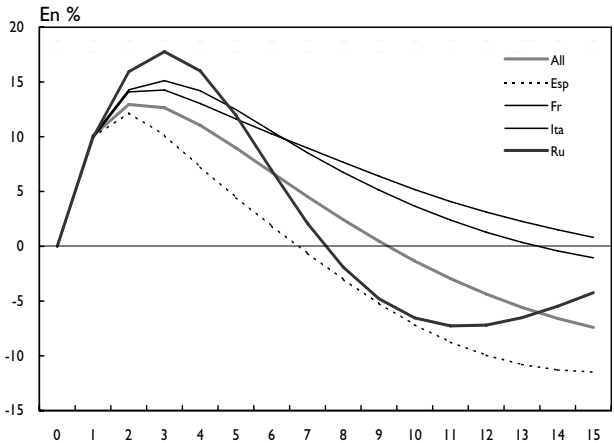

Réponse du PIB

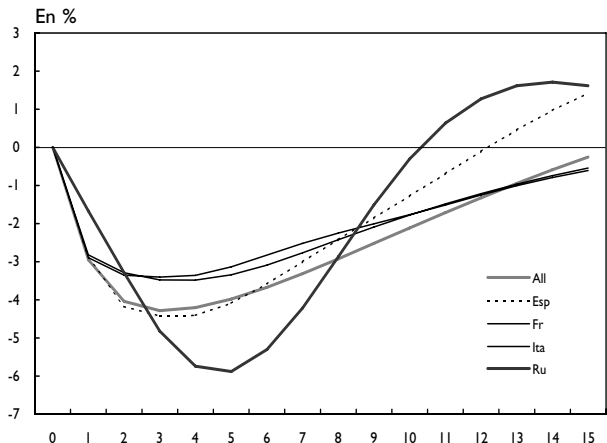

Réponse de la population active

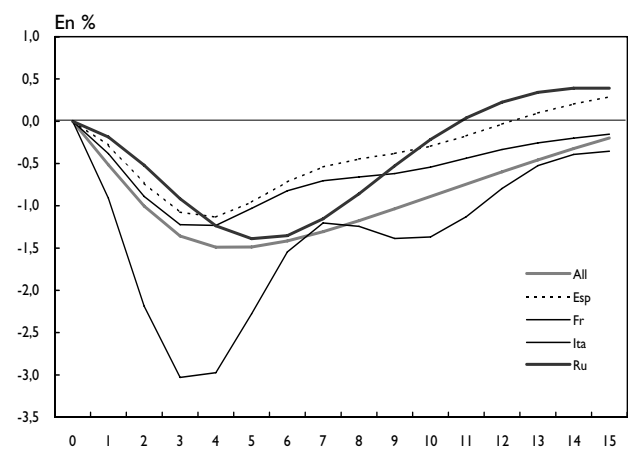




\section{Réponse à un choc asymétrique de $10 \%$ sur le prix du PIB} en Europe

\section{B. Petits pays}

Réponse des salaires nominaux

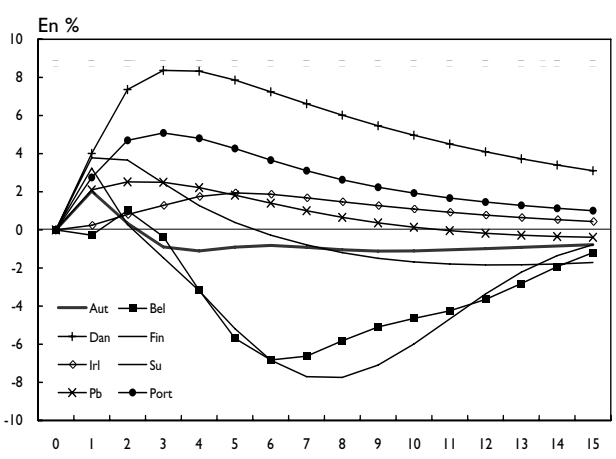

Réponse de l'emploi

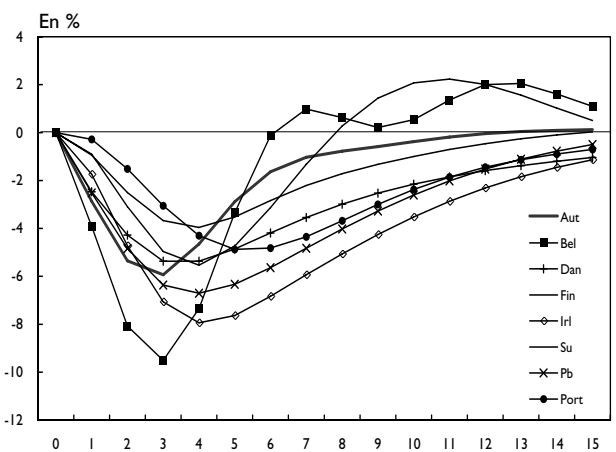

Réponse du taux de chômage

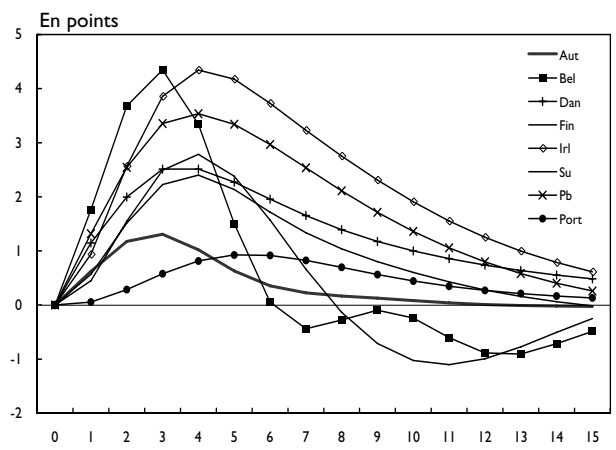

Réponse du prix du PIB

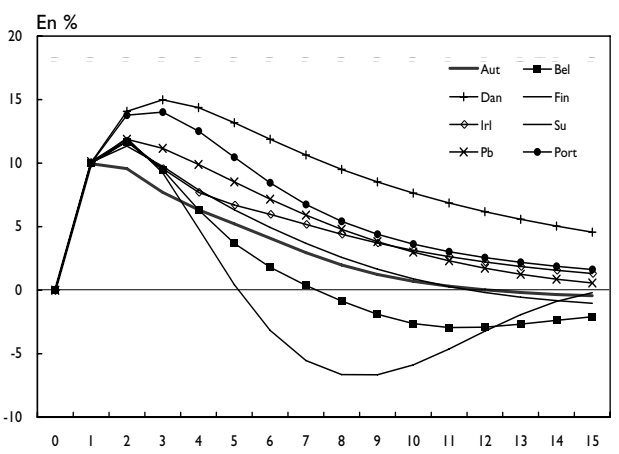

Réponse du PIB

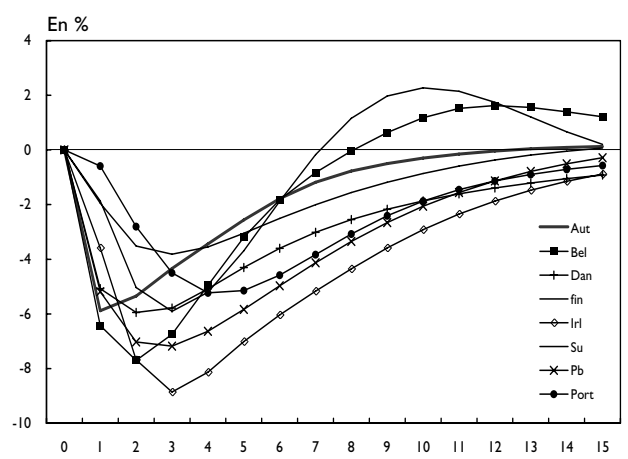

Réponse de la population active

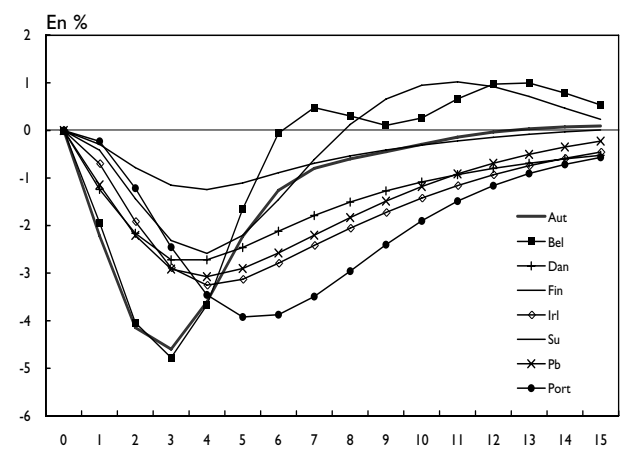

Source : Calculs des auteurs. 


\section{Conclusion et enseignements pour le fonctionnement de l'Union monétaire}

L'étude de la flexibilité des coûts et des prix relatifs à l'aide d'une maquette macroéconomique estimée pour les 14 pays européens a d'abord permis de caractériser d'une manière simple les pays européens, à partir de quelques paramètres représentatifs des ajustements comme le délai d'ajustement de l'emploi, la sensibilité des salaires réels au chômage, la flexibilité des taux d'activité et les élasticités-prix du commerce extérieur. Ces paramètres reflètent d'une manière complexe les formes institutionnelles propres à chaque pays. Des institutions plus libérales ne débouchent pas mécaniquement sur une plus grande flexibilité salariale au niveau macroéconomique. Néanmoins, les mesures de libéralisation prises depuis la fin des années 1970 se sont traduites par un mouvement général dans tous les pays de réduction des délais d'ajustement de l'emploi. C'est en Espagne, en Italie, en France, en Belgique et en Autriche que ce mouvement a été le plus poussé. En revanche, la rigidité des salaires, mesurée par la sensibilité à moyen terme du taux de chômage, n'a pas été réduite d'une manière uniforme. Elle a sensiblement baissé en Allemagne, en Autriche, en Belgique, en Espagne, et dans une moindre mesure, au Royaume-Uni.

La maquette est ensuite utilisée pour étudier les conséquences de chocs d'offre ou de demande asymétriques affectant un pays, et pour comparer les capacités de réaction des pays européens. Les ajustements par le marché du travail et, plus largement, par la flexibilité des prix et des coûts relatifs ne permettent qu'un rééquilibrage incomplet et très lent (au-delà de dix ans). Une distinction peut être établie entre les chocs de demande qui peuvent également être traités par la politique budgétaire et les chocs d'offre pour lesquels une hausse temporaire du chômage est inévitable. Face à un choc négatif sur la demande interne, l'emploi et la production ne retrouvent pas leur niveau initial et le taux de chômage demeure plus élevé. Face à un choc d'offre sur les salaires, les gains en termes de croissance sont transitoires, le dérapage inflationniste entraîne un ralentissement de l'activité et la hausse des prix est maîtrisée sans être effacée. Face à un choc d'offre inflationniste sur le prix du PIB et à la perte de compétitivité, la hausse du chômage qui en résulte ne permet qu'un ajustement progressif et incomplet.

Contrairement à ce qui avait parfois été envisagé par les promoteurs de la monnaie unique et à ce qui est encore avancé dans la période récente face à des évolutions asymétriques comme en Irlande (Blanchard, 200I), ces mécanismes ne peuvent servir de substitut au taux de change comme variable d'ajustement en compensant la 
disparition de la monnaie et des taux d'intérêt comme instruments nationaux de régulation conjoncturelle. Ceci pose d'autant plus problème pour le fonctionnement de l'Union monétaire que d'une part les marges de manœuvre des politiques budgétaires nationales sont réduites dans le cadre des contraintes du Pacte de stabilité, et d'autre part qu'il n'existe pas de politique budgétaire fédérale capable de jouer un rôle de rééquilibrage. Ce résultat est cohérent avec les enseignements des travaux plus anciens sur la désinflation compétitive, qui avaient souligné la lenteur de l'ajustement.

Les disparités de réaction entre pays face à un choc de même ampleur apparaissent, enfin, non négligeables entre grands et petits pays, notamment en raison des inégalités dans le degré d'ouverture qui, dans les petits pays, donnent plus de poids aux effets de la compétitivité- prix. Cette plus grande capacité de réaction des petits pays face à des chocs négatifs peut être rapprochée des meilleures performances en matière d'emploi et de chômage enregistrées en moyenne par ces derniers durant les années 1980-1990. Mais ces divergences dans les évolutions face à un même choc s'observent également entre pays de même taille, du fait des différences structurelles existant dans le fonctionnement du marché du travail comme dans la formation des prix ou dans les échanges extérieurs. Des pays comme le RoyaumeUni, l'Italie ou encore la Suède se distinguent assez clairement. Sans surestimer l'ampleur de ces divergences, celles-ci sont plus marquées que ne l'indiquaient des études récentes (Cadiou, Guichard et Maurel, 1999). Elles sont source d'asymétries et compliquent la conduite de la politique économique dans l'Union monétaire, particulièrement en ce qui concerne la politique monétaire commune.

Ces résultats ont été obtenus à partir d'une analyse portant sur la deuxième moitié des années 1980 et sur les années 1990, durant lesquelles d'importants changements institutionnels sont intervenus. Avec la mise en place de l'euro, des transformations plus profondes peuvent se produire, dans la mesure où le changement de régime monétaire sera plus clairement perceptible pour l'ensemble des acteurs. En matière de salaires, deux scénarios polaires sont avancés.

- Selon le scénario " hollandais », chaque pays cherche à préserver sa compétitivité par des pressions sur les salaires et l'emploi, avec une efficacité faible et un risque de freinage cumulatif de la croissance lorsque cette stratégie se généralise à l'ensemble des pays européens.

- Selon le scénario "Allemagne de l'Est », les salariés des pays à plus bas salaires et à niveau de productivité plus faible s'appuient sur des comparaisons en euros pour revendiquer et obtenir des hausses de salaires, d'où un effet négatif sur la compétitivité et la croissance de ces zones, et un renforcement de la polarisation des activités au profit des pays du centre de l'Europe. 
Ces deux scénarios correspondent à des configurations extrêmes, bien que l'on puisse penser que le premier est le plus probable et a, en partie au moins, déjà été à l'œuvre depuis les années 1980. Une combinaison des deux n'est d'ailleurs pas impossible, le premier se limitant alors aux pays du centre. Une évaluation précise des conséquences de ces deux (ou trois) scénarios serait envisageable avec le modèle multinational simplifié précédent, mais n'a pas été réalisée au stade actuel de la recherche.

Les caractéristiques structurelles telles qu'elles ont été résumées et les chocs élémentaires précédemment réalisés suggèrent tout au plus deux conclusions.

- Une évolution allant dans le sens d'un accroissement supplémentaire de la flexibilité du marché du travail correspond à des tendances qui sont toujours à l'œuvre, sous l'impulsion de certains gouvernements et des organisations patronales. Les résultats obtenus montrent cependant que les paramètres macroéconomiques caractéristiques de l'ajustement par le marché du travail s'articulent d'une manière non univoque avec les institutions et les réglementations adoptées. La marche vers toujours plus de flexibilité aurait donc une traduction macroéconomique incertaine. Son efficacité pour rendre plus rapide et plus complet le rééquilibrage par les prix et les coûts relatifs et pour trouver ainsi un substitut au taux de change le serait encore plus. Une telle voie ne serait donc pas sans risque.

- Une solution alternative consisterait à réhabiliter les politiques salariales au niveau européen, pour donner plus de cohérence au policy mix traditionnel. Cette question est très largement ignorée dans les formes actuelles de la construction européenne, conformément à la doctrine libérale qui a présidé à l'élaboration de l'Europe de Maastricht et d'Amsterdam, et selon laquelle la détermination des salaires ne relève que du marché et se fait de manière décentralisée, Boyer (1999), Maurice(1999). Une harmonisation des évolutions salariales au niveau des pays européens pourrait passer par l'instauration d'un système de négociations à plusieurs niveaux, fondé sur une anticipation des taux d'inflation et intégrant les spécificités nationales en termes de différentiel de productivité ou de niveaux de taux de chômage. De tels arrangements sont complexes à mettre en place. Ils pourraient prendre appui sur des pratiques déjà existantes en fonction des traditions propres à chaque pays (négociations régionales de branches en Allemagne, négociations interprofessionnelles en Suède, négociations de branches aux Pays-Bas). L'expérience des « pactes sociaux 》 signés dans plusieurs pays européens aux structures sociales fort diverses pour satisfaire dans les délais requis les critères de Maastricht, pourrait être valorisée. Des évolutions salariales différenciées par pays devraient en résulter, en préservant, au terme d'une démarche d'apprentissage progressive, une cohérence avec les composantes du policy mix. Cet effort de concertation et de rapprochement pourrait être favorisé par 
les pouvoirs publics, en suscitant des rencontres entre partenaires sociaux et en améliorant les comparaisons internationales en matière de salaires, de productivité et de coûts. Le « dialogue macroéconomique " inscrit dans le processus de Cologne apparaît comme une première étape méritant d'être développée.

\section{Mobilité de la main-d'œurre, ajustements par les prix relatifs: le cas américain}

La flexibilité des prix et des coûts relatifs ne permet que des possibilités d'ajustement limitées face à des chocs ou des évolutions asymétriques affectant un pays en Union monétaire. Ce constat obtenu dans le cas de l'Union européenne rejoint des conclusions voisines établies dans le cas des États américains à partir de l'utilisation d'un modèle VAR (Blanchard et Katz, 1992). Face à un choc négatif sur l'emploi, les ajustements par le salaire nominal ou réel s'avèrent insuffisants. L'emploi diminue à court terme et se redresse à moyen terme, mais demeure durablement inférieur au niveau initial. Pourtant, face à un choc négatif sur la demande de travail, les réponses dynamiques montrent que le taux de chômage, après s'être accrû, revient à son niveau de départ après environ 5 à 7 ans. L'évolution du taux d'activité présente le même profil. Ceci conduit à conclure que le choc initial est en partie absorbé par les mouvements de migration des travailleurs. Ces derniers quitteraient les États affectés par des pertes d'emplois, ce qui faciliterait la résorption du chômage. Ce résultat est cohérent avec des observations faites de longue date sur la dynamique de l'emploi aux États-Unis. La croissance de l'emploi est durablement plus rapide ou plus lente dans certains États que dans d'autres. À l'inverse, aucun État n'est affecté par un taux de chômage plus élevé que la moyenne d'une manière durable.

Cette question de la place respective des ajustements par les prix relatifs et par la mobilité de la main-d'œuvre dans le cas de l'économie américaine va être réexaminée en retenant un découpage fictif de celleci en quatre régions, le Nord-Est, le Sud, le Midwest et l'Ouest. Pour chacune de ces régions, une maquette macroéconomique s'inscrivant dans le même cadre méthodologique que celle de la première partie, mais complétée par une étude des migrations de main-d'œuvre, sera utilisée. Après une présentation des principales caractéristiques du découpage des États-Unis en quatre entités régionales, nous exposons les équations structurelles de la maquette, puis les résultats économétriques obtenus au niveau des quatre régions fictives constitutives de l'économie américaine; enfin, nous décrivons les simulations effectuées. 


\section{Une dynamique macroéconomique régionale contrastée}

Les grands traits de la dynamique régionale sont d'abord présentés à l'aide de graphiques décrivant l'évolution des variables d'une manière relative, c'est-à-dire rapportée à la moyenne des États-Unis, avant d'examiner plus particulièrement la question de la mobilité de la maind'œuvre.

Le découpage retenu est celui des quatre régions de l'US Census (Midwest, Nord-Est, Sud et Ouest), dont la carte ci-dessous donne une représentation (graphique 4). Ces quatre régions représentent des entités économiques d'un poids comparable à celui des grands États européens (de 96 millions d'habitants, pour la plus grande région, le Sud, à $5 \mathrm{I}$ millions pour le Nord-Est en 1999). Deux régions sont particulièrement en croissance depuis 1980, l'Ouest, dont la population est en hausse de plus de $40 \%$, et à un degré moindre le Sud (+ $28 \%$ ).

La dynamique macroéconomique régionale des États-Unis apparaît contrastée, bien que dominée par la dynamique nationale. Chaque région a été différemment affectée par les deux récessions de 1982 et $199 \mathrm{I}$ et a réagi d'une manière spécifique. Sur l'ensemble des deux décennies, le Nord-Est enregistre avec le Midwest les plus mauvaises

\section{Les quatre régions américaines}

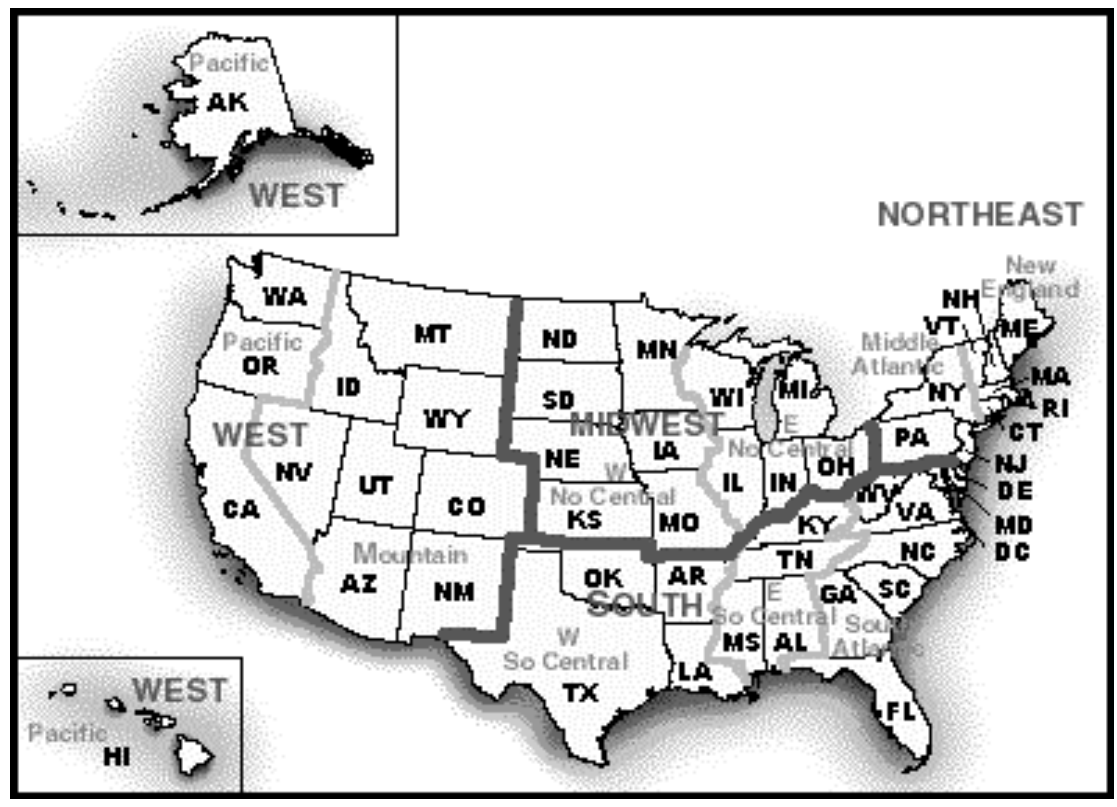

Source : Census. 
performances en termes de croissance, alors que le Sud, grâce au rattrapage des années 1990, enregistre avec l'Ouest de meilleures performances. Le contraste est de ce point de vue frappant avec le Nord-Est (graphique 5).

Les facteurs de divergence apparaissent plus durables en termes d'emploi qu'en termes de PIB régional. L'Ouest et le Sud sont d'une manière permanente plus créateurs d'emplois que le Midwest, et le Nord-Est (graphique 6). Cette opposition ne se retrouve pas au niveau du taux de chômage et il n'y a pas de régions durablement affectées par un chômage plus élevé. Le Midwest, particulièrement atteint par la crise du début des années 1980 avec une forte poussée du chômage, a vu son taux baisser sous la moyenne dès 1992. À l'inverse, au NordEst, les restructurations et la reprise des années 1980 ont permis de faire fortement baisser le taux de chômage avant une nouvelle remontée (graphique 7).

Cette divergence entre les évolutions de l'emploi et du taux de chômage est à rapprocher de celle de la population. C'est dans les régions où la croissance de la population en âge de travailler a été la plus rapide que les créations d'emplois ont été les plus fortes, ce qui explique, par exemple, que le taux de chômage soit plus élevé que la moyenne dans l'Ouest à la fin des années 1990, malgré le grand nombre d'emplois créés. Mais le même constat peut être fait avec la population corrigée des effets de l'immigration nette intra-américaine (graphique 8). Les ajustements par les migrations de main-d'œuvre n'interviendraient que d'une manière secondaire pour éviter que les écarts en termes de création d'emplois ne se traduisent par des écarts persistants en termes de taux de chômage. C'est l'une des questions auxquelles on s'efforcera de répondre plus loin. Par contre, les fluctuations des taux d'activité ont un impact sur les variations des taux de chômage. On remarque aussi le haut niveau du taux d'activité du Midwest, qui compense en partie la faiblesse de la croissance de la population (graphique 9).

En raison de l'indexation incomplète et retardée, les vagues d'inflation et de désinflation ont eu un impact sensible sur le pouvoir d'achat du salaire par tête, qui se retrouve dans l'ensemble des régions, mais d'une manière inégale d'une région à l'autre. La croissance du salaire réel a été plus rapide au Sud et plus lente à l'Ouest et au Midwest, permettant ainsi une légère réduction de la hiérarchie des salaires régionaux (graphique 10). Au niveau des prix à la consommation, les écarts apparaissent faibles entre les régions et reflètent davantage des réponses à des chocs sans caractère permanent. En conséquence, la tendance au resserrement se retrouve dans les salaires régionaux en dollars, bien que la hiérarchie soit demeurée stable. Malgré une croissance légèrement plus rapide, les salaires par tête du Sud demeurent inférieurs de près de $10 \%$ à la moyenne américaine (graphique II). 


\section{Jacques Mazier, Joël Oudinet et Sophie Saglio}

\section{Indice du PIB relatif par régions}

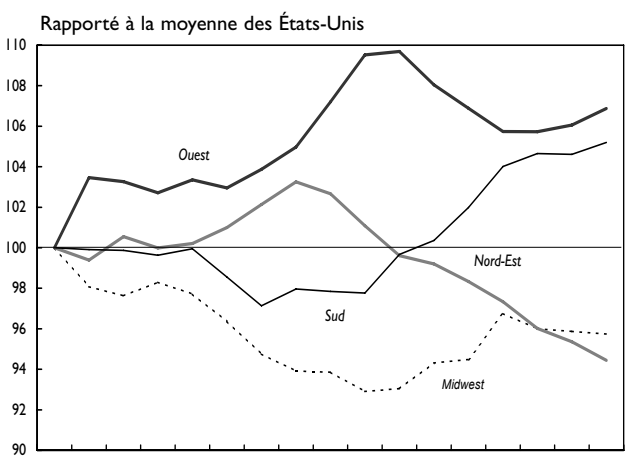

19811982198319841985198619871988198919901991199219931994199519961997

Source : Calcul des auteurs à partir des données du Bureau of Economic Activity.

\section{Indice de l'emploi relatif}

Rapporté à la moyenne des États-Unis

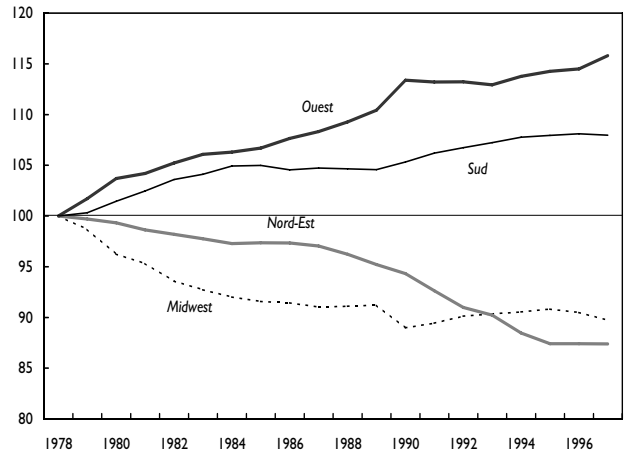

\section{Indice du taux de chômage relatif par régions}

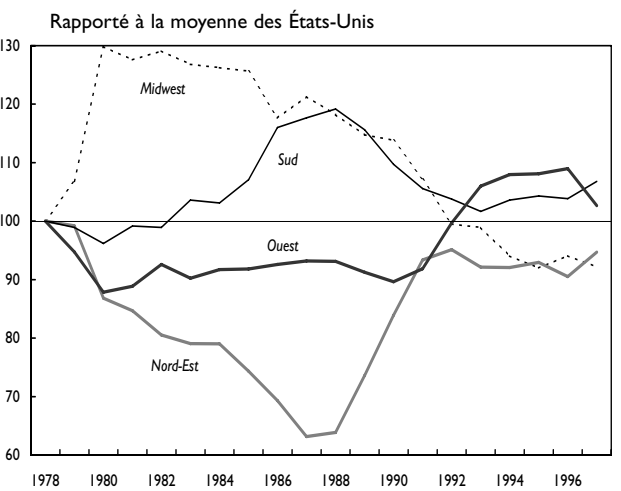

Source : Calcul des auteurs à partir des données du Bureau of Labor Statistics.
8. Indice de population en âge de travailler relative déflatée des migrations internes

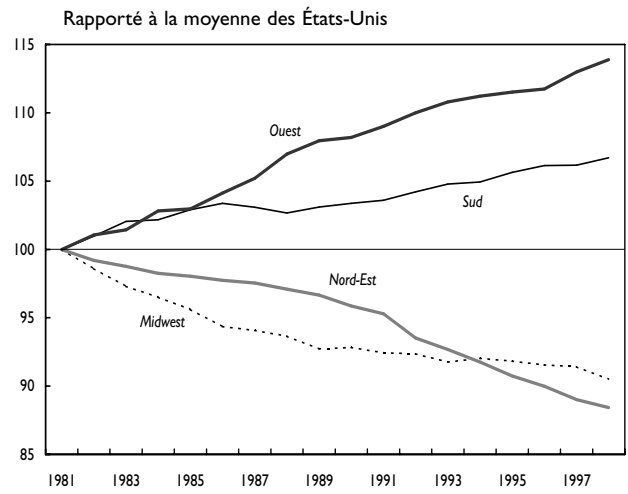




\section{Niveau du taux d'activité relatif}

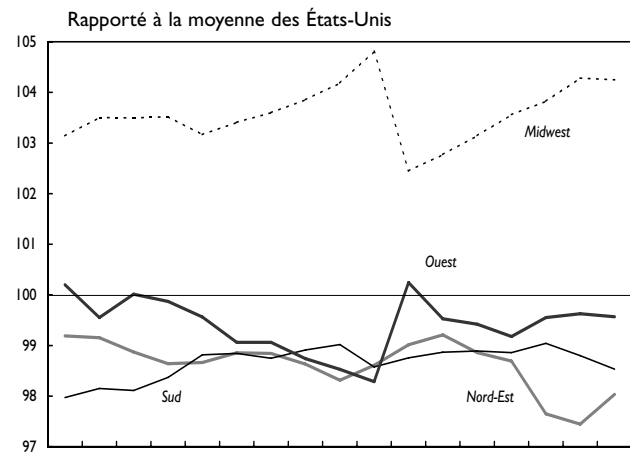

19811982198319841985198619871988198919901991199219931994199519961997

Sources : Calcul des auteurs à partir des données du Census et du bureau of Labor Statistics.

\section{Indice de salaires réels relatifs par régions}

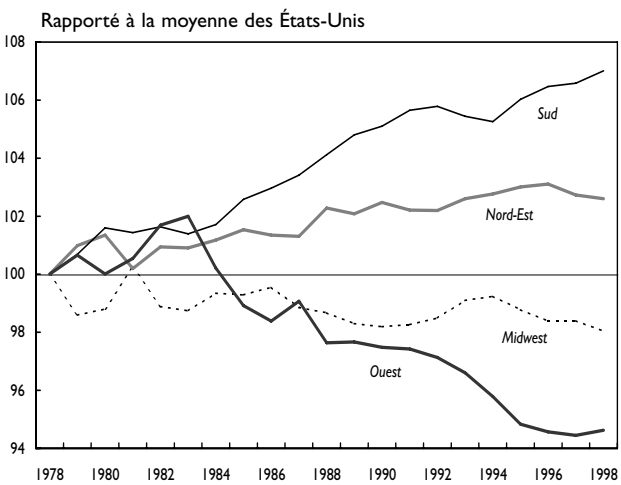

Source : Calcul des auteurs à partir des données du Bureau of Labo Statistics.

\section{Niveau de salaires nominaux relatifs}

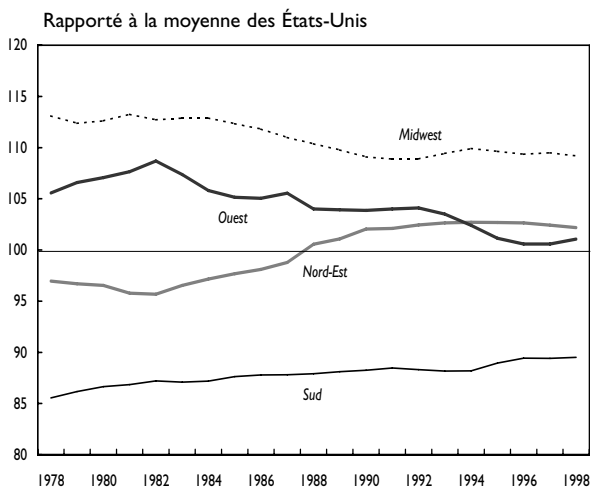

Source : Calcul des auteurs à partir des données du Bureau of Labor Statistics.

\section{Solde migratoire interne cumulé}

En milliers

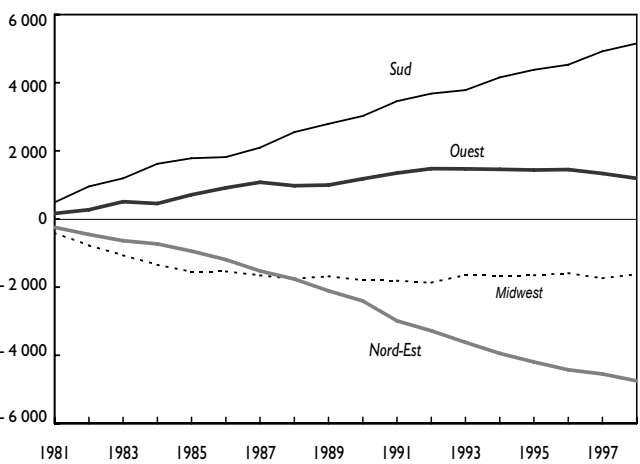

Source : Calcul des auteurs à partir du Census. 


\section{La mobilité de la main-d'œurre aux États-Unis}

Deux régions sont des régions d'immigration nette, le Sud et, dans une moindre mesure, l'Ouest, alors que deux régions sont d'émigration nette, le Nord- Est et, d'une manière moins marquée depuis le milieu des années 1980, le Midwest. Les flux de population concernés sont importants, puisque le Sud a gagné plus de 5 millions de personnes en termes cumulés entre 1981 et 1998, alors que le Nord-Est en perdait 4,7 millions pendant le même temps (graphiques 12 et 13). Dans cette approche, bien que l'on ne s'intéresse qu'aux flux de migration intra-régionaux, les mouvements d'immigrants étrangers d'une région à l'autre sont pris en compte. Les taux de migration sont de l'ordre de 0,8 à I,6\% de la population totale. Ils sont, sans surprise, très au-dessus des chiffres équivalents pour les pays européens. En Allemagne, pays qui accueille le plus d'immigrés de nationalité européenne, ces derniers ne représentent que $0,2 \%$ de la population en 1997, contre 0,I \% au Royaume-Uni et moins de 0,I \% dans les autres pays (tableau 3).

L'immigration nette de la région Ouest jusqu'au milieu des années 1990, avec un flux d'immigrants déclinant de $2 \%$ à I,I5\% de la population totale et un flux d'émigrants également déclinants de I,9\% à $1,3 \%$, peut être rapprochée d'un niveau de salaire légèrement supérieur à la moyenne nationale, et d'une capacité plus grande à créer des emplois. Par contre, l'immigration nette de la région Sud (I,58\% de la population totale à l'entrée et $\mathrm{I}, 23 \%$ à la sortie) ne peut s'expliquer que par la croissance de l'emploi et non par un salaire inférieur en niveau à la moyenne nationale. C'est aussi la faiblesse relative des emplois créés qui vraisemblablement, exerce une incitation à l'émigration nette au Nord-Est. De même, les gens quittent le Midwest, malgré un taux de salaire supérieur à la moyenne.

\section{Immigration et émigration}

Flux intra-zone

En \% de la population totale

\begin{tabular}{lll|lll}
\hline \multicolumn{1}{c}{ Taux immigration } & 1985 & 1997 & Taux émigration & 1985 & 1997 \\
\hline Midwest & 1,43 & 1,05 & Midwest & 1,79 & 1,30 \\
Nord-Est & 0,97 & 0,93 & Nord-Est & 1,37 & 1,16 \\
Sud & 1,63 & 1,42 & Sud & 1,44 & 1,01 \\
Ouest & 2,08 & 1,16 & Ouest & 1,53 & 1,36 \\
\hline Allemagne & 0,110 & 0,184 & Allemagne & 0,136 & 0,194 \\
Espagne & 0,007 & 0,035 & Espagne & & \\
France & 0,018 & 0,011 & France & & \\
Italie & 0,012 & 0,016 & Italie & 0,004 & 0,005 \\
Royaume-Uni & 0,036 & 0,105 & Royaume-Uni & 0,018 & 0,055 \\
\hline
\end{tabular}

Source : US Census et Eurostat. 


\section{3a. Immigration interne}

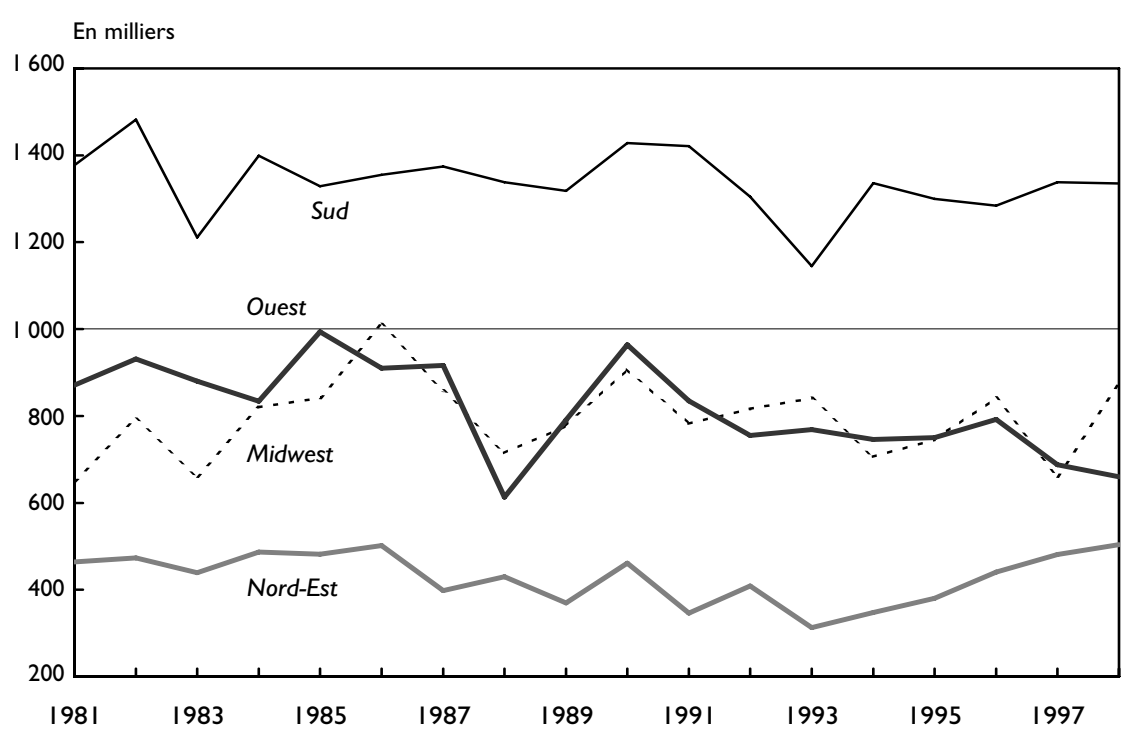

I3b. Emigration interne

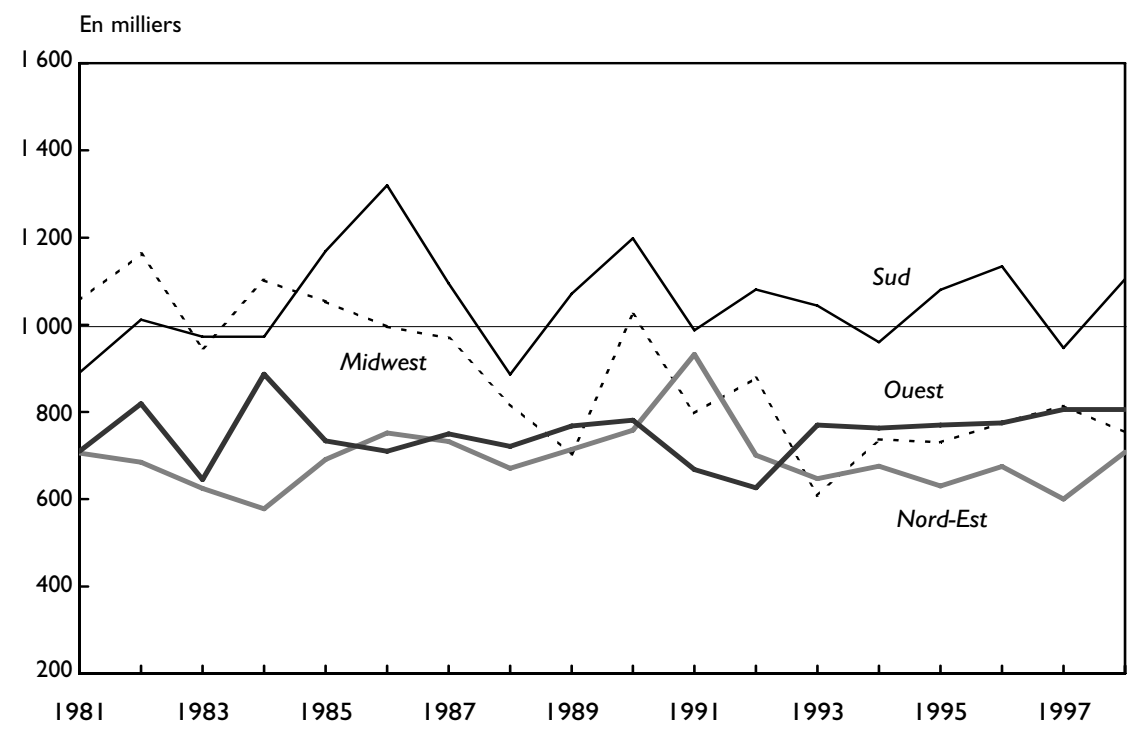

Source : Census. 


\section{Les facteurs explicatifs des migrations et leur impact sur l'emploi}

Les facteurs explicatifs des migrations sont de plusieurs ordres. Certains sont liés à l'état du marché du travail (différences de salaires et recherche d'un emploi). D'autres renvoient à certaines caractéristiques des pays d'accueil ou d'origine ou à une analyse plus fine des comportements des migrants.

Les différences de salaires entre régions sont l'une des variables les plus souvent avancées, les migrants se déplaçant des zones à faibles salaires vers les zones à salaires plus élevés. Cette variable semble jouer d'une manière plus significative dans le cas des États-Unis que dans celui des pays européens (Eichengreen, 1993). Les gains escomptés grâce à la migration dépendent également des perspectives d'emplois comparées dans les deux régions. D'où un effet de répulsion, les travailleurs étant incités à quitter les régions à taux de chômage relatif élevé, et un effet d'attraction exercé par les régions plus fortement créatrices d'emplois. Le taux de chômage relatif ou le taux de croissance comparé de l'emploi entre deux zones peuvent ainsi servir de variables explicatives. Les estimations réalisées dans le cas américain conduisent à donner plus de poids aux perspectives d'emplois et à l'effet d'attraction, Houseman et Abraham (199I), Gruidi et Pulver (199I). Les résultats sont moins bons avec le taux de chômage relatif, en partie parce que le chômage est en général plus important pour les groupes les moins mobiles de la population (travailleurs non qualifiés ou plus âgés) et qu'un niveau élevé de chômage dans l'ensemble des zones (récession généralisée) réduit la probabilité de migrer, Pissarides et Wadsworth (1989), Eichengreen (1993).

Les analyses précédentes conduisent à retenir des variables explicatives identiques (salaire relatif, taux de croissance comparé de l'emploi, taux de chômage relatif), mais jouant en sens inverse pour l'immigration et l'émigration. Une corrélation négative devrait donc s'observer entre flux entrant et sortant d'une même zone. Or tel n'est pas le cas, puisque l'on constate une corrélation positive entre les deux pour le Midwest $(+0,195)$ et quasi-nulle pour le Sud et l'Ouest $(+0,006$ et $+0,004)$; seul le Nord-Est a une corrélation négative $(-0,257)$. Cette observation a conduit des auteurs comme Schachter et Althaus (1989) à relativiser le rôle de ces variables explicatives et à souligner, au contraire, celui de facteurs attractifs propres à certaines régions, tels que le climat (la température moyenne est alors utilisée comme proxy), le niveau des équipements publics, la qualité de l'environnement ou encore l'effet «langue ». En outre, la mobilité de la main-d'œuvre est d'autant plus grande que la croissance globale est forte, ce qui fournit un dernier facteur commun jouant dans le même sens sur les deux flux de migration (Greenwood, Hunt et McDowell, 1986). 
Des facteurs complémentaires interviennent également tels que l'effet « diaspora », c'est-à- dire l'effet d'attraction exercé par un stock de migrants déjà en place, ou l'influence des coûts de transport et de distance, ce dernier effet jouant très peu en pratique. Des analyses plus fines conduisent à mettre l'accent sur certaines caractéristiques des migrants : le sexe, les hommes émigrant en premier, mais avec un phénomène de regroupement familial pouvant intervenir ensuite ; l'âge, les jeunes actifs ayant une plus forte tendance à émigrer; ou la qualification, les individus mieux formés étant plus mobiles. La prise en compte de l'hétérogénéité des migrants et de leurs comportements est d'ailleurs mise en avant par certains auteurs pour expliquer le parallélisme, a priori surprenant, entre flux entrants et flux sortants (Evans, 1990). Ces différents paramètres faisant appel à une plus grande finesse d'analyse sont en général difficiles à intégrer dans une approche de type macroéconomique qui se limite à des déterminants plus globaux. Ils plaident cependant pour une analyse séparée de l'émigration et de l'immigration, et non pour une approche limitée aux seuls soldes, c'est-à-dire à la migration nette.

Soulignons enfin que les facteurs explicatifs des migrations ne jouent pas d'une manière mécanique et que des configurations institutionnelles adaptées doivent exister. Ainsi aux États-Unis, bien que les salaires du Sud aient été inférieurs de moitié à ceux du Nord, les migrations sont restées très limitées jusqu'à la Seconde Guerre mondiale. II a fallu attendre des changements institutionnels majeurs dans le cadre du New Deal et un fort choc de demande dans le Nord pour enclencher un processus d'émigration.

Les migrations exercent deux effets distincts sur l'emploi: d'une part, un effet direct sur l'offre de travail, qui a un rôle rééquilibrant dans le pays d'origine ; d'autre part un effet indirect sur la demande de biens et services dans le pays d'accueil, qui peut avoir un impact positif sur la production et sur l'emploi de celui-ci, et limiter ainsi la réduction des disparités en matière de chômage et d'emploi entre les deux pays induite par le mécanisme précédent.

Face à un choc négatif sur la demande qui entraîne une augmentation du chômage et une baisse du salaire, l'émigration réduit l'offre de travail dans le pays d'origine, atténuant ainsi la montée du chômage et la pression sur les salaires. Dans le pays d'accueil, l'arrivée des migrants accroît l'offre de travail mais n'a qu'un très faible effet sur les salaires des autochtones (négatif pour ceux qui ont un emploi substituable et positif pour ceux qui sont complémentaires, Borjas, 1994). Par contre, il paraît utile de prendre en compte la flexion des taux d'activité qui peut intervenir dans le pays d'origine à la suite du départ des migrants, et dans le pays d'accueil à la suite de leur arrivée. Cette flexion des taux d'activité contribuerait à rendre le chômage davantage persistant (Bartik, 199I). 
Les flux migratoires peuvent enfin avoir un impact sur la demande dans le pays d'accueil si les migrants arrivent avec un certain patrimoine et si des investissements en infrastructures ou en équipements sociaux sont rendus nécessaires et effectués. L'accroissement de la population par les flux migratoires peut ainsi induire une hausse de la production et des créations d'emplois dans le pays d'accueil. Certaines estimations dans le cas des États-Unis confirment cette forte capacité à créer des emplois (un emploi créé pour une migration supplémentaire, d'après Greenwood et Hunt, 1984).

\section{Une maquette représentative des ajustements par la mobilité de la main-d'œurre et les prix relatifs}

Sans retenir l'ensemble des variables précédemment envisagées, une modélisation très simple de la mobilité de la main-d'œuvre est proposée. Elle est combinée avec une étude de l'ajustement par les prix relatifs assez semblable à celle retenue pour les pays européens. Les relations de bouclage macroéconomique par la demande ne pouvant être testées économétriquement en raison de l'absence des données correspondantes donneront lieu à un simple calibrage. Pour faciliter les comparaisons avec le cas européen, les valeurs des paramètres (élasticités-prix et revenu du commerce extérieur, propension à dépenser) seront supposées égales aux valeurs moyennes estimées au niveau de l'ensemble des pays européens. Le tableau 4 compare, pour l'année 1997 où des statistiques sont disponibles, les degrés d'ouverture des quatre régions américaines aux degrés d'ouverture des pays européens. II montre que les échanges intrarégionaux aux États-Unis occupent, en pourcentage du PIB régional, une place sensiblement supérieure à celle des échanges intra-

4. Comparaison des degrés d'ouverture intra-régionaux aux Etats-Unis et intra-européens en Europe*

En \%

Etats-Unis

Année 1997

\begin{tabular}{c|c|c|c}
\hline Midwest & Nord-Est & Sud & Ouest \\
\hline 33,7 & 24,8 & 25,8 & 20,1 \\
\hline
\end{tabular}

Europe

Moyenne 1997-1998-1999

\begin{tabular}{c|c|c|c|c|c|c|c|c|c|c|c|c|c}
\hline All & Aut & Bel & Dan & Esp & Fin & Fra & Gre & Irl & Ita & PB & Port & Ru & Su \\
\hline 12,4 & 20,4 & 48,6 & 17,6 & 14,7 & 16,8 & 13,2 & 9,8 & 38,3 & 11,2 & 30,2 & 22,6 & 11,6 & 19,6 \\
\hline
\end{tabular}

* (Exportations + Importations intra-régionales/2) / PIB, calculs effectués sur l'ensemble des biens. Source : US Bureau of Transportations et CHELEM. 
européens pour les grands pays, mais comparable à celle des petits pays européens. Par contre, on retient des relations salaires-prixchômage au niveau de chaque région, conformément à certaines estimations obtenues au niveau des Etats américains, Hyclak et Johnes (1989), Payne (1995), sans indexation unitaire à long terme.

\section{Mobilité de la main-d'cuvre}

Compte tenu de la corrélation positive entre les taux d'immigration et ceux d'émigration, nous effectuons des estimations séparées des taux, avec, comme variables explicatives liées à l'état du marché du travail, les salaires ou revenus relatifs, et les perspectives d'emploi ou le taux de chômage relatif. La migration nette est la résultante comptable de ces deux équations de comportement.

$$
\begin{gathered}
I M / P O P=f\left(w / w * \text { ou } \frac{Q / N}{(Q / N) *}, U / U * \text { ouN } / N^{*}, c\right) \\
E M / P O P=f\left(\begin{array}{c}
w / w * \text { ou } \frac{Q / N}{(Q / N)^{*}}, U / U * \text { ouN } / N^{*}, c \\
E M T=a 2 E M \quad M N=I M-E M
\end{array}\right) \\
\left.I M T=a 1 I M \quad \begin{array}{c}
E M T=I M T-E M T \\
M N T=I M T
\end{array}\right)
\end{gathered}
$$

Avec $I M$ et $E M=$ flux d'immigrants entrants et sortants dans l'année en provenance ou en direction des autres régions américaines, $P O P=$ population totale de la région, $w / w^{*}=$ salaire par tête relatif par rapport à la moyenne des autres régions américaines concurrentes,

$(Q / N) /(Q / N)^{*}=$ productivité par tête relative prise comme approximation du revenu par tête relatif,

$U / U^{*}=$ taux de chômage relatif avec un effet négatif, ou $N / N^{*}=$ emploi relatif avec un effet positif,

$c=$ constantes spécifiques

$I M T$ et $E M T=$ flux de migrants en âge de travailler (I8-64ans); $a 1$ vaut 71 \% pour le Midwest et le Sud, $69 \%$ pour le Nord-Est et l'Ouest; $a 2$ vaut $67,5 \%$ pour le Midwest et le Sud, $72,5 \%$ pour le Nord-Est et l'Ouest (cf. annexe statistique)

$M N=$ migration nette de la région,

$M N T=$ migration nette en âge de travailler de la région .

\section{Population active}

L'équation de flexion des taux d'activité dépend classiquement des créations d'emplois mais aussi des flux d'entrées de migrants, par un effet d'entraînement. 


$$
\begin{gathered}
\frac{P A}{P A T}=\left(\frac{N}{P A T}\right)^{\alpha}\left(\frac{I M T}{P A T}\right)^{\beta} \\
P O P=P O P R+I M-E M \quad P A T=P A T R+I M T-E M T
\end{gathered}
$$

Avec $P A=$ population active de la région, $N=$ emploi de la région, $P O P=$ population totale, $P O P R=$ population déflatée de la migration nette, $P A T=$ population en âge de travailler de la région (I8-64 ans), $P A T R=$ population en âge de travailler diminuée de la migration nette en âge de travailler.

\section{Une synthèse des résultats}

Les équations ont été testées pour l'ensemble des quatre régions américaines avec la méthode SUR (Seemingly Unrelated Regressions), qui permet d'avoir des contraintes inter-équations sur les coefficients, avec, dans certains cas, une formulation du type de modèle à correction d'erreur. Les résultats des estimations portant sur la période 1982-1997 sont annexés.

\section{Les équations de migration, de population active et d'emploi}

Le salaire du secteur manufacturier et du secteur privé en termes relatifs n'est pas significatif et il est apparu préférable de retenir, toujours en termes relatifs, le PIB régional par tête c'est-à-dire la productivité du travail, comme variable représentative des revenus attendus par les migrants. Cette variable, joue positivement dans le cas de l'immigration avec une élasticité de 0,9 , mais n'est pas significative dans le cas de l'émigration. Si l'augmentation du salaire de la région d'accueil tend à attirer des immigrants, quelle que soit la région (puisque le coefficient est similaire pour les quatre régions), celle du salaire de la région d'origine n'a pas d'impact sur le comportement des émigrants (tableau 5).

Ce sont les perspectives d'emploi, et non pas le taux de chômage, qui sont fondamentales dans le choix de migrer, avec des semi-élasticités élevées, 3,5 et 3,8. Les importantes créations d'emplois dans le Sud et dans l'Ouest sont cohérentes avec les niveaux plus élevés du taux d'immigration et le déclin des taux d'émigration. À l'inverse pour le Midwest et le Nord-Est, le déclin de l'emploi contribue à expliquer le niveau relativement élevé de l'émigration et la faiblesse de l'immigration. Les aménités régionales comme les conditions climatiques ou les dotations en infrastructures influencent les choix de migration, mais ne sont pris en compte que d'une manière globale à travers l'introduction d'effets fixes par régions. 


\section{Elasticités du taux d'immigration et d'émigration}

\begin{tabular}{l|c|c}
\hline \multicolumn{1}{c|}{$1982-1997$} & Taux d'immigration (Log IM/POP) & Taux d'émigration (Log EM/POP) \\
\hline $\log ((\mathrm{Q} / \mathrm{N}) /(\mathrm{Q} / \mathrm{N}) *)$ & 0,905 & $\mathrm{~ns}$ \\
$\operatorname{dlog}\left(\mathrm{N} / \mathrm{N}^{*}\right)$ & 3,588 & $-3,887$ \\
Trend & $-0,020$ & - \\
\hline
\end{tabular}

Source : Calculs des auteurs.

À ces deux équations de taux de migration s'ajoutent une équation de taux d'activité et une équation d'emploi. L'élasticité à long terme de la population active par rapport à l'emploi est comprise entre 0,55 et 0,59 dans le Midwest, le Sud et l'Ouest. L'élasticité est plus forte dans le Nord-Est $(0,65)$, ce qui tend à réduire l'amplitude des mouvements de chômage, mais peut favoriser des phénomènes de persistance du chômage. L'équation de population active décrit aussi une flexion du taux d'activité en fonction des taux d'immigration. Un flux croissant d'entrées de migrants entraîne un relèvement du taux d'activité, mais l'élasticité faible à long terme (entre 0,0 l et 0,047 ) indique que les migrants n'ont pas un impact très fort sur la flexion du taux d'activité des résidents dans les régions américaines. C'est encore au Nord-Est que cet effet est le plus marqué (tableau 6).

L'équation d'emploi a une configuration habituelle avec une élasticité à court terme comprise entre 0,34 dans le Midwest et 0,62 dans le Nord-Est. C'est la faible force de rappel $(-0,17)$ qui explique un délai moyen d'ajustement plus élevé au Sud. Les délais des trois autres régions sont légèrement plus élevés que ceux des pays européens, puisqu'ils sont compris entre I,I et I,8 année alors que plusieurs pays européens ont un délai inférieur à l'année pour cette période.

6. Elasticités de long terme provenant des équations du taux d'activité, d'emploi et de salaire

\begin{tabular}{l|c|c|c|c}
\hline \multicolumn{1}{c|}{ 1982-1997 } & Midwest & Nord-Est & Sud & Ouest \\
\hline N/PAT & 0,546 & 0,651 & 0,565 & 0,589 \\
IM/PAT & 0,013 & 0,047 & 0,025 & 0,029 \\
Délais moyens d'ajustement & 1,823 & 1,129 & 3,232 & 1,382 \\
Rigidité réelle & 2,76 & 1,83 & 1,41 & 1,59 \\
\hline
\end{tabular}

Source : Calculs des auteurs. 


\section{Les équations de salaires et de prix}

Deux équations de salaires de type Philips ont été testées, la première limitée au secteur manufacturier, la seconde portant sur l'ensemble du secteur privé (voir annexes). L'indexation des salaires sur les prix est incomplète, même à long terme, et est plus faible au niveau du secteur privé. Ce résultat, qui est conforme avec ce qui est généralement obtenu, est différent de l'indexation unitaire retenu à long terme pour les pays européens. La sensibilité au taux de chômage est comprise entre 0,2 et 0,4 . C'est dans le Midwest, région la plus syndiquée, qu'elle est la plus faible. De plus, une indexation partielle par rapport à la productivité du travail s'observe dans plusieurs cas.

Deux équations de prix de production et de prix à la consommation ont également été retenues et sont données en annexe.

Une synthèse des paramètres représentatifs des ajustements par le marché du travail peut être faite à partir des trois paramètres que sont le délai moyen d'ajustement de l'emploi, la rigidité réelle des salaires (mesurée par le rapport du degré d'indexation des salaires sur les prix à la sensibilité du taux de salaire au chômage) et l'élasticité à long terme de la population active à l'emploi (tableau 6). Le Sud se caractérise par un long délai d'ajustement de l'emploi compensé par une faible rigidité salariale. Par contre, le Midwest semble la région la moins flexible, puisque rien ne vient compenser une forte rigidité salariale. Les deux autres régions, l'Ouest et le Nord-Est semblent assez proches, si l'on excepte une forte flexibilité du taux d'activité qui caractérise le Nord-Est.

\section{Les simulations de chocs}

Comme dans la première partie portant sur l'Union européenne, deux types de chocs sont effectués, des chocs de demande négatifs et des chocs d'offre sur les salaires. À l'instar des pays européens, il s'agit de choc asymétrique affectant une région particulière. Le modèle fonctionne avec les quatre régions américaines interdépendantes en supposant, pour simplifier et faute de données, que les élasticités volume et prix des échanges intra et extra-américains sont les mêmes pour toutes les régions et sont égales aux valeurs moyennes estimées pour les pays européens. 


\section{Les effets d'une baisse de la demande interne}

Un choc négatif sur la production équivalent à I \% du PIB (graphiques 14) réduit l'emploi et fait monter le chômage. Les salaires et les prix baissent. La contraction de la demande induite par la baisse des salaires et de l'emploi rend plus durable les effets du ralentissement initial. Trois mécanismes de rééquilibrage jouent.

- L'ajustement par les prix relatifs intervient comme dans le cas des pays européens, la baisse des prix stimulant l'offre au détriment des autres régions et améliorant l'emploi. Ce réajustement est d'une ampleur inégale selon les régions. II est assez faible au Midwest où la rigidité salariale est la plus forte. À l'inverse, la flexibilité salariale du Sud permet un retour de l'emploi vers l'équilibre, mais qui est ralenti par la faible vitesse d'ajustement de l'emploi. C'est au Sud que le rééquilibrage par les prix relatifs est le plus long à se dessiner, l'inflexion de l'emploi n'intervenant qu'au bout de huit ans.

- La flexion du taux d'activité par rapport à l'emploi permet de réduire la hausse du chômage. Cet effet est plus particulièrement sensible au Nord-Est et à l'Ouest. Ainsi, la baisse initiale de l'emploi à l'Ouest de 0,57 \% ne provoque qu'une hausse du chômage inférieure à 0,2 point.

- L'immigration diminue avec la baisse des salaires combinée à celle des perspectives de l'emploi, limitant la croissance de la population active et faisant baisser le chômage. Mais cet effet est faible, compte tenu de la valeur des paramètres, et joue surtout à court terme. Les déterminants principaux des migrations sont en effet de nature structurelle et liés aux caractéristiques des régions ou des migrants (qualité des infrastructures ou climat, âge ou qualification des migrants). La faiblesse de cet effet d'ajustement par les migrations est illustrée en comparant le résultat des simulations avec ceux obtenus à l'aide d'un modèle où le bloc migration a été retiré. Les résultats des deux simulations apparaissent très proches (tableau 7). Le chômage augmente légèrement moins à court terme dans le modèle avec migration, mais les prix et les salaires sont plus élevés et la croissance du PIB plus réduite.

Au total, les effets sur l'emploi d'un choc négatif sur la production présentent un caractère persistant avec un rééquilibrage partiel, l'emploi perdant encore $0,6 \%$ au bout de 13 ans. L'inflexion des tendances se situe autour de la sixième année, et c'est au Nord-Est que l'ajustement est le plus fort. Le rééquilibrage, bien qu'également incomplet, est plus marqué concernant le chômage, en partie grâce à la flexion des taux d'activité. Enfin, les mouvements migratoires jouent bien un rôle d'ajustement pour limiter la hausse du chômage, mais cet effet est d'une ampleur modeste. Dans l'ensemble, les ajustements sont d'un ordre de grandeur comparable à celui des grands pays européens. 
7. Comparaison des effets d'un choc négatif de I \% sur le PIB entre les deux modèles avec ou sans le bloc migration (avec-sans)

\begin{tabular}{l|c|c|c|c|c|c}
\hline & Salaire & Prix & Emploi & PIB & $\begin{array}{c}\text { Taux de } \\
\text { chômage }\end{array}$ & $\begin{array}{l}\text { Population } \\
\text { active }\end{array}$ \\
\hline Midwest & & & & & & $-0,0016$ \\
I an & 0,0003 & 0,0001 & 0,0000 & 0,0000 & $-0,0015$ & $-0,0,0140$ \\
3 ans & 0,0079 & 0,0021 & 0,0003 & 0,0006 & $-0,0134$ & $-0,0,0015$ \\
I3 ans & 0,0124 & 0,0103 & $-0,0016$ & $-0,0020$ & 0,0029 & 0,0015 \\
\hline Nord-Est & & & & & & \\
I an & 0,0128 & 0,0053 & 0,0009 & 0,0015 & $-0,0416$ & $-0,0435$ \\
3 ans & 0,0444 & 0,0249 & 0,0013 & 0,0013 & $-0,0169$ & $-0,0164$ \\
I3 ans & 0,0306 & 0,0402 & $-0,0139$ & $-0,0148$ & 0,0212 & 0,0085 \\
\hline Sud & & & & & & \\
I an & 0,0230 & 0,0054 & 0,0010 & 0,0023 & $-0,0578$ & $-0,0614$ \\
3 ans & 0,0490 & 0,0166 & 0,0014 & 0,0023 & $-0,0194$ & $-0,0194$ \\
I3 ans & 0,0771 & 0,0678 & $-0,0095$ & $-0,0144$ & 0,0158 & 0,0071 \\
\hline Ouest & & & & & & \\
I an & 0,0092 & 0,0019 & 0,0008 & 0,0013 & $-0,0262$ & $-0,0274$ \\
3 ans & 0,0272 & 0,0111 & 0,0017 & 0,0021 & $-0,0110$ & $-0,0100$ \\
I3 ans & 0,0335 & 0,0366 & $-0,0087$ & $-0,0101$ & 0,0085 & 0,0003 \\
\hline
\end{tabular}

Source : Calculs des auteurs.

\section{Les effets d'une hausse des salaires}

Face à une hausse de $10 \%$ des salaires (graphiques 15), les prix augmentent et la production diminue au profit des autres régions. Le choc sur les salaires exerce un effet de relance à court terme qui accroît les pressions inflationnistes initiales. À moyen terme la relance fait place à une baisse de la production et de l'emploi et à une montée du chômage.

Trois facteurs de rééquilibrage sont présents.

- La hausse du chômage pèse sur les salaires et sur les prix, ce qui contribue à redresser la compétitivité et permet un redressement de la production. Mais ce réajustement est, comme précédemment, progressif et d'une ampleur limitée. Seul le Nord-Est connaît un retour des salaires vers l'équilibre à moyen terme en raison de la plus forte sensibilité des salaires au chômage.

- La flexion à la baisse des taux d'activité, particulièrement sensible à l'Ouest et plus réduite dans le Sud, limite la hausse du chômage mais ceci atténue en sens inverse la pression sur les salaires et les prix. 
- Les flux migratoires interviennent en dernier lieu avec une baisse de l'immigration nette en raison de la chute des revenus par tête et de l'emploi à long terme. Ceci réduit la population active et, par suite, le chômage, ce qui entraîne également à terme une moindre pression sur les salaires et les prix. L'ampleur de cet ajustement par les flux migratoires demeure faible, même au Nord-Est comme le montre à nouveau la comparaison des simulations effectuées avec et sans bloc migration (tableau 8). L'effet d'accroissement à court terme de l'immigration nette liée à la hausse des salaires et des revenus n'entraîne qu'une hausse légère du chômage mais cet effet n'est pas durable et une évolution de sens inverse s'observe à moyen avec le mouvement de baisse de la production.

Au total les effets d'une hausse de $10 \%$ des salaires nominaux présentent un caractère persistant. Les rééquilibrages par les prix relatifs et par les migrations n'interviennent qu'à plus long terme sans pouvoir se manifester à l'horizon de la simulation (graphiques 14). Malgré la flexion du taux d'activité le taux de chômage demeure durablement plus élevé avec l'amorce d'une inflexion à moyen terme seulement au Nord-Est. Les flux migratoires n'ont qu'un impact limité. Les ajustements sont proches de ceux observés dans le cas des pays européens, bien que d'une ampleur plus réduite dans l'ensemble.

8. Comparaison des effets d'un choc de $10 \%$ sur les salaires nominaux entre les deux modèles avec ou sans le bloc migration (avec - sans)

\begin{tabular}{l|c|c|c|c|c|c}
\hline & Salaire & Prix & Emploi & PIB & $\begin{array}{c}\text { Taux de } \\
\text { chômage }\end{array}$ & $\begin{array}{c}\text { Population } \\
\text { active }\end{array}$ \\
\hline Midwest & & & & & & \\
I an & $-0,0005$ & $-0,0001$ & 0,0000 & $-0,0001$ & 0,0022 & 0,0024 \\
3 ans & $-0,0083$ & $-0,0022$ & $-0,0003$ & $-0,0005$ & 0,0066 & 0,0068 \\
I3 ans & 0,0324 & 0,0125 & 0,0011 & 0,0009 & $-0,0160$ & $-0,0155$ \\
\hline Nord-Est & & & & & & \\
I an & $-0,0181$ & $-0,0070$ & $-0,0012$ & $-0,0020$ & 0,0529 & 0,0551 \\
3 ans & $-0,0286$ & $-0,0189$ & 0,0002 & 0,0012 & $-0,0494$ & $-0,0515$ \\
I3 ans & 0,2784 & 0,2173 & $-0,0179$ & $-0,0242$ & $-0,0274$ & $-0,0474$ \\
\hline Sud & & & & & \\
I an & $-0,0286$ & $-0,0063$ & $-0,0012$ & $-0,0027$ & 0,0650 & 0,0687 \\
3 ans & $-0,0475$ & $-0,0153$ & $-0,0013$ & $-0,0020$ & 0,0105 & 0,0100 \\
I3 ans & 0,2633 & 0,1051 & 0,0058 & 0,0058 & $-0,0635$ & $-0,0617$ \\
\hline Ouest & & & & & & \\
I an & $-0,0166$ & $-0,0031$ & $-0,0013$ & $-0,0023$ & 0,0427 & 0,0448 \\
3 ans & $-0,0341$ & $-0,0153$ & $-0,0018$ & $-0,0018$ & $-0,0097$ & $-0,0121$ \\
I3 ans & 0,1520 & 0,0893 & 0,0025 & 0,0001 & $-0,0309$ & $-0,0300$ \\
\hline
\end{tabular}

Source : Calculs des auteurs. 


\section{Réponse à un choc asymétrique négatif de I \% sur le PIB dans les régions américaines}

Réponse des salaires nominaux

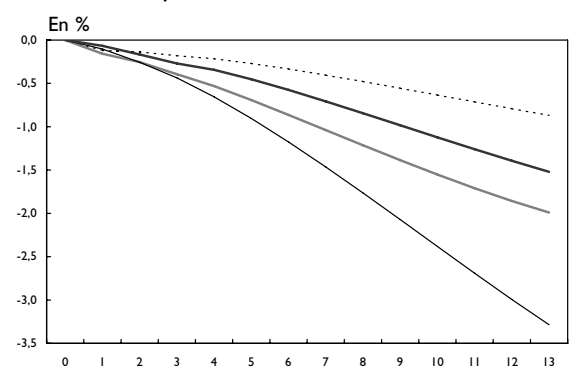

Réponse de l'emploi

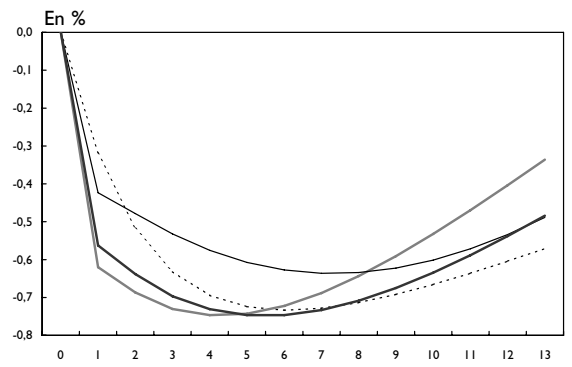

Réponse du taux de chômage

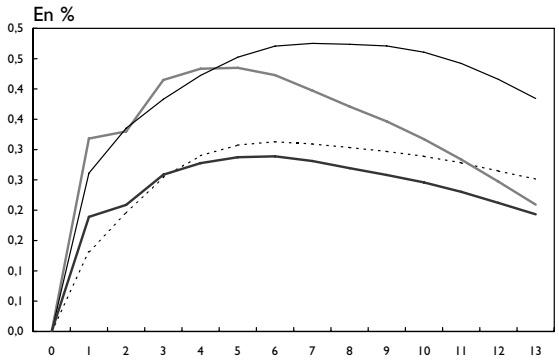

Réponse du flux d'émigration

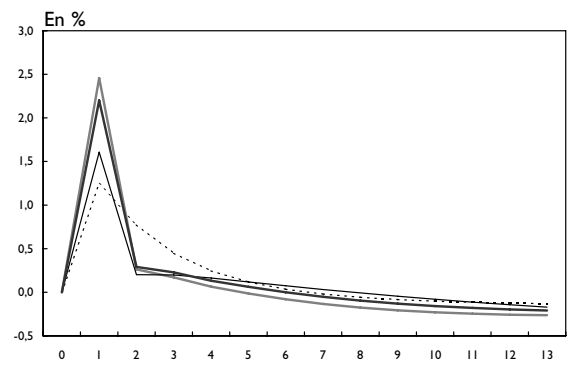

Source : Calculs des auteurs.
Réponse du prix du PIB

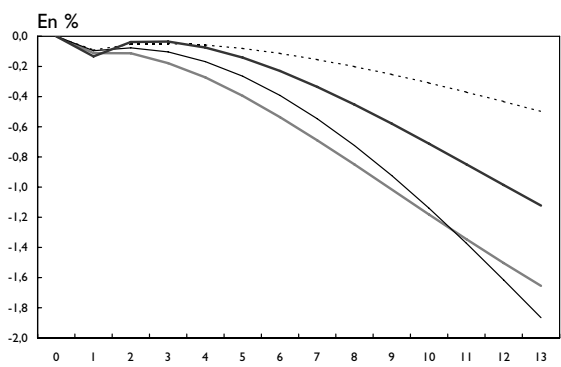

Réponse du PIB

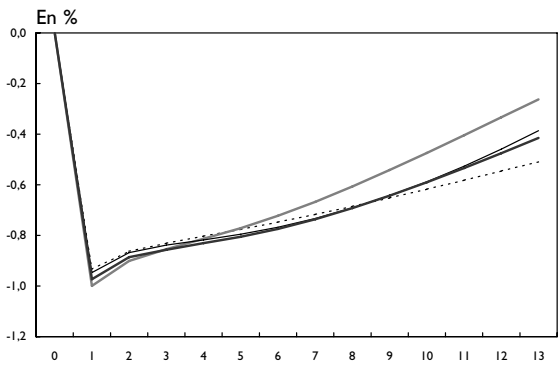

Réponse de la population active

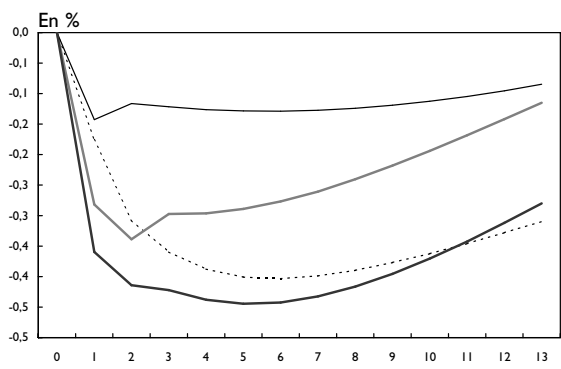

Réponse du flux d'immigration

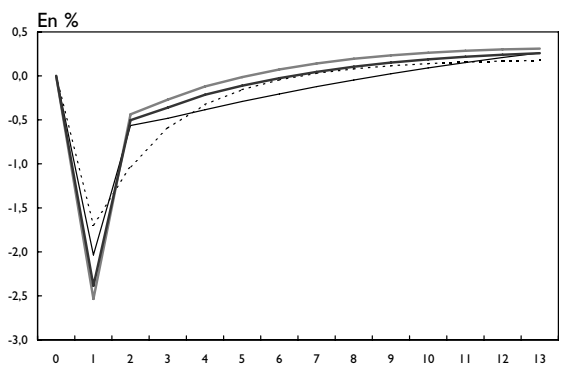

Légende : — Sud — Ouest — Nord-Est -..--.-.-. Midwest 


\section{Réponse à un choc asymétrique de $10 \%$ sur les salaires nominaux dans les régions américaines}
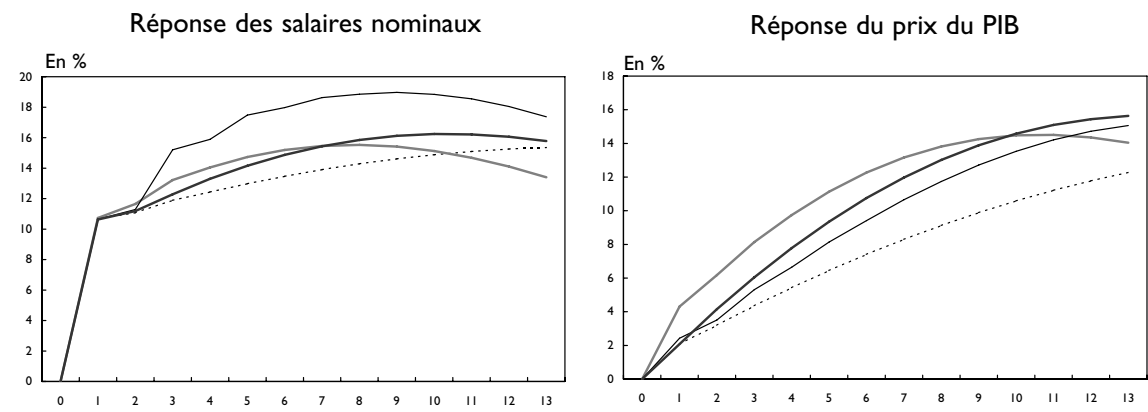

Réponse de l'emploi
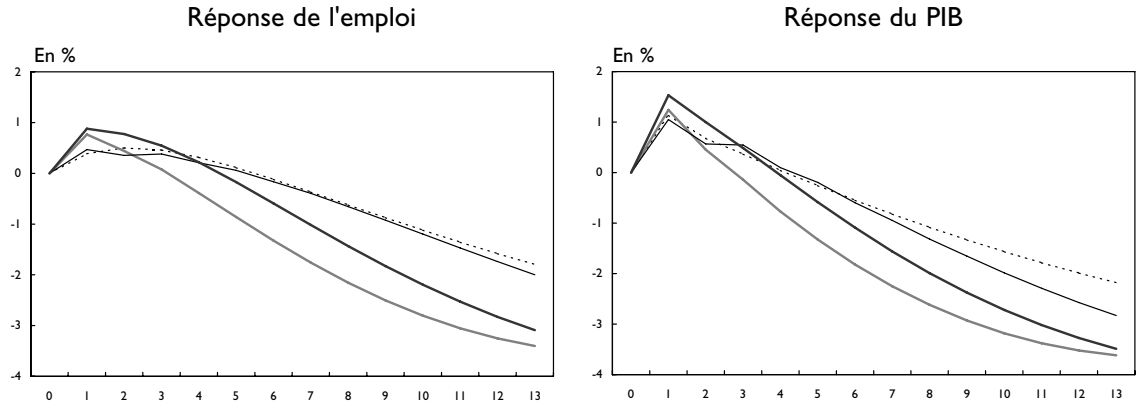

Réponse du taux de chômage

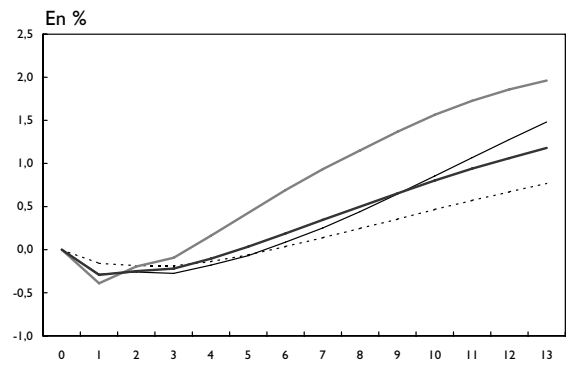

Réponse de la population active

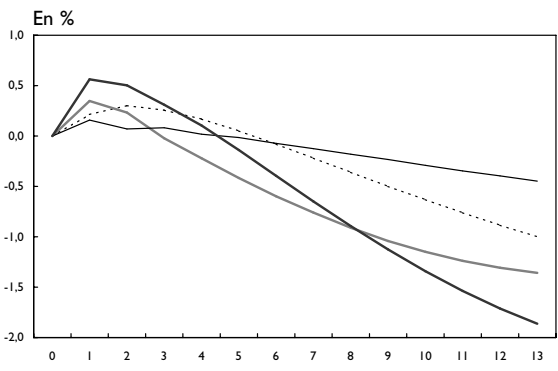

Réponse du flux d'émigration
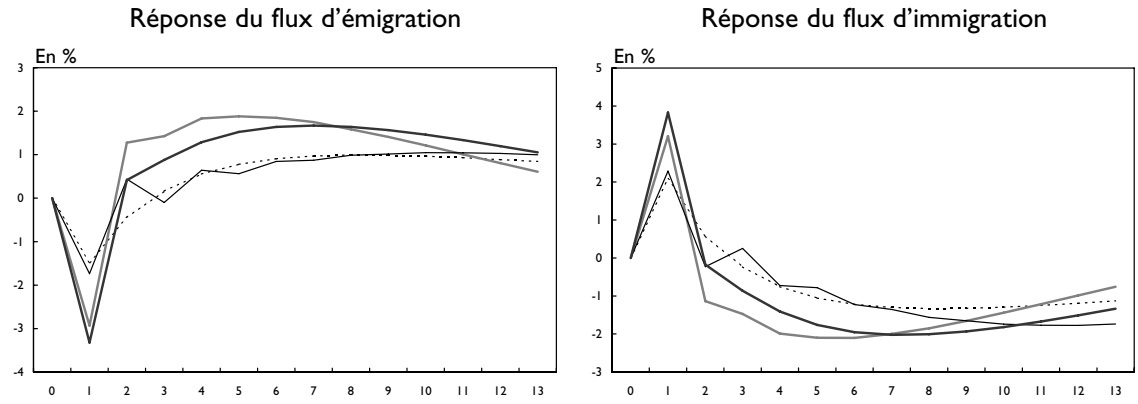

Source : Calculs des auteurs.

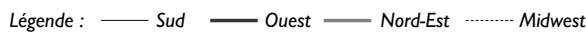




\section{Conclusion}

L'utilisation d'une maquette décrivant au niveau de chaque région américaine, d'une part la dynamique de l'emploi et la mobilité de la main-d'œuvre, d'autre part les ajustements par les salaires et les prix relatifs permet de répondre aux interrogations formulées. La flexibilité des prix et des coûts relatifs n'autorise que des ajustements limités face à des chocs affectant une région, comme cela a déjà été montré dans le modèle de Blanchard et Katz (1992).

Un choc négatif sur le PIB réduit l'emploi et fait monter le chômage. Les salaires et les prix baissent, mais cette stimulation de l'offre au détriment des autres régions ne permet qu'un rééquilibrage très partiel à moyen terme, même au Nord-Est où le phénomène est plus marqué. La flexion à la baisse du taux d'activité atténue cependant la poussée du chômage, surtout à l'Ouest.

Un choc positif sur les salaires nominaux entraîne à court terme une relance de la production et de l'emploi. Les prix augmentent, entraînant à moyen terme une réduction de la production au profit des autres régions et une montée du chômage. La pression sur les prix et les salaires qui en résulte n'est pas suffisante comme force de rappel à l'horizon de la simulation.

La mobilité de la main-d'œuvre ne joue enfin qu'un rôle de rééquilibrage réduit, à la différence de ce qu'avançaient les deux auteurs précédents. La comparaison des simulations du modèle avec et sans bloc migration montre que les écarts apparaissent très réduits. Les mouvements migratoires répondent essentiellement à des évolutions structurelles, même aux États-Unis (qualité des infrastructures, âge ou qualification des migrants).

Des enseignements peuvent en être tirés pour le fonctionnement de l'Union monétaire européenne face à des chocs ou à des évolutions asymétriques. La recherche d'une plus grande flexibilité du marché du travail, outre qu'elle aurait une traduction macroéconomique incertaine, n'aurait qu'une efficacité limitée pour accroître l'ampleur du rééquilibrage par le jeu des coûts et des prix relatifs, comme l'illustre le cas américain pourtant considéré par certains comme un modèle de flexibilité. L'espoir également entretenu, qu'une plus grande mobilité intra-européenne de la main-d'œuvre pourrait constituer une réponse au moins partielle, serait tout aussi vain.

En cas de choc de demande spécifique affectant un État, le recours à l'instrument budgétaire apparaît préférable et a alimenté une abondante littérature en raison des contraintes existantes. En cas de choc d'offre une plus grande flexibilité salariale peut contribuer à l'ajustement mais son efficacité serait faible et son coût élevé. 


\section{Références bibliographiques}

BARTIK T. J., I99I : «Who benefits from local job growth : Migrants or the original Residents ? ॥, Regional Studies, vol. 27-4, Pp. 297-3 I I.

BLANCHARD O. J et L. F. KATZ, 1992 : « Regional evolution », in Brainard and Perry (eds), Brookings Papers on Economic Activity, $\mathrm{n}^{\circ} \mathrm{I}$, Pp. I-75.

Blanchard O. J. et P.-A. Muet, 1993 : « Competitiveness through Disinflation : An Assessment of the French Macroeconomic Strategy », Economic Policy, $n^{\circ} 16$, avril.

BLANCHARD O. J., 2000 : « Country adjustments within Euroland. Lessons after two years », Working Paper MIT, janvier 2000, n²8.

BOYER R., 1999 : « Le gouvernement économique de la zone euro », Rapport du Commisariat Général du Plan, La Documentation Française.

BORJAS G. J., 1994 : « The Economics of Immigration », Journal of Economic Literature, $\mathrm{n}^{\circ}$ 32, pp.1667-1717.

BUITER W., 1995 : « Macroeconomic policy during a transition to monetary union », Revue d'Économie Politique, $\mathrm{n}^{\circ} 5$.

Cadiou L., S. Guichard et M. Maurel, 1999 : « Ajustements sur les Marchés du Travail en Europe », Document de travail, CEPII, mai.

COMMISSION EUROPÉENNE, 1990 : « Marché unique monnaie unique », Économie européenne, $n^{\circ} 44$, octobre.

EICHENGREEN B., 1993 : « Labor markets and European monetary unification ॥, in Masson and Taylor (eds.) Policy issues in the operation of currency unions, Cambridge University Press, Pp.I30-162.

Evans A.W., 1990 : «The Assumption of Equilibrium in the Analysis of Migration and Interregional Differences : A Review and some Recent Research ॥, Journal of Regional Science, $n^{\circ}$ 30, pp. 5I5-53I.

Fontagné L., M. Freudenberg et N. Péridy, 1998 : « Intra-Industry Trade and the Single Market : Quality Matters ॥, CEPR Discussion Paper, $n^{\circ} 1953$.

Guichard S et J. P. Laffargue, 200I : « Comparaison de la formation des salaires dans un panel de pays industrialisés », Écononmie et Prévision, $\mathrm{n}^{\circ}$ 147, pp. 37-5I.

Greenwood M. J, G. L. Hunt et J. M. Dowell, 1986 : « Migration and Employment Change : Empirical Evidence on the Spatial and Temporal Dimensions of the Linkage », Journal of the Regional Science, $n^{\circ} 26$, pp. 223-234. 
Greenwood M. J. et G. L. Hunt, 1984 : « Migration and Interregional Employment Redistribution in the United States ", American Economic Review, $\mathrm{n}^{\circ}$ 74, pp. 957-969.

GrUIDI J.S et PULVER G. C., I99I : «A dynamic analysis of net migration and state employment change », Review of Regional Studies, $\mathrm{n}^{\circ} 2 \mathrm{I}$, Pp. 2I-38.

HeRVÉ K., 200I : « Estimations des élasticités du commerce extérieur sur l'ensemble des biens et services pour un panel de 17 pays ॥, Économie et Prévision, pp. 19-36.

Houseman S. N et K. G. Abraham, 199I : Regional Labor Market Responses to Demand Shocks : A Comparison of the United States and West Germany, Association for Public Policy and Management, San Francisco.

MAURICe J. (président), 1999 : Emploi, Négociations Collectives, Protection Sociale: Vers Quelle Europe Sociale ?, Rapport du Commissariat Général du Plan, La Documentation Française.

Midelfart-Knarvik K. H., H. G. Overman, S. J. Redding et A. J. Venables, 2000 : "The Location of European Industry », Economic Papers, European Commission, $\mathrm{n}^{\circ} \mathrm{I} 42$.

MelitZ J. et ZUMer F., 2002 : « Partage du risque dans l'UE, expériences interrégionales et internationales », Revue de l'OFCE, hors série, mars.

PAYNĖs M., 1995 : «A Note on Real Wage Rigidity and State Unemployment Rates », Journal of Regional Science, vol. 35, $\mathrm{n}^{\circ}$ 2, pp. 319-332.

PISSARIDES C. et WADSWORTH, 1989 : " Unemployment and the Interregional Mobility of Labour », Economic Journal, septembre.

SChachter J. et Althaus P.G., 1989 : «An Equilibrium Model of Gross Migration », Journal of Regional Science, $\mathrm{n}^{\circ} 29$, pP I43-I59. 


\section{ANNEXE I : Les données utilisées et les résultats des estimations pour l'Europe}

\section{A. les données utilisées}

Les données sont tirées des Perspectives économiques de l'OCDE. Certaines variables non disponibles comme les exportations et les importations intra-européennes en volume, les demandes européennes ou les prix des échanges extérieurs intra-européens ont dû être estimés à partir des données d'échanges bi-latéraux tirées de la base CHELEM. Faute d'information, nous avons fait l'hypothèse qu'il n'y avait pas de différentiation à l'exportation et que les prix étaient les mêmes pour les exportations intra et extra-européennes.

Trois indicateurs de prix ont dû être calculés, le prix des importations intra-européennes, le prix des exportations des concurrents intra-européen et extra-européen, et une variable de volume, la demande intra-européenne. Selon l'hypothèse retenue, les prix d'exportations intra et extra-européens sont les prix d'exportations toutes zones. Les données sur les échanges extérieurs sont limitées aux seuls produits manufacturiers.

\section{Le prix des importations intra-européennes}

Le prix des importations intra-européennes du pays $\mathrm{i}$ est une moyenne géométrique des prix des exportations toutes zones des concurrents $j$, pondérée par les importations du pays $i$.

$$
\log (P M I N i)=\sum_{j}[(M I N i j / M I N i) * \log (P X j)]
$$

Les $j$ pays sont les pays de l'Union monétaire.

\section{Le prix des exportations des concurrents européens du pays $i$}

Le prix intra-européen des exportations des concurrents européens du pays $i$ est une moyenne géométrique des prix des importations des pays $j$ concurrents au pays $i$, pondérée par l'importance du pays $j$ dans les exportations du pays $i$.

Soit le prix d'importation du pays $j \sum k(X k j / M j) * \log (P X k)$ pour $k$ différent de $i$.

$$
\begin{gathered}
\log (P X C I N i)= \\
\Sigma_{\mathrm{j}}\left[((X i j / X i) /(1-(X i j / M j))) *\left(\sum_{k}(X k j / M j) * \log (P X k)\right)\right]
\end{gathered}
$$

Les pays $j$ sont les pays de l'Union monétaire. 


\section{Le prix des exportations des concurrents hors Union monétaire du pays $i$}

Le prix extra-européen des exportations des concurrents du pays $i$ est une moyenne géométrique des prix des importations des pays $h$ concurrents au pays $i$, pondérée par l'importance du pays $h$ dans les exportations du pays $i$.

Soit le prix d'importation du pays $h, \Sigma_{k}(X k h / M h) * \log (P X k)$ pour $k$ différent de $i$.

$$
\begin{gathered}
\log (P X C E)= \\
\sum h\left[((X i h / X i) /(1-(X i h / M h))) *\left(\Sigma_{k}(X k h / M h) * \log (P X k)\right)\right]
\end{gathered}
$$

Les $h$ pays sont au nombre de 12 : les États-Unis, le Canada, la Norvège, l'Islande, la Suisse, la Turquie, le Japon, l'Australie, la Nouvelle Zélande, le Mexique, la Corée du Sud, la Chine, et 5 groupes de pays (selon le découpage des perspectives économiques de l'OCDE), l'Amérique latine (moins le Mexique), l'Europe centrale et orientale, l'Afrique et le Moyenne Orient, l'Asie dynamique, et le reste de l'Asie.

Les $k$ pays sont les pays concurrents au pays $h$ comprenant les pays hors de l'Union monétaire et les pays de l'Union monétaire.

\section{La demande intra-européenne}

La demande intra-européenne d'un pays $i$ est une moyenne arithmétique des importations de chaque partenaire intra-européen du pays $i$, pondérée par une part de marché fixée conventionnellement à la valeur d'une année de base, ici nous avons retenu comme année de base 1991.

$$
\left.D E I N i=\Sigma_{j}[X i j(1991) / M j(1991))^{*} M j\right]
$$

Les $j$ pays sont les pays de l'Union monétaire. 


\section{B. Les résultats des estimations pour l'Europe}

Al.I. Résultats des estimations des équations de salaire nominal sur les deux périodes retenues

$$
\begin{aligned}
\Delta \log (w) & =a_{0}+a_{1} * \Delta \log (P c)+a_{2} * \Delta \log \left(P c_{-1}\right)+a_{3} * \Delta \log (Y / N)+a_{4} * \Delta U \\
& +a_{5} *\left[\log (W / P c)-\log (Y / N)-a_{5} * U\right]_{1}
\end{aligned}
$$

\begin{tabular}{|c|c|c|c|c|c|c|c|c|}
\hline & $a_{0}$ & $a_{1}$ & $a_{2}$ & $a_{3}$ & $a_{4}$ & $a_{5}$ & $a_{6}$ & $\mathrm{R}^{2}$ \\
\hline \multicolumn{9}{|l|}{ Grands pays } \\
\hline \multirow[t]{2}{*}{ Allemagne } & $-0,4$ & 0,63 & 0,02 & 0,5 & $-0,0017$ & $-0,0122$ & $-0,21$ & 0,83 \\
\hline & $-7,92$ & 17,64 & ns & 8,43 & $-1,69 *$ & $-2,82$ & $-8,79$ & \\
\hline \multirow[t]{2}{*}{ Espagne } & $-1,18$ & 0,63 & 0,36 & $0, I$ & $-0,0017$ & $-0,0276$ & $-0,2 \mid$ & 0,92 \\
\hline & 7,99 & 17,64 & 3,39 & ns & $-1,69 *$ & $-6,43$ & $-8,79$ & \\
\hline \multirow[t]{2}{*}{ France } & $-0,68$ & 0,63 & 0,5 & 0,64 & $-0,0017$ & $-0,0206$ & $-0,21$ & 0,96 \\
\hline & $-8,09$ & 17,64 & 9,7 & 4,81 & $-1,69 *$ & $-5,24$ & $-8,79$ & \\
\hline \multirow[t]{2}{*}{ Italie } & $-1,69$ & 0,63 & $-0,04$ & 0,19 & $-0,0017$ & $-0,0703$ & $-0,21$ & 0,97 \\
\hline & $-7,86$ & 17,64 & ns & $1,49 * * *$ & $-1,69 *$ & $-7,13$ & $-8,79$ & \\
\hline \multirow[t]{2}{*}{ Royaume-Uni } & $-0,12$ & 0,63 & $-0,02$ & 0,32 & $-0,0017$ & $-0,0074$ & $-0,2 \mid$ & 0,79 \\
\hline & $-4,21$ & 17,64 & ns & $1,69 * *$ & $-1,69 *$ & $n s$ & $-8,79$ & \\
\hline \multicolumn{9}{|l|}{ Petits pays } \\
\hline \multirow[t]{2}{*}{ Autriche } & $-0,78$ & 0,63 & $-0,04$ & 0,04 & $-0,0017$ & $-0,0362$ & $|-0,2|$ & 0,84 \\
\hline & $-7,98$ & 17,64 & ns & ns & $-1,69 *$ & $-2,45^{*}$ & $-8,79$ & \\
\hline \multirow[t]{2}{*}{ Belgique } & $-1,09$ & 0,63 & 0,52 & 0,7 & $-0,0017$ & $-0,0116$ & $-0,21$ & 0,91 \\
\hline & $-8,55$ & 17,64 & 6,97 & 5,46 & $-1,69 *$ & $-2,7$ & $-8,79$ & \\
\hline \multirow[t]{2}{*}{ Danemark } & $-0,68$ & 0,63 & 0,15 & 0,28 & $-0,0017$ & $-0,036$ & $-0,21$ & 0,80 \\
\hline & $-7,8$ & 17,64 & ns & ns & $-1,69 *$ & $-4,22$ & $-8,79$ & \\
\hline \multirow[t]{2}{*}{ Finlande } & $-0,52$ & 0,63 & $-0,17$ & $-0,13$ & $-0,0017$ & $-0,0637$ & $-0,21$ & 0,87 \\
\hline & $-6,59$ & 17,64 & $-1,65 * *$ & ns & $-1,69 *$ & $-4,75$ & $-8,79$ & \\
\hline \multirow[t]{2}{*}{ Pays-Bas } & $-0,45$ & 0,63 & 0,4 & 0,56 & $-0,0017$ & $-0,0171$ & $-0,21$ & 0,91 \\
\hline & $-7,94$ & 17,64 & 2,75 & 3,26 & $-1,69 *$ & $-2,42$ & $-8,79$ & \\
\hline \multirow[t]{2}{*}{ Suède } & $-0,64$ & 0,63 & 0,17 & $-0,09$ & $-0,0017$ & $-0,122 \mid$ & $-0,21$ & 0,61 \\
\hline & $-7,06$ & 17,64 & ns & ns & $-1,69 *$ & $-2,12 *$ & $-8,79$ & \\
\hline \multirow[t]{2}{*}{ Irlande } & $-0,06$ & 0,63 & 0,16 & 0,22 & $-0,0017$ & $-0,0265$ & $-0,21$ & 0,88 \\
\hline & $-2,31 *$ & 17,64 & $1,69 *$ & ns & $-1,69 *$ & $-4,38$ & $-8,79$ & \\
\hline \multirow[t]{2}{*}{ Portugal } & $-1,05$ & 0,63 & 0,62 & $-0,14$ & $-0,0017$ & $-0,0977$ & $-0,21$ & 0,73 \\
\hline & $-7,47$ & 17,64 & 4,78 & ns & $-1,69 *$ & $-5,24$ & $-8,79$ & \\
\hline \multirow[t]{2}{*}{ Grèce } & $-|, 2|$ & 0,63 & 0,17 & $I, 0 I$ & $-0,0017$ & $-0,0389$ & $-0,21$ & 0,09 \\
\hline & $-8,27$ & 17,64 & $1,57 * * *$ & 7,87 & $-1,69 *$ & $-3,83$ & $-8,79$ & \\
\hline
\end{tabular}

\section{A. Période 1973-1989}

ns : non significatif ; ${ }^{*}$ significatif au seuil de $5 \%$; ${ }^{* *}$ significatif au seuil de $10 \%$; ${ }^{* * *}$ significatif au seuil de $15 \%$. Les valeurs en italiques correspondent au t de Student. 
I Jacques Mazier, Joël Oudinet et Sophie Saglio

$$
\begin{aligned}
\Delta \log (w) & =a_{0}+a_{1} * \Delta \log (P c)+a_{2} * \Delta \log \left(P c_{-1}\right)+a_{3} * \Delta \log (Y / N)+a_{4} * \Delta U \\
& +a_{6} *\left[\log (w / P c)-\log (Y / N)-a_{5} * U\right]_{1}
\end{aligned}
$$

\begin{tabular}{|c|c|c|c|c|c|c|c|c|}
\hline & $a_{0}$ & $a_{1}$ & $a_{2}$ & $a_{3}$ & $a_{4}$ & $a_{5}$ & $a_{6}$ & $\mathrm{R}^{2}$ \\
\hline \multicolumn{9}{|l|}{ Grands pays } \\
\hline \multirow[t]{2}{*}{ Allemagne } & $-0,16$ & 0,65 & $-0,09$ & 0,96 & $-0,0013$ & $-0,0659$ & $-0,11$ & 0,9 \\
\hline & $-2,84$ & $|2,3|$ & ns & 17,04 & ns & $-2,11 *$ & $-4,4$ & \\
\hline \multirow[t]{2}{*}{ Espagne } & $-0,47$ & 0,65 & 0,26 & $-0,96$ & 0,0083 & $-0,0712$ & $-0,11$ & 0,91 \\
\hline & $-3,06$ & 12,31 & $1,63 * * *$ & $-1,62 * * *$ & 2,68 & $-3,44$ & $-4,4$ & \\
\hline \multirow[t]{2}{*}{ France } & $-0,35$ & 0,65 & 0,35 & $\mathrm{I}, 04$ & 0,0013 & $-0,022$ & $-0, I I$ & 0,94 \\
\hline & $-4,22$ & $|2,3|$ & 5,18 & 6,71 & ns & $-2,04 *$ & $-4,4$ & \\
\hline \multirow[t]{2}{*}{ Italie } & $-0,9 \mid$ & 0,65 & $0,5 I$ & 1,42 & $-0,0247$ & $-0,0519$ & $-0,11$ & 0,87 \\
\hline & $-4,35$ & $|2,3|$ & 3,64 & 5,79 & $-5,1$ & $-1,58^{* * *}$ & $-4,4$ & \\
\hline \multirow[t]{2}{*}{ Royaume-Uni } & $-0,05$ & 0,65 & 0,41 & 0,35 & $-0,0054$ & $-0,0218$ & $-0,11$ & 0,8 \\
\hline & $-2,7$ & $|2,3|$ & $2,20^{*}$ & ns & $-1,8 * *$ & $-1,52^{* * *}$ & $-4,4$ & \\
\hline
\end{tabular}

\section{B. Période 1983-1999}

\begin{tabular}{|c|c|c|c|c|c|c|c|c|}
\hline Autriche & $\begin{array}{c}-0,37 \\
-3,81\end{array}$ & $\begin{array}{c}0,65 \\
12,31\end{array}$ & $\begin{array}{c}0,14 \\
n s\end{array}$ & $\begin{array}{c}0,18 \\
n s\end{array}$ & $\begin{array}{c}-0,0186 \\
-3,16\end{array}$ & $\begin{array}{l}-0,0706 \\
-2,7\end{array}$ & $\begin{array}{l}-0,11 \\
-4,4\end{array}$ & 0,45 \\
\hline Belgique & $\begin{array}{l}-0,5 \\
-3,9\end{array}$ & $\begin{array}{c}0,65 \\
12,31\end{array}$ & $\begin{array}{l}0,62 \\
8,4\end{array}$ & $\begin{array}{l}0,45 \\
3,15\end{array}$ & $\begin{array}{l}-0,004 \\
-2,02 *\end{array}$ & $\begin{array}{l}-0,0601 \\
-3,34\end{array}$ & $\begin{array}{l}-0,1 \mathrm{I} \\
-4,4\end{array}$ & 0,8 \\
\hline Danemark & $\begin{array}{l}-0,34 \\
-3,88\end{array}$ & $\begin{array}{l}0,65 \\
12,31\end{array}$ & $\begin{array}{l}0,29 \\
1.67 * *\end{array}$ & $-\begin{array}{c}0,01 \\
n s\end{array}$ & $\begin{array}{l}0,0077 \\
2,25^{*}\end{array}$ & $\begin{array}{c}-0,0238 \\
n s\end{array}$ & $\begin{array}{l}-0,1 \mathrm{I} \\
-4,4\end{array}$ & 0,59 \\
\hline Finlande & $\begin{array}{l}-0,27 \\
-3,72\end{array}$ & $\begin{array}{c}0,65 \\
12,31\end{array}$ & $\begin{array}{c}0,03 \\
n s\end{array}$ & $\begin{array}{l}0,22 \\
2,25^{*}\end{array}$ & $\begin{array}{l}-0,0066 \\
-6,03\end{array}$ & $\begin{array}{l}-0,0338 \\
-4,62\end{array}$ & $\begin{array}{l}-0, \text { II } \\
-4,4\end{array}$ & 0,82 \\
\hline Pays-Bas & $\begin{array}{l}-0,22 \\
-4,01 \\
\end{array}$ & $\begin{array}{c}0,65 \\
|2,3| \\
\end{array}$ & $\begin{array}{c}0,11 \\
\text { ns }\end{array}$ & $\begin{array}{l}0,28 \\
3,44\end{array}$ & $\begin{array}{l}0,0024 \\
2,26^{*}\end{array}$ & $\begin{array}{l}-0,01 \\
-1,68^{* *}\end{array}$ & $\begin{array}{l}-0,11 \\
-4,4\end{array}$ & $0,4 I$ \\
\hline Suède & $\begin{array}{l}-0,29 \\
-3,39\end{array}$ & $\begin{array}{l}0,65 \\
12,31\end{array}$ & $\begin{array}{l}-0,44 \\
-2,62\end{array}$ & $\begin{array}{l}0,74 \\
1,95^{*}\end{array}$ & $\begin{array}{c}-0,0012 \\
n s\end{array}$ & \begin{tabular}{|l|}
$|-0,089|$ \\
$-3,13$
\end{tabular} & $\begin{array}{l}-0,1 \mathrm{I} \\
-4,4\end{array}$ & 0,66 \\
\hline Irlande & $\begin{array}{l}-0,21 \\
-5,78 \\
\end{array}$ & $\begin{array}{c}0,65 \\
12,3 \mid \\
\end{array}$ & $\begin{array}{l}0,51 \\
4,12 \\
\end{array}$ & $\begin{array}{l}0,61 \\
5,59\end{array}$ & $\begin{array}{l}0,0042 \\
2 *\end{array}$ & $\begin{array}{l}0,0664 \\
5,11\end{array}$ & $\begin{array}{l}-0,1 \mathrm{II} \\
-4,4 \\
\end{array}$ & 0,71 \\
\hline Portugal & $\begin{array}{l}-0,56 \\
-4,06\end{array}$ & $\begin{array}{c}0,65 \\
12,31\end{array}$ & $\begin{array}{l}0,24 \\
3,29\end{array}$ & $\begin{array}{l}0,29 \\
2,68\end{array}$ & $\begin{array}{c}-0,0032 \\
n s\end{array}$ & $\begin{array}{c}-0,0256 \\
n s\end{array}$ & $\begin{array}{l}-0, I I \\
-4,4\end{array}$ & 0,88 \\
\hline Grèce & $\begin{array}{l}-0,31 \\
-1,99 *\end{array}$ & $\begin{array}{c}0,65 \\
12,31\end{array}$ & $\begin{array}{l}-0,5 \\
-3,08\end{array}$ & $\begin{array}{l}0,7 \\
4,07\end{array}$ & $\begin{array}{c}0,0054 \\
n s\end{array}$ & $\begin{array}{l}-0,2555 \\
-3,57\end{array}$ & $\begin{array}{l}-0,1 \mathrm{II} \\
-4,4\end{array}$ & 0,58 \\
\hline
\end{tabular}

\section{Petits pays}

ns : non significatif ; ${ }^{*}$ significatif au seuil de $5 \%$; ** significatif au seuil de $10 \%$; *** significatif au seuil de $15 \%$. Les valeurs en italiques correspondent au t de Student. 


\section{Al.2. Résultats des estimations des équations de prix du PIB} sur la période 1983-1999

$$
\begin{aligned}
\Delta \log (P) & =b_{0}+b_{1} * \Delta \log (w N / Y)+b_{2} *(w N / Y)_{-1}+b_{3} * \Delta \log (P)_{-} \\
& +b_{4} * \Delta \log (\text { tuc })+b_{5} *[\log (P)-\log (w N / Y)]_{1}
\end{aligned}
$$

\begin{tabular}{|c|c|c|c|c|c|c|c|c|}
\hline & $b_{0}$ & $b_{1}$ & $b_{2}$ & $b_{3}$ & $\mathrm{~b}_{4}$ & $\mathrm{~b}_{5}$ & Dum $_{2}$ & $\mathrm{R}^{2}$ \\
\hline \multicolumn{9}{|l|}{ Grands pays } \\
\hline \multirow[t]{2}{*}{ Allemagne } & 0,011 & $0,17^{*}$ & $-0,02$ & 0,34 & 0,12 & $-0,14$ & 0,02 & 0,82 \\
\hline & 6,08 & 2,08 & ns & 11,35 & 4,65 & $-10,93$ & 2,6 & \\
\hline \multirow[t]{2}{*}{ Espagne } & 0,02 & 0,45 & $-0,19$ & 0,34 & 0,12 & $-0,14$ & & 0,89 \\
\hline & 5,21 & 6,26 & $-2,78$ & 11,35 & 4,65 & $-10,93$ & & \\
\hline \multirow[t]{2}{*}{ France } & 0,01 & 0,35 & $-0,06$ & 0,34 & 0,12 & $-0,14$ & & 0,96 \\
\hline & 6,79 & 3,21 & ns & 11,35 & 4,65 & $-10,93$ & & \\
\hline \multirow[t]{2}{*}{ Italie } & 0,03 & 0,38 & $-0,14$ & 0,34 & 0,12 & $-0,14$ & & 0,92 \\
\hline & 7,58 & 4,03 & $-1,71 * *$ & 11,35 & 4,65 & $-10,93$ & & \\
\hline \multirow[t]{2}{*}{ Royaume-Uni } & 0,0031 & 0,62 & 0,08 & 0,34 & 0,12 & $-0,14$ & & 0,76 \\
\hline & ns & 5,11 & ns & 11,35 & 4,65 & $-10,93$ & & \\
\hline
\end{tabular}

\section{Petits pays}

\begin{tabular}{l|c|c|c|c|c|c|c|c}
\hline Autriche & 0,011 & 0,45 & $-0,17$ & 0,34 & 0,12 & $-0,14$ & & 0,82 \\
& 4,98 & 6,04 & $-2,25$ & 11,35 & 4,65 & $-10,93$ & & \\
\hline Belgique & 0,015 & 0,3 & $-0,12$ & 0,34 & 0,12 & $-0,14$ & & 0,67 \\
& 5,04 & 2,69 & $n s$ & 11,35 & 4,65 & $-10,93$ & & \\
\hline Danemark & 0,019 & 0,12 & 0,09 & 0,34 & 0,12 & $-0,14$ & & 0,71 \\
& 7,37 & 4,08 & 2,72 & 11,35 & 4,65 & $-10,93$ & & \\
\hline Finlande & 0,03 & 0,47 & $-0,25 *$ & 0,34 & 0,12 & $-0,14$ & & 0,72 \\
& 6,28 & 3,78 & $-2,05$ & 11,35 & 4,65 & $-10,93$ & & \\
\hline Pays-Bas & 0,01 & 0,18 & $-0,16$ & 0,34 & 0,12 & $-0,14$ & & 0,46 \\
& 5,17 & 2,91 & $-2,86$ & 11,35 & 4,65 & $-10,93$ & & \\
\hline Suède & 0,0027 & 0,51 & 0,16 & 0,34 & 0,12 & $-0,14$ & & 0,84 \\
& $n s$ & 5,1 & $1,44^{* * *}$ & 11,35 & 4,65 & $-10,93$ & & \\
\hline Irlande & 0,02 & 0,55 & $-0,52$ & 0,34 & 0,12 & $-0,14$ & & 0,40 \\
& 4,92 & 3,53 & $-4,13$ & 11,35 & 4,65 & $-10,93$ & & \\
\hline Portugal & 0,01 & 0,46 & 0,1 & 0,34 & 0,12 & $-0,14$ & & 0,94 \\
& 2,27 & 5,36 & $n s$ & 11,35 & 4,65 & $-10,93$ & & \\
\hline Grèce & $-0,0036$ & 0,22 & 0,36 & 0,34 & 0,12 & $-0,14$ & & 0,83 \\
& $n s$ & 4,34 & 5,59 & 11,35 & 4,65 & $-10,93$ & & \\
\hline
\end{tabular}

ns : non significatif ; $*$ significatif au seuil de $5 \%$; $* *$ significatif au seuil de $10 \%$; *** significatif au seuil de $15 \%$. Les valeurs en italiques correspondent au t de Student. 


\section{Al.3. Résultats des estimations des équations d'emploi total} sur la période 1983-1999

$$
\begin{aligned}
\Delta \log (N)= & c_{0}+c_{1} * \Delta \log (Y)+c_{2} * \Delta \log \left(N_{-1}\right)+c_{3} * \Delta \log \left(Y_{-1}\right) \\
& +c_{4} *\left[\log (N)-\log (Y)+c_{5} * \text { trend }\right]_{1}
\end{aligned}
$$

\begin{tabular}{|c|c|c|c|c|c|c|c|c|}
\hline & $\mathrm{C}_{0}$ & $c_{1}$ & $c_{2}$ & $\mathrm{C}_{3}$ & $\mathrm{C}_{4}$ & $C_{5}$ & Dum & $\mathrm{R}^{2}$ \\
\hline \multicolumn{9}{|l|}{ Grands pays } \\
\hline \multirow[t]{2}{*}{ Allemagne } & 0,25 & 0,48 & $-0,05$ & $-0,12$ & $-0,76$ & $-0,0244$ & 0,2 & 0,89 \\
\hline & 7,82 & 19,48 & ns & $-3,22$ & $-27,33$ & $-11,78$ & 21,15 & \\
\hline \multirow[t]{2}{*}{ Espagne } & 0,32 & 0,48 & 0,58 & $-0,12$ & $-0,76$ & $-0,0188$ & & 0,8 \\
\hline & $17,7 \mid$ & 19,48 & 6,92 & $-3,22$ & $-27,33$ & $-26,26$ & & \\
\hline \multirow[t]{2}{*}{ France } & 0,3 & 0,48 & 0,58 & $-0,12$ & $-0,76$ & $-0,0165$ & & 0,21 \\
\hline & 17,75 & 19,48 & 5 & $-3,22$ & $-27,33$ & $-24,29$ & & \\
\hline \multirow[t]{2}{*}{ Italie } & 0,36 & 0,48 & 0,68 & $-0,12$ & $-0,76$ & $-0,0213$ & & 0,48 \\
\hline & 20,61 & 19,48 & 4,33 & $-3,22$ & $-27,33$ & $-36,81$ & & \\
\hline \multirow[t]{2}{*}{ Royaume-Uni } & 0,28 & 0,48 & 0,24 & $-0,12$ & $-0,76$ & $-0,0172$ & & 0,89 \\
\hline & 21,69 & 19,48 & 3,03 & $-3,22$ & $-27,33$ & $-45,77$ & & \\
\hline
\end{tabular}

\begin{tabular}{|c|c|c|c|c|c|c|c|}
\hline \multicolumn{8}{|c|}{ Petits pays } \\
\hline \multirow[t]{2}{*}{ Autriche } & 0,31 & 0,48 & 0,41 & $-0,12$ & $-0,76$ & $-0,0172$ & 0,77 \\
\hline & 22,51 & 19,48 & 4,76 & $-3,22$ & $-27,33$ & $-47,58$ & \\
\hline \multirow[t]{2}{*}{ Belgique } & 0,32 & 0,48 & 0,6 & $-0,12$ & $-0,76$ & $-0,018$ & 0,53 \\
\hline & 22,78 & 19,48 & 5,91 & $-3,22$ & $-27,33$ & $-45,57$ & \\
\hline \multirow[t]{2}{*}{ Danemark } & 0,24 & 0,48 & 0,11 & $-0,12$ & $-0,76$ & $-0,0152$ & 0,76 \\
\hline & 16,76 & 19,48 & ns & $-3,22$ & $-27,33$ & $-23,13$ & \\
\hline \multirow[t]{2}{*}{ Finlande } & 0,42 & 0,48 & 0,29 & $-0,12$ & $-0,76$ & $-0,0265$ & 0,96 \\
\hline & 23,74 & 19,48 & 6,07 & $-3,22$ & $-27,33$ & $-68,66$ & \\
\hline \multirow[t]{2}{*}{ Pays-Bas } & 0,14 & 0,48 & 0,09 & $-0,12$ & $-0,76$ & $-0,0078$ & 0,83 \\
\hline & 17,04 & 19,48 & ns & $-3,22$ & $-27,33$ & $-19,71$ & \\
\hline \multirow[t]{2}{*}{ Suède } & 0,32 & 0,48 & 0,16 & $-0,12$ & $-0,76$ & $-0,0206$ & 0,80 \\
\hline & 19,72 & 19,48 & $1,99 *$ & $-3,22$ & $-27,33$ & $-32,47$ & \\
\hline \multirow[t]{2}{*}{ Irlande } & 0,51 & 0,48 & $-0,05$ & $-0,12$ & $-0,76$ & $-0,028 \mid$ & 0,78 \\
\hline & 17,52 & 19,48 & ns & $-3,22$ & $-27,33$ & $-21,78$ & \\
\hline \multirow[t]{2}{*}{ Portugal } & 0,42 & 0,48 & $-0,03$ & $-0,12$ & $-0,76$ & $-0,0258$ & 0,37 \\
\hline & 15,28 & 19,48 & ns & $-3,22$ & $-27,33$ & $-19,12$ & \\
\hline \multirow[t]{2}{*}{ Grèce } & 0,24 & 0,48 & 0,09 & $-0,12$ & $-0,76$ & $-0,0123$ & 0,04 \\
\hline & 13,38 & 19,48 & ns & $-3,22$ & $-27,33$ & $-13,06$ & \\
\hline
\end{tabular}

ns : non significatif ; ${ }^{*}$ significatif au seuil de $5 \%$.

Les valeurs en italiques correspondent au $\mathrm{t}$ de Student. 


\section{Al.4. Résultats des estimations de l'équation de population active sur la période 1983-1999}

$$
\Delta \log (P A)=d_{0}+d_{1} * \Delta \log (N)+\left(1-d_{1}\right) * \Delta \log (P A T)
$$

\begin{tabular}{|c|c|c|c|c|}
\hline & $\mathrm{d}_{0}$ & $d_{1}$ & Dum I & $\mathrm{R}^{2}$ \\
\hline \multicolumn{5}{|l|}{ Grands pays } \\
\hline \multirow[t]{2}{*}{ Allemagne } & 0,001 & 0,36 & 0,04 & 0,9976 \\
\hline & $2,05^{*}$ & 6,4 & 7,22 & \\
\hline \multirow[t]{2}{*}{ Espagne } & 0,002 & 0,2 & & 0,25 \\
\hline & $2,09 *$ & 5,41 & & \\
\hline \multirow[t]{2}{*}{ France } & 0,01 & 0,28 & & 0,08 \\
\hline & ns & 3,57 & & \\
\hline \multirow[t]{2}{*}{ Italie } & 0 & 0,65 & & 0,63 \\
\hline & ns & 7,49 & & \\
\hline \multirow[t]{2}{*}{ Royaume-Uni } & 0,01 & 0,23 & & 0,58 \\
\hline & ns & 4,46 & & \\
\hline \multicolumn{5}{|l|}{ Petits pays } \\
\hline \multirow[t]{2}{*}{ Autriche } & 0,001 & 0,77 & & 0,92 \\
\hline & 2,8 & 16,37 & & \\
\hline \multirow[t]{2}{*}{ Belgique } & ns & 0,49 & & 0,94 \\
\hline & 8,25 & 8,25 & & \\
\hline \multirow[t]{2}{*}{ Danemark } & 0 & 0,5 & & 0,49 \\
\hline & ns & 8,67 & & \\
\hline \multirow[t]{2}{*}{ Finlande } & 0 & 0,31 & & 0,79 \\
\hline & ns & 9,39 & & \\
\hline \multirow[t]{2}{*}{ Pays-Bas } & 0,003 & 0,45 & & 0,17 \\
\hline & $1,95^{*}$ & 6,13 & & \\
\hline \multirow[t]{2}{*}{ Suède } & 0 & 0,46 & & 0,87 \\
\hline & ns & 13,6 & & \\
\hline \multirow[t]{2}{*}{ Irlande } & 0 & 0,4 & & 0,80 \\
\hline & ns & 6,54 & & \\
\hline \multirow[t]{2}{*}{ Portugal } & 0 & 0,8 & & 0,90 \\
\hline & ns & 16,36 & & \\
\hline \multirow[t]{2}{*}{ Grèce } & 0,005 & 1 & & 0,73 \\
\hline & $2,05 *$ & 12,03 & & \\
\hline
\end{tabular}

ns : non significatif ; * significatif au seuil de $5 \%$.

Les valeurs en italiques correspondent au t de Student. 


\section{Al.5. Résultats des estimations de l'équation d'exportation intra-européenne sur la période 1981-1997}

$$
\begin{aligned}
\Delta \log \left(X_{i}\right)= & x_{0}+x_{1} \Delta \log (D E I)+x_{2} * \Delta \log \left(P C X_{i} / P X\right)+x_{3} * \\
& {\left[\log \left(X_{i}\right)-\log (D E I)-x_{4} * \Delta \log \left(P X C_{i} / P X\right)-x_{5} * \text { trend }\right]_{-1} }
\end{aligned}
$$

\begin{tabular}{l|c|c|c|c|c|c|c}
\hline & $\mathrm{x}_{0}$ & $\mathrm{x}_{1}$ & $\mathrm{x}_{2}$ & $\mathrm{x}_{3}$ & $\mathrm{x}_{4}$ & $\mathrm{x}_{5}$ & $\mathrm{R}^{2}$ \\
\hline Grand pays & 0,03 & $\mathrm{I}, \mathrm{II}$ & $0,4 \mathrm{I}$ & $-0,77$ & $0,6 \mathrm{I}$ & $-0,0074$ & 0,85 \\
& $1,62 * *$ & $1 \mathrm{I}, 7$ & 3,3 & $-16,58$ & 2,9 & $-3,12$ & \\
\hline Allemagne & $-0,58$ & 0,83 & 0,59 & $-0,77$ & $\mathrm{I}, \mathrm{I7}$ & 0,0664 & 0,80 \\
& $-11,56$ & 4,58 & 2,59 & $-16,58$ & 6,47 & 22,21 & \\
\hline Espagne & $-0,04$ & 0,83 & 0,88 & $-0,77$ & 0,4 & 0,0058 & 0,83 \\
& $-4,36$ & 8 & 3,73 & $-16,58$ & $1,5 * * *$ & 4,52 & \\
\hline France & $-0,13$ & 0,93 & 0,77 & $-0,77$ & $\mathrm{I}, 36$ & 0,0126 & 0,38 \\
& $-6,02$ & 6,13 & 7,14 & $-16,58$ & 10,85 & 5,68 & \\
\hline Italie & $-0,07$ & $\mathrm{I}, 2 \mathrm{I}$ & 0,45 & $-0,77$ & 0,98 & 0,0096 & $0,8 \mathrm{I}$ \\
& $-2,95$ & 8,6 & 3,34 & $-16,58$ & 3,88 & 3,26 & \\
\hline
\end{tabular}

\begin{tabular}{|c|c|c|c|c|c|c|c|}
\hline \multirow[t]{2}{*}{ Autriche } & $-0,15$ & 0,86 & 0,99 & $-0,77$ & 0,73 & 0,0181 & 0,64 \\
\hline & $-4,77$ & 4,47 & 4,67 & $-16,58$ & $2,3^{*}$ & 6,46 & \\
\hline \multirow[t]{2}{*}{ Belgique } & 0,04 & 0,79 & 0,81 & $-0,77$ & 0,77 & 0 & 0,40 \\
\hline & 3,68 & 4,75 & $2,18^{*}$ & $-16,58$ & $2,1^{*}$ & ns & \\
\hline \multirow[t]{2}{*}{ Danemark } & 0,03 & 0,84 & 1,44 & $-0,77$ & 1,56 & 0 & 0,81 \\
\hline & 4,77 & 7,53 & 4,89 & $-16,58$ & 8,93 & ns & \\
\hline \multirow[t]{2}{*}{ Finlande } & 0,06 & $|, 0|$ & 0,23 & $-0,77$ & 0,84 & 0 & 0,61 \\
\hline & 3,05 & 4,35 & $1,42^{* * *}$ & $-16,58$ & 4,47 & ns & \\
\hline \multirow[t]{2}{*}{ Pays-Bas } & 0,27 & 1,03 & 1,23 & $-0,77$ & 1,2 & $-0,0172$ & 0,22 \\
\hline & 6,8 & 4,32 & 60,1 & $-16,58$ & 4,96 & $-4,76$ & \\
\hline \multirow[t]{2}{*}{ Suède } & 0,16 & 1,17 & 0 & $-0,77$ & 1,39 & $-0,0129$ & 0,46 \\
\hline & 6,8 & 5,07 & ns & $-16,58$ & 7,27 & $-5,02$ & \\
\hline \multirow[t]{2}{*}{ Irlande } & $-0,23$ & 1,05 & 0,78 & $-0,77$ & 1,26 & 0,0376 & 0,66 \\
\hline & $-5,48$ & 4,27 & 4,53 & $-16,58$ & 4,68 & 9,89 & \\
\hline \multirow[t]{2}{*}{ Portugal } & $-0,52$ & 2,24 & 0 & $-0,77$ & 0,69 & 0,0501 & 0,45 \\
\hline & $-8,79$ & 7,19 & ns & $-16,58$ & $2,24^{*}$ & 8,85 & \\
\hline \multirow[t]{2}{*}{ Grèce } & $-0,02$ & 1,35 & 1,42 & $-0,77$ & 0,55 & 0 & 0,70 \\
\hline & ns & 2,52 & 4,17 & $-16,58$ & 2,65 & ns & \\
\hline
\end{tabular}

\section{Petits pays}

ns : non significatif ; $*$ significatif au seuil de $5 \%$; ** significatif au seuil de $10 \%$; *** significatif au seuil de I5\%. Les valeurs en italiques correspondent au $\mathrm{t}$ de Student. 


\section{Al.6. Résultats des estimations de l'équation d'importation intra-européenne pour la période 1981-1997}

$$
\begin{aligned}
\Delta \log \left(M_{i}\right)= & m_{0}+m_{1} \Delta \log (D F)+m_{2} \Delta \log \left(P M_{i} / P\right)+ \\
& m_{3}\left[\log \left(M_{i}\right)-\log (D F)-m_{4} \Delta \log \left(P M_{i} / P\right)-m_{5} \text { trend }\right]_{1}
\end{aligned}
$$

\begin{tabular}{|c|c|c|c|c|c|c|c|c|}
\hline & $\mathrm{m}_{0}$ & $\mathrm{~m}_{1}$ & $\mathrm{~m}_{2}$ & $\mathrm{~m}_{3}$ & $\mathrm{~m}_{4}$ & $\mathrm{~m}_{5}$ & Dum I & $\mathrm{R}^{2}$ \\
\hline \multicolumn{9}{|l|}{ Grands pays } \\
\hline \multirow[t]{2}{*}{ Allemagne } & 0,11 & 0,65 & $-0,79$ & $-0,59$ & $-0,52$ & 0 & $-0,06$ & 0,62 \\
\hline & 8 & 4,07 & $-6,21$ & $-13,9$ & $-7,72$ & ns & $-2,26 *$ & \\
\hline \multirow[t]{2}{*}{ Espagne } & 0,17 & 1,17 & $-0,76$ & $-0,59$ & $-0,52$ & 0 & & 0,12 \\
\hline & 4,06 & 3,81 & $-3,6$ & $-13,9$ & $-7,72$ & ns & & \\
\hline \multirow[t]{2}{*}{ France } & $-0,02$ & $\mathrm{I}, 03$ & $-0,5$ & $-0,59$ & $-0,52$ & 0,006 & & 0,58 \\
\hline & ns & 4,2 & $-3,16$ & $-13,9$ & $-7,72$ & $1,94 * *$ & & \\
\hline \multirow[t]{2}{*}{ Italie } & 0,16 & 0 & $-0,44$ & $-0,59$ & $-0,52$ & 0 & & 0,34 \\
\hline & 6,1 & ns & $-1,83 * *$ & $-13,9$ & $-7,72$ & ns & & \\
\hline \multirow[t]{2}{*}{ Royaume-Uni } & $-0,11$ & $\mathrm{I}, 0 \mathrm{I}$ & $-0,24$ & $-0,59$ & $-0,52$ & 0,0246 & & 0,71 \\
\hline & $-3,71$ & 2,81 & $-1,41 * * *$ & $-13,9$ & $-7,72$ & $6,96^{*}$ & & \\
\hline \multicolumn{9}{|l|}{ Petits pays } \\
\hline \multirow[t]{2}{*}{ Autriche } & 0,16 & 1,13 & $-1,34$ & $-0,59$ & $-0,52$ & $-0,0129$ & & 0,69 \\
\hline & 5,58 & 5,34 & $-4,94$ & $-13,9$ & $-7,72$ & $-4,62$ & & \\
\hline \multirow[t]{2}{*}{ Belgique } & 0,04 & 0,69 & $-0,59$ & $-0,59$ & $-0,52$ & $0,007 \mid$ & & 0,78 \\
\hline & 3,2 & 8,5 & $-6,62$ & $-13,9$ & $-7,72$ & 3,72 & & \\
\hline \multirow[t]{2}{*}{ Danemark } & 0,25 & 0 & $-1,2$ & $-0,59$ & $-0,52$ & $-0,0182$ & & 0,43 \\
\hline & 8,1 & ns & $-7,62$ & $-13,9$ & $-7,72$ & $-5,19$ & & \\
\hline \multirow[t]{2}{*}{ Finlande } & 0,29 & 0 & $-0,43$ & $-0,59$ & $-0,52$ & $-0,0198$ & & 0,34 \\
\hline & 8,79 & ns & $-2,15$ & $-13,9$ & $-7,72$ & $-6,91$ & & \\
\hline \multirow[t]{2}{*}{ Pays-Bas } & 0,05 & 0,66 & $-0,47$ & $-0,59$ & $-0,52$ & 0 & & 0,63 \\
\hline & 4,21 & 3,89 & $-2,61$ & $-13,9$ & $-7,72$ & ns & & \\
\hline \multirow[t]{2}{*}{ Suède } & 0,21 & 0 & $-0,24$ & $-0,59$ & $-0,52$ & $-0,0142$ & & 0,55 \\
\hline & 9,15 & ns & $-2,35^{*}$ & $-13,9$ & $-7,72$ & $-5,22$ & & \\
\hline \multirow[t]{2}{*}{ Irlande } & 0,27 & 0 & 0 & $-0,59$ & $-0,52$ & $-0,035$ & & 0,12 \\
\hline & 6,77 & ns & ns & $-13,9$ & $-7,72$ & $-7,1$ & & \\
\hline \multirow[t]{2}{*}{ Portugal } & 0,03 & 0,47 & 0 & $-0,59$ & $-0,52$ & 0 & & 0,41 \\
\hline & ns & $1,65 * *$ & $n s$ & $-13,9$ & $-7,72$ & $n s$ & & \\
\hline \multirow[t]{2}{*}{ Grèce } & 0,11 & 0,49 & $-0,51$ & $-0,59$ & $-0,52$ & $-0,0239$ & & 0,29 \\
\hline & 3,1 & $2,45^{*}$ & $-1,79 * *$ & $-13,9$ & $-7,72$ & $-4,86$ & & \\
\hline
\end{tabular}

ns : non significatif ; $*$ significatif au seuil de $5 \%$; $* *$ significatif au seuil de $10 \% ; * * *$ significatif au seuil de $15 \%$. Les valeurs en italiques correspondent au $\mathrm{t}$ de Student. 


\section{Al.7. Résultats des estimations de l'équation d'exportation extra-européenne sur la période 1981-1997}

$$
\begin{aligned}
\Delta \log \left(X_{e}\right)= & x x_{0}+x x_{1} * \Delta \log (D E)+x x_{2} * \Delta \log \left(P C X_{e} / P X\right) \\
& x x_{3} *\left[\log \left(X_{e}\right)-\log (D E)-x x_{4} * \Delta \log \left(P X C_{e} / P X\right)-x x_{5} * \text { trend }\right]_{-1}
\end{aligned}
$$

\begin{tabular}{|c|c|c|c|c|c|c|c|}
\hline & $x_{0}$ & $\mathrm{XX}_{1}$ & $\mathrm{xx}_{2}$ & $\mathrm{xX}_{3}$ & $\mathrm{XX}_{4}$ & $\mathrm{XX}_{5}$ & $\mathrm{R}^{2}$ \\
\hline \multicolumn{8}{|l|}{ Grand pays } \\
\hline \multirow[t]{2}{*}{ Allemagne } & 0,21 & 1,19 & 0 & $-0,78$ & 0,61 & $-0,0244$ & 0,9 \\
\hline & 8,2 & 5,9 & ns & $-8,6$ & 3,9 & $-10,98$ & \\
\hline \multirow[t]{2}{*}{ Espagne } & $-0,2$ & 1,09 & 1,32 & $-1,36$ & $\mathrm{I}, 76$ & 0,015 & 0,97 \\
\hline & $-6,2$ & 7,56 & 13,29 & $-9,25$ & 35,33 & 11,04 & \\
\hline \multirow[t]{2}{*}{ France } & 0 & 1,37 & 0,39 & $-0,59$ & 0,99 & $-0,008$ & 0,85 \\
\hline & ns & 7,53 & $2,22 *$ & $-3,39$ & 2,95 & $-2,36^{*}$ & \\
\hline \multirow[t]{2}{*}{ Italie } & 0,02 & 0,64 & 0,83 & $-1,36$ & 1,2 & 0,0034 & 0,89 \\
\hline & ns & 3,63 & 7,64 & $-9,73$ & 16,09 & $2,53^{*}$ & \\
\hline \multirow[t]{2}{*}{ Royaume-Uni } & 0,12 & 0 & 0 & $-0,59$ & 1,13 & $-0,0075$ & 0,55 \\
\hline & 3,54 & ns & ns & $-5,36$ & 3,47 & $-1,98^{*}$ & \\
\hline
\end{tabular}

Petits pays

\begin{tabular}{l|c|c|c|c|c|c|c}
\hline Autriche & 0,04 & 0 & 0,66 & $-0,89$ & 0,88 & 0 & 0,72 \\
& 3,61 & $n s$ & 3,04 & $-4,83$ & 3,21 & $n s$ & \\
\hline Belgique & $-0,02$ & 1,33 & 0,79 & $-0,67$ & 1,19 & 0 & 0,78 \\
& $n s$ & 4,04 & 4,19 & $-3,32$ & 3 & $n s$ & \\
\hline Danemark & 0,13 & 1,66 & 0,53 & $-0,61$ & $I, 09$ & $-0,0193$ & 0,77 \\
& $2,54 *$ & $4,45^{*}$ & 2,27 & $-5,1$ & 2,76 & $-2,43^{*}$ & \\
\hline Finlande & $-0,08$ & 0,91 & 0 & $-1,12$ & 0,82 & 0,0173 & 0,54 \\
& $-1,59 * * *$ & $2,09 *$ & $n s$ & $-11,24$ & 6,54 & 4,09 & \\
\hline Pays-Bas & 0,36 & 1,65 & 0,69 & $-0,79$ & 2,56 & $-0,0311$ & 0,7 \\
& 5,72 & 3,95 & 3,03 & $-7,15$ & 6,77 & $-6,95$ & \\
\hline Suède & 0,07 & 0,51 & 0,39 & $-0,45$ & 1,73 & $-0,0084$ & 0,79 \\
& 3,32 & 2,99 & 4,35 & $-8,13$ & 7,46 & $-2,34 *$ & \\
\hline Irlande & $-0,25$ & 1,12 & $I, 06$ & $-0,58$ & 3,31 & 0,0547 & 0,48 \\
& $-2,88$ & 3,79 & 2,73 & $-4,2$ & 3,17 & 9,82 & \\
\hline Portugal & $-0,2$ & 1,29 & 0 & $-0,73$ & $I, 47$ & 0,0237 & 0,63 \\
& $-2,86$ & 3,6 & $n s$ & $-4,03$ & 2,65 & 4,19 & \\
\hline Grèce & 0,04 & 0,96 & 1,28 & $-0,54$ & 0,71 & 0 & 0,73 \\
& $1,51 * * *$ & 2,87 & 3,89 & $-3,7$ & $2,15 *$ & $n s$ & \\
\hline
\end{tabular}

ns : non significatif ; $*$ significatif au seuil de $5 \%$; ** significatif au seuil de $10 \%$; *** significatif au seuil de $15 \%$. Les valeurs en italiques correspondent au t de Student. 


\section{Al.8. Résultats des estimations de l'équation d'importation extra-européenne pour la période 1981-1997}

$$
\begin{aligned}
\Delta \log (M E)= & m m_{0}+m m_{1} * \Delta \log (D F)+m m_{2} * \Delta \log \left(P M_{e} / P\right) \\
& m m_{3}\left[\log (D F)-m m_{4} * \Delta \log \left(P M_{e} / P\right)-m m_{5} * \text { trend }\right]_{1}
\end{aligned}
$$

\begin{tabular}{|c|c|c|c|c|c|c|c|c|}
\hline & $\mathrm{mm}_{0}$ & $\mathrm{~mm}_{1}$ & $\mathrm{~mm}_{2}$ & $\mathrm{~mm}_{3}$ & $\mathrm{~mm}_{4}$ & $\mathrm{~mm}_{5}$ & Dum I & $\mathrm{R}^{2}$ \\
\hline \multicolumn{9}{|l|}{ Grands pays } \\
\hline \multirow[t]{2}{*}{ Allemagne } & $-0,07$ & 2,49 & $-0,52$ & $-0,44$ & $-0,78$ & & $-0,11$ & 0,92 \\
\hline & $-5,25$ & 10,7 & $-9,26$ & $-5,34$ & $-|1,6|$ & & $-4,09$ & \\
\hline \multirow[t]{2}{*}{ Espagne } & $-0,06$ & 2,97 & $-0,72$ & $-1,2$ & $-1,12$ & & & 0,90 \\
\hline & $-2,47^{*}$ & 5,75 & $-5,18$ & $-9,24$ & $-30,34$ & & & \\
\hline \multirow[t]{2}{*}{ France } & $-0,05$ & 2,62 & $-0,5$ & $-0,35$ & $-1,24$ & & & 0,86 \\
\hline & $-3,63$ & 7,5 & $-6,56$ & $-3,31$ & $-9,1$ & & & \\
\hline \multirow[t]{2}{*}{ Italie } & $-0,03$ & $3,7 \mathrm{I}$ & 0 & $-0,43$ & $-0,68$ & & & 0,79 \\
\hline & $-1,64 * *$ & 7,39 & ns & $-3,08$ & $-6,44$ & & & \\
\hline \multirow[t]{2}{*}{ Royaume-Uni } & 0,05 & 1,98 & $-0,26$ & $-0,36$ & $-1,35$ & & & 0,49 \\
\hline & 2,26 & 3,42 & $-1,58 * * *$ & $-2,24 *$ & $-4,83$ & & & \\
\hline \multicolumn{9}{|l|}{ Petits pays } \\
\hline \multirow[t]{2}{*}{ Autriche } & $-0,12$ & 2,23 & $-0,76$ & $-0,75$ & $-1,08$ & & & 0,45 \\
\hline & $-2,79$ & $2,39 *$ & $-3,27$ & $-4,37$ & $-6,83$ & & & \\
\hline \multirow[t]{2}{*}{ Belgique } & $-0,02$ & 2,25 & $-0,47$ & $-0,31$ & $-0,85$ & & & 0,81 \\
\hline & ns & 7,65 & $-5,73$ & $-2,32$ & $-5,42$ & & & \\
\hline \multirow[t]{2}{*}{ Danemark } & $-0,09$ & 0,88 & $-0,49$ & $-1,25$ & $-0,65$ & $-0,0067$ & & 0,54 \\
\hline & $-4,91$ & 3,03 & $-5,61$ & $-9,29$ & $-5,61$ & $-1,55^{* * *}$ & & \\
\hline \multirow[t]{2}{*}{ Finlande } & 0,11 & 2,09 & $-0,81$ & $-0,55$ & $-1,5$ & & & 0,71 \\
\hline & 3,29 & 4,3 & $-4,82$ & $-3,59$ & $-7,16$ & & & \\
\hline \multirow[t]{2}{*}{ Pays- Bas } & 0,02 & $|, 2|$ & $-0,4 I$ & $-0,25$ & $-|, 0|$ & & & 0,73 \\
\hline & ns & 4,41 & $-5,55$ & $-2,24 *$ & $-3,99$ & & & \\
\hline \multirow[t]{2}{*}{ Suède } & 0,08 & 2,7 & $-0,47$ & $-0,65$ & $-0,88$ & $-0,013$ & & 0,62 \\
\hline & ns & 3,51 & $-2,93$ & $-3,33$ & $-3,35$ & $-1,73^{* *}$ & & \\
\hline \multirow[t]{2}{*}{ Irlande } & $-0,02$ & 2,51 & $-0,2$ & $-0,43$ & $-0,94$ & & & 0,57 \\
\hline & ns & 5,43 & $-1,59 *$ & $-4,37$ & $-5,67$ & & & \\
\hline \multirow[t]{2}{*}{ Portugal } & 0,17 & 3,33 & 0 & $-0,56$ & $-1,08$ & $-0,037$ & & 0,85 \\
\hline & 2,65 & 9,42 & ns & $-4,5$ & $-6,03$ & $-3,46$ & & \\
\hline \multirow[t]{2}{*}{ Grèce } & $-0,07$ & 0 & 0 & $-1,02$ & $-1,19$ & & & 0,67 \\
\hline & $-2,34$ & ns & ns & $-7,93$ & $-9,55$ & & & \\
\hline
\end{tabular}

ns : non significatif ; * significatif au seuil de $5 \%$; *** significatif au seuil de $10 \%$; *** significatif au seuil de $15 \%$. Les valeurs en italiques correspondent au $\mathrm{t}$ de Student. 
Al.9. Résultats des estimations de l'équation de consommation des ménages pour l'ensemble des pays européens pour la période 1981-1997

$$
\Delta \log (\text { cons })=c_{0}+c_{1} * \Delta \log (w N / p c)+c_{2} *\left[\log (\text { cons })-c_{3} * \log (w N / p c)\right]_{1}
$$

\begin{tabular}{c|c|c|c}
\hline$c_{1}$ & $c_{2}$ & $c_{3}$ & $\mathrm{R}^{2}$ moyen \\
\hline 0,31 & $-0,05$ & 0,6 & 0,44 \\
13,12 & $-3,13$ & 2 & \\
\hline
\end{tabular}

ns : non significatif.

Les valeurs en italiques correspondent au t de Student.

Équations empilées pour les 14 pays 


\section{ANNEXE II: Les données utilisées et les équations pour les États-Unis}

\section{A. Les données utilisées}

La majorité des données provient de la banque de données de l'US Bureau of the Census : plusieurs recompositions ont été nécessaires pour obtenir des données par région. Les autres données ont été agrégées à partir des huit régions du Bureau of Economic Activity (BEA), ou bien à partir des séries par État du Bureau of Labor Statistics (BLS).

- Les données de population sont tirées de deux séries du Bureau of the Census : Resident Population for Selected Age Groups (1980 to 1989), et Population Estimates for the U.S., Regions, and States by Selected Age Groups and Sex (1990 to 1999). Les données de population en âge de travailler (I8-64 ans) sont calculées à partir des séries par groupe d'âge (I8-24, 25-44 et 45-64 ans).

- Les données d'emploi et de chômage sont des données par État du BLS: l'addition des États permet le calcul de la population active, de l'emploi, du nombre de chômeurs et du taux de chômage par région.

- La donnée concurrentielle à une région $x^{*}$ est la moyenne des trois autres régions: par exemple, le taux de chômage concurrentiel au Midwest $U^{*}$, est calculé en faisant le rapport de la somme des chômeurs du Nord-Est, du Sud et de l'Ouest sur la population active de ces trois régions. Le taux de chômage du Midwest est relatif aux trois autres régions concurrentes $\left(U / U^{*}\right)$.

- Le salaire moyen horaire de l'industrie est fourni pour chaque État en dollars courants: pour calculer le salaire de chaque région, nous avons fait la moyenne géométrique de ces salaires pondérée par le nombre d'employés par État dans l'industrie.

- Le salaire moyen du secteur privé provient des séries régionales du BEA. Il correspond à la masse salariale divisée par le nombre d'emplois à temps plein ou à temps partiel.

- Les prix à la consommation (Consumers Price Index All Urban Consumers) sont en base 100 en 1984. Le prix concurrentiel $p c^{*}$ est une moyenne des trois autres régions pondérée par le PIB de la région.

- La production de chaque région est calculée à partir du PIB (GSP: Gross State Product) des régions du BEA. Le PIB est dispo- 
nible en dollars courants et en dollars constants 1992. Le rapport des deux séries nous donne donc le prix de production $p$.

- Les flux de migrations internes par région (IM et $E M$ ) proviennent des séries de migrations de I'US Census (Annual Immigration, Outmigration, Net Migration, and Movers from Abroad for Regions). Des données d'émigration par tranches d'âge permettent de calculer le nombre d'émigrants en âge de travailler (18-64 ans) des quatre régions pour les années 1998 et 1999. La moyenne obtenue nous permet d'estimer un paramètre pour chaque région, rapport des émigrants en âge de travailler $(E M T)$ au total des émigrants $(E M)$, constant par hypothèse. La moyenne pondérée des EMT des trois autres régions permet d'estimer les immigrants en âge de travailler $(I M T)$, la pondération étant fonction du nombre d'immigrants. 


\section{B. Les résultats des estimations pour les États-Unis sur la période 1982-1987}

\begin{tabular}{|c|c|c|c|c|}
\hline \multicolumn{5}{|c|}{ All.I. Les équations d'immigration et d'émigration } \\
\hline \multicolumn{5}{|c|}{ Taux d'immigration : log (IM/POP) } \\
\hline & Midwest & Nord-Est & Sud & Ouest \\
\hline $\log \left((\mathrm{Q} / \mathrm{N}) /(\mathrm{Q} / \mathrm{N})^{*}\right)$ & \multicolumn{4}{|c|}{0,905} \\
\hline $\operatorname{dlog}\left(\mathrm{N} / \mathrm{N}^{*}\right)$ & \multicolumn{4}{|c|}{3,588} \\
\hline trend & \multicolumn{4}{|c|}{$-0,020$} \\
\hline Dummy 1988 & ns & ns & ns & $\begin{array}{c}-0,341 \\
(-3,9)\end{array}$ \\
\hline Effets fixes & $-4,047$ & $-4,866$ & $-3,917$ & $-4,004$ \\
\hline $\mathrm{R}^{2}$ & \multicolumn{4}{|c|}{0,992} \\
\hline Durbin-Watson & \multicolumn{4}{|c|}{$\mathrm{I}, 765$} \\
\hline \multicolumn{5}{|c|}{ Taux d'émigration : $\log (\mathrm{EM} / \mathrm{POP})$} \\
\hline & Midwest & Nord-Est & Sud & Ouest \\
\hline $\log \left((\mathrm{Q} / \mathrm{N}) /(\mathrm{Q} / \mathrm{N})^{*}\right)$ & \multicolumn{4}{|c|}{ ns } \\
\hline $\operatorname{dlog}(\mathrm{N} / \mathrm{N} *)$ & \multicolumn{4}{|c|}{$\begin{array}{c}-3,887 \\
(-2,4)\end{array}$} \\
\hline trend & $\begin{array}{c}-0,030 \\
(-4,9)\end{array}$ & ns & $\begin{array}{c}-0,015 \\
(-2,7)\end{array}$ & $\begin{array}{c}-0,018 \\
(-3,1)\end{array}$ \\
\hline Effets fixes & $-4,008$ & $-4,295$ & $-4,279$ & $-4,096$ \\
\hline $\mathrm{R}^{2}$ & \multicolumn{4}{|c|}{0,839} \\
\hline Durbin-Watson & \multicolumn{4}{|c|}{1,991} \\
\hline
\end{tabular}


I Jacques Mazier, Joël Oudinet et Sophie Saglio

All.2. Les équations du taux d'activité

\begin{tabular}{|c|c|c|c|c|}
\hline \multicolumn{5}{|c|}{ Taux d'activité : dlog(PA/PAT) } \\
\hline & Midwest & Nord-Est & Sud & Ouest \\
\hline dlog(N/PAT) & $\begin{array}{c}0,546 \\
(6,6)\end{array}$ & $\begin{array}{c}0,383 \\
(3,6)\end{array}$ & $\begin{array}{c}0,191 \\
(1,7)\end{array}$ & $\begin{array}{c}0,589 \\
(7,2)\end{array}$ \\
\hline $\operatorname{dlog}(\mathrm{N} / \mathrm{PAT})_{-1}$ & ns & $\begin{array}{c}0,267 \\
(2,0)\end{array}$ & $\begin{array}{c}0,374 \\
(2,8)\end{array}$ & ns \\
\hline dlog(IMT/PAT) & ns & $\begin{array}{c}0,020 \\
(2,1)\end{array}$ & $\begin{array}{c}0,025 \\
(2,5)\end{array}$ & $\begin{array}{c}0,009 \\
(1,7)\end{array}$ \\
\hline $\operatorname{dlog}(\text { IMT/PAT })_{-1}$ & $\begin{array}{c}0,013 \\
(1,6)\end{array}$ & $\begin{array}{c}0,027 \\
(2,7)\end{array}$ & ns & $\begin{array}{c}0,019 \\
(3,2)\end{array}$ \\
\hline Dummy I & $\begin{array}{c}0,010 \\
(2,4)\end{array}$ & $\begin{array}{c}0,014 \\
(1,9)\end{array}$ & $\begin{array}{c}0,012 \\
(3,6)\end{array}$ & $\begin{array}{c}0,021 \\
(3,9)\end{array}$ \\
\hline Dummy 2 & ns & $\begin{array}{c}-0,010 \\
(-1,9)\end{array}$ & $\begin{array}{c}-0,006 \\
(-1,9)\end{array}$ & $\begin{array}{c}-0,007 \\
(-1,9)\end{array}$ \\
\hline Effets fixes & $-0,002$ & 0,000 & 0,000 & $-0,001$ \\
\hline $\mathrm{R}^{2}$ & \multicolumn{4}{|c|}{0,751} \\
\hline Durbin-Watson & \multicolumn{4}{|c|}{1,215} \\
\hline
\end{tabular}

All.3. Les équations d'emploi

\begin{tabular}{l|c|c|c|c}
\hline \multicolumn{5}{c|}{ Emploi : dlogN } \\
\hline dlog(Y) & Midwest & Nord-Est & Sud & Ouest \\
\hline force rappel & 0,340 & 0,619 & 0,446 & 0,577 \\
& $(4,8)$ & $(8,4)$ & $(6,6)$ & $(6, I)$ \\
\hline trend & $-0,362$ & $-0,337$ & $-0,172$ & $-0,306$ \\
& $(-5,0)$ & $(-3,9)$ & $(-2,6)$ & $(-3,2)$ \\
\hline Effets fixes & $-0,00038$ & $-0,00055$ & $-0,00025$ & $-0,00022$ \\
& $(-4, I)$ & $(-3,5)$ & $(-3,1)$ & $(-2,4)$ \\
\hline dummy & 1,156 & 0,983 & 0,559 & 0,948 \\
\hline $\mathrm{R}^{2}$ & $-0,014$ & $\mathrm{~ns}$ & 0,012 & $\mathrm{~ns}$ \\
\hline Durbin-Watson & $(-1,9)$ & & $(2, I)$ & \\
\hline
\end{tabular}




\section{All.4. Les équations de salaire nominal}

\begin{tabular}{|c|c|c|c|c|}
\hline \multicolumn{5}{|c|}{ Salaire nominal du secteur industriel : dlog w } \\
\hline & Midwest & Nord-Est & Sud & Ouest \\
\hline $\operatorname{dlog}\left(\mathrm{Pc}_{-1}\right)$ & \multicolumn{4}{|c|}{$\begin{array}{c}0,248 \\
(4,8)\end{array}$} \\
\hline $\operatorname{dlog}\left(\mathrm{Pc}_{-2}\right)$ & \multicolumn{4}{|c|}{$\begin{array}{c}0,311 \\
(6,3)\end{array}$} \\
\hline$U$ & $\begin{array}{c}-0,202 \\
(-4, I)\end{array}$ & $\begin{array}{c}-0,306 \\
(-3,7)\end{array}$ & $\begin{array}{c}-0,398 \\
(-4,2)\end{array}$ & $\begin{array}{c}-0,351 \\
(-2,6)\end{array}$ \\
\hline $\operatorname{dlog}(\mathrm{Y} / \mathrm{N})$ & $\begin{array}{c}0,149 \\
(3,5)\end{array}$ & $\begin{array}{c}0,160 \\
(1,9)\end{array}$ & ns & $\begin{array}{c}0,195 \\
(1,9)\end{array}$ \\
\hline Dummy 1985 & \multicolumn{4}{|c|}{$\begin{array}{c}0,013 \\
(5,6)\end{array}$} \\
\hline Effets fixes & 0,015 & 0,025 & 0,035 & 0,024 \\
\hline $\mathrm{R}^{2}$ & \multicolumn{4}{|c|}{0,868} \\
\hline Durbin-Watson & \multicolumn{4}{|c|}{2,065} \\
\hline \multicolumn{5}{|c|}{ Salaire nominal du secteur privé : dlog(wp) } \\
\hline & Midwest & Nord-Est & Sud & Ouest \\
\hline $\operatorname{dlog}\left(\mathrm{Pc}_{-1}\right)$ & \multicolumn{4}{|c|}{$\begin{array}{c}0,306 \\
(3,6)\end{array}$} \\
\hline $\operatorname{dlog}\left(\mathrm{Pc}_{-2}\right)$ & \multicolumn{4}{|c|}{$\begin{array}{c}0,121 \\
(2,0)\end{array}$} \\
\hline$\cup$ & \multicolumn{4}{|c|}{$\begin{array}{c}-0,285 \\
(-3,6)\end{array}$} \\
\hline $\operatorname{dlog}(\mathrm{Y} / \mathrm{N})$ & ns & $\begin{array}{c}0,384 \\
(5,1)\end{array}$ & ns & $\begin{array}{c}0,231 \\
(4,2)\end{array}$ \\
\hline Dummy 1993 & \multicolumn{4}{|c|}{$\begin{array}{c}-0,018 \\
(-3,2)\end{array}$} \\
\hline Constante & \multicolumn{4}{|c|}{$\begin{array}{c}0,040 \\
(7,4)\end{array}$} \\
\hline $\mathrm{R}^{2}$ & \multicolumn{4}{|c|}{0,605} \\
\hline Durbin-Watson & \multicolumn{4}{|c|}{1,990} \\
\hline
\end{tabular}




\section{All.5. Les équations de prix du PIB}

\begin{tabular}{|c|c|c|c|c|}
\hline \multicolumn{5}{|c|}{ Prix du PIB : dlog P } \\
\hline & Midwest & Nord-Est & Sud & Ouest \\
\hline dlog (OG_usa) & \multicolumn{4}{|c|}{$\begin{array}{c}0,202 \\
(3,9)\end{array}$} \\
\hline dlog (CSUP) & $\begin{array}{c}0,195 \\
(2,9)\end{array}$ & $\begin{array}{c}0,408 \\
(4,8)\end{array}$ & $\begin{array}{c}0,229 \\
(2,5)\end{array}$ & $\begin{array}{c}0,185 \\
(1,8)\end{array}$ \\
\hline $\log (p / C S U p)_{-1}$ & $\begin{array}{c}-0,136 \\
(-4,7)\end{array}$ & $\begin{array}{c}-0,257 \\
(-6,7)\end{array}$ & $\begin{array}{c}-0,|3| \\
(-2,8)\end{array}$ & $\begin{array}{c}-0,26 \\
(-2,9)\end{array}$ \\
\hline Effets fixes & $-1,140$ & $-2,129$ & $-1,094$ & $-2,241$ \\
\hline Dummy I & $\begin{array}{c}0,016 \\
(2,3)\end{array}$ & ns & $\begin{array}{c}0,017 \\
(2,7)\end{array}$ & $\begin{array}{c}0,022 \\
(3,2)\end{array}$ \\
\hline Dummy 2 & \multicolumn{4}{|c|}{$\begin{array}{c}0,0 \mid 4 \\
(3,8)\end{array}$} \\
\hline $\mathrm{R}^{2}$ & \multicolumn{4}{|c|}{0,717} \\
\hline Durbin-Watson & \multicolumn{4}{|c|}{$\mathrm{I}, 8 \mathrm{I}$} \\
\hline
\end{tabular}

All.6. Les équations de prix de la consommation

\begin{tabular}{|c|c|c|c|c|}
\hline \multicolumn{5}{|c|}{ Prix à la consommation : $\operatorname{dlog}(\mathrm{pc})$} \\
\hline & Midwest & Nord-Est & Sud & Ouest \\
\hline $\operatorname{dlog}\left(\mathrm{P}_{-1}\right)$ & \multicolumn{4}{|c|}{$\begin{array}{c}0,245 \\
(4,9)\end{array}$} \\
\hline $\log (p c / p)_{-1}$ & \multicolumn{4}{|c|}{$\begin{array}{c}-0,202 \\
(-3,7)\end{array}$} \\
\hline $\log (p c \$ / p)_{-1}$ & \multicolumn{4}{|c|}{$\begin{array}{c}0,043 \\
(1,8)\end{array}$} \\
\hline Effets fixes & 0,072 & 0.087 & 0.072 & 0.078 \\
\hline Dummy 1986 & $\begin{array}{r}-0,021 \\
(-4,6)\end{array}$ & $\begin{array}{c}-0.018 \\
(-3,2)\end{array}$ & $\begin{array}{c}-0.017 \\
(-4,1)\end{array}$ & $\begin{array}{r}-0.014 \\
(-2,9)\end{array}$ \\
\hline Dummy 1990 & $\begin{array}{c}0,010 \\
(2,3)\end{array}$ & $\begin{array}{l}0,021 \\
(3,7)\end{array}$ & $\begin{array}{c}0,014 \\
(3,3)\end{array}$ & $\begin{array}{c}0.017 \\
(3,5)\end{array}$ \\
\hline $\mathrm{R}^{2}$ & \multicolumn{4}{|c|}{0,779} \\
\hline Durbin-Watson & \multicolumn{4}{|c|}{1,84} \\
\hline
\end{tabular}

